A young architect came to ask a question.

'I dream of spaces full of wonder. Spaces that rise and envelop flowingly without beginning, without end, of a jointless material white and gold.'

'When I place the first line on paper to capture the dream, the dream becomes less.' 


\section{AN ARCHITECTURAL DIALOGUE WITH THE ELEATIC STRANGER}

by

\section{Christian Jacob Squire}

A thesis submitted to the Victoria University of Wellington

in partial fulfilment of the requirements for the degree of:

\section{Master of Architecture [Prof.]}

Victoria University of Wellington

$$
\text { [2012] }
$$

Under the supervision of Associate Professor Daniel K. Brown 


\section{TABLE OF CONTENTS}

Table of Contents

Abstract

Preface \& Acknowledgement

Thesis Structure

Chapter One - Volume Zero

Introduction

Stoicism

The Sophist

Theory of Forms

Plato, Stoicism, and Notions of Retreat

\section{Chapter Two - Louis I. Kahn}

Introduction

The Dialogue between Silence and Light

ChapterThree-Context

Introduction

Cultural and Carnal Excess

Program

\section{Chapter Four - Dialogue as a Methodology 63 \\ Introduction \\ The Stranger, the Student, and Socrates 70 \\ Day and Night $\quad 76$ \\ Oppositional Dialogues $\quad 77$ \\ Liminal Dialogues 81 \\ The Setting of the Dialogues - Kahn's Ruin 83}

Chapter Five - The Architectural Dialogues 89 Introduction 90

The Triage of the Day

The Triage of the Night 113

Between: Day and Night $\quad 116$

$\begin{array}{ll}\text { Chapter Six-Conclusion } & 121\end{array}$

List of Figures $\quad 126$

Bibliography $\quad 130$ 


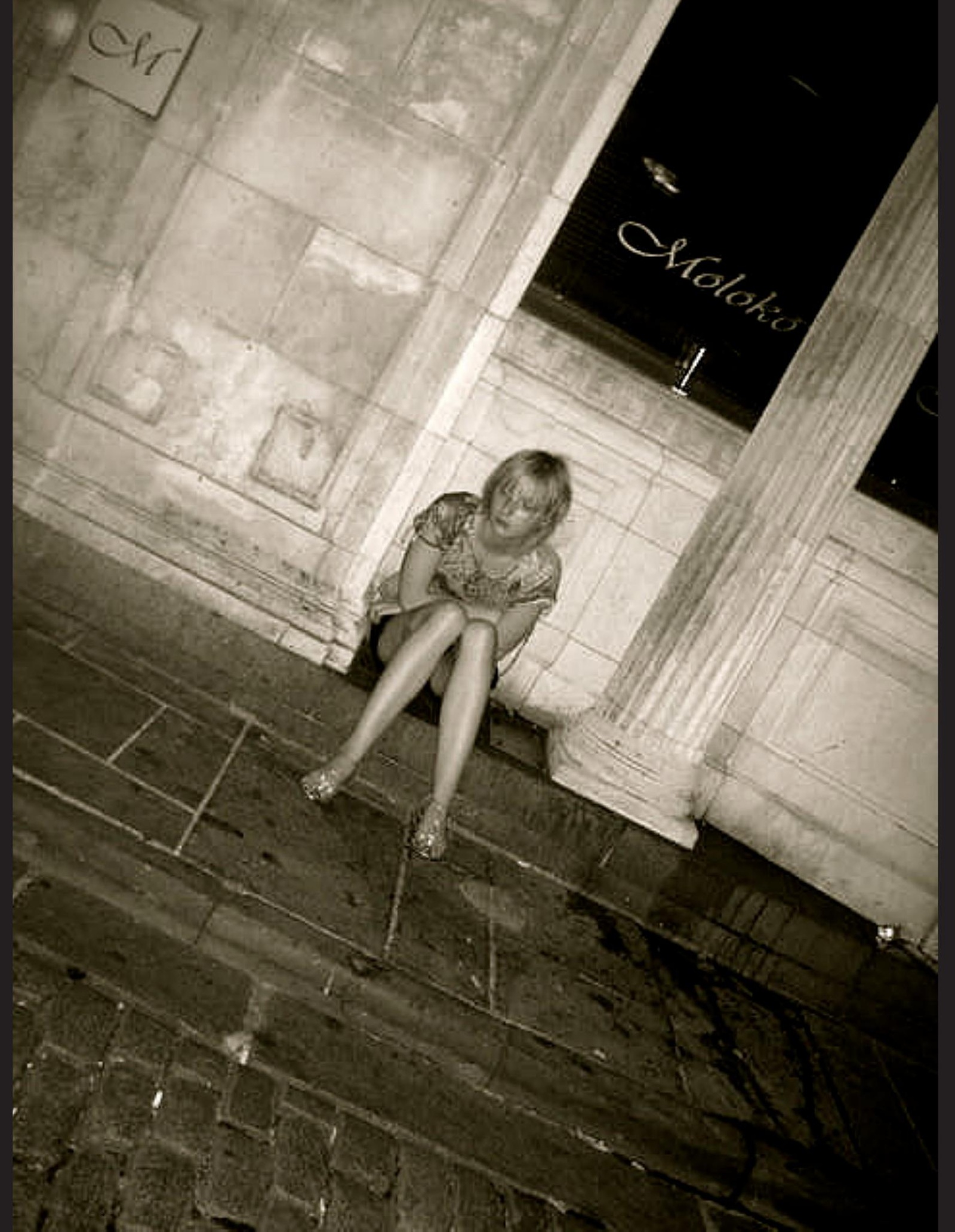




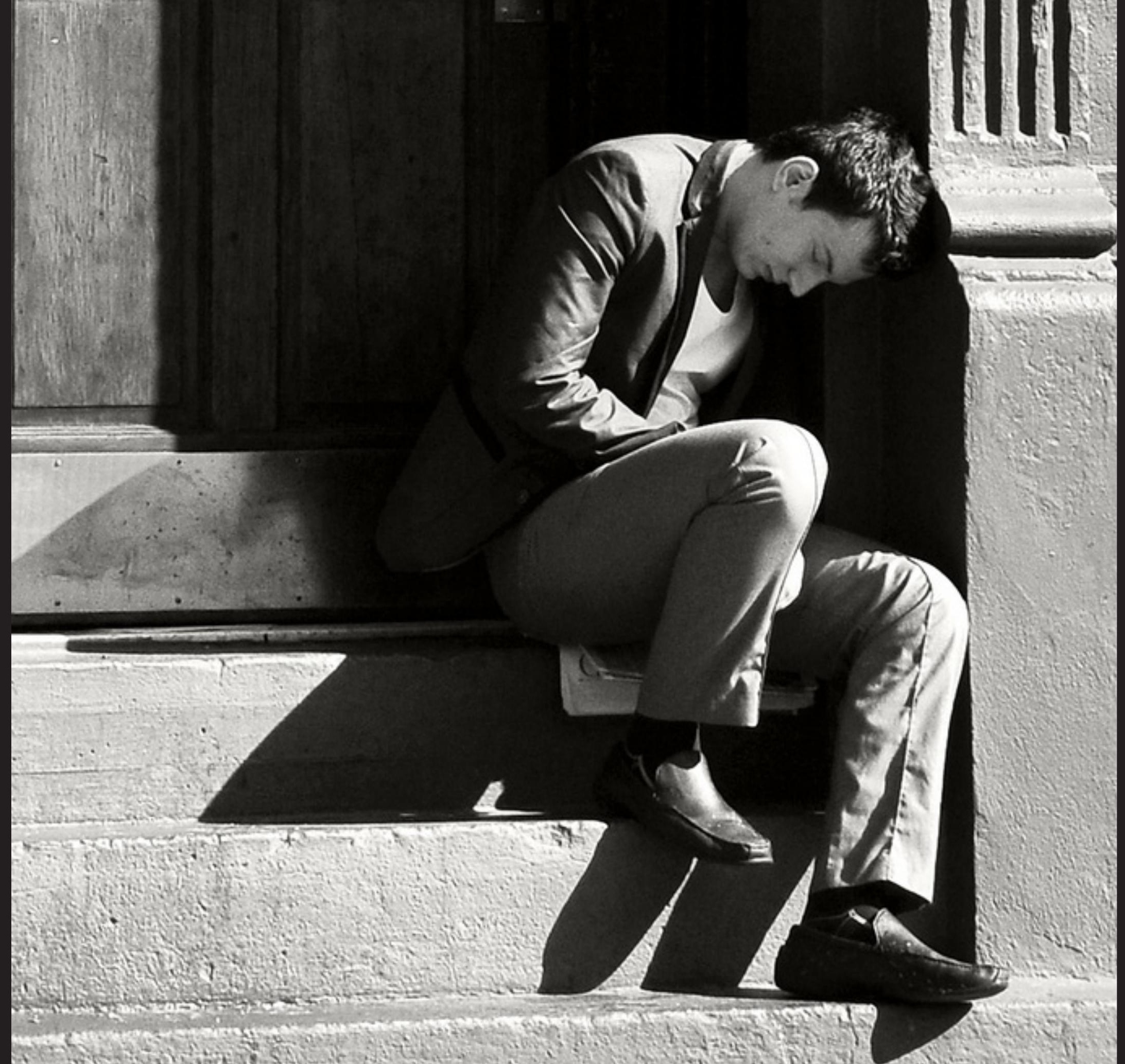




\section{Fig. 1 (pg. 3)}

"Drunk, lost and

alone" by Flickr user 'A

thinkingphoto' (2009)

\section{Fig. 2}

"I've lost my keys" by Flickr user 'Around the Lense' (2009).

\section{ABSTRACT}

Reports throughout New Zealand have highlighted a chronic and growing problem in our urban centres - the effects of alcohol abuse and binge drinking leave our youth vulnerable and unprotected.

The results can sometimes be catastrophic. Makeshift paramedic tents have recently been erected in Wellington to provide aid and retreat, but these are temporary structures and only available two nights per week. The vulnerability of New Zealand's youth occurs not only on nights with too much alcohol, but also in response to the daily stresses brought on by contemporary urban life. New Zealand youth suicide rates are the highest out of 30 OECD nations and more than twice the OECD average (Chapman). Likewise the secularization of contemporary urban society has resulted in the loss of spiritual retreats previously found within churches and religious centres. This thesis examines the need for a permanent urban retreat for all those who are temporarily vulnerable. 
The thesis investigates how architectural form can provide a new approach to urban retreat by critically engaging analogous theories found in the writings of Plato and Louis Kahn. Both Plato's theory of Forms (discussed in Plato's “Dialogues”) and Louis Kahn's 1961 essay "Form and Design" are centred on the idea of achieving an enlightened state of mind, freeing the mind from the physical realm. Plato's theory of Forms posits that the universe is separated into two realms: an intelligible realm and a sensible realm. All objects that exist in the sensible realm - perceivable to us by our senses - are merely imperfect shadows of their essences or Forms. By understanding this, we can free our minds from the distractions of life which so often lead to stress and despair. Plato's theory of Forms has many parallels with the architectural theory of Louis
Kahn, as evidenced in Kahn's "Form and Design". Kahn describes the 'measurable' and 'immeasurable' realms, which are analogous to Plato's sensible and intelligible realms.

This thesis critically engages these analogous theories of Plato and Kahn - achieving an enlightened state of mind, freeing the mind from the physical realm - to establish how architectural form can provide urban retreat for those who are temporarily vulnerable. The site for the design research investigation is the nameless alleyway in the Courtenay Place precinct which separates Wellington's historic St James Theatre from The Mermaid bar and brothel - a site which symbolizes the conflicting stimuli to which our urban residents are now continually exposed.
Fig. 3

"Binge Drinking" by Flickr user 'chrisie.b' (2010). 


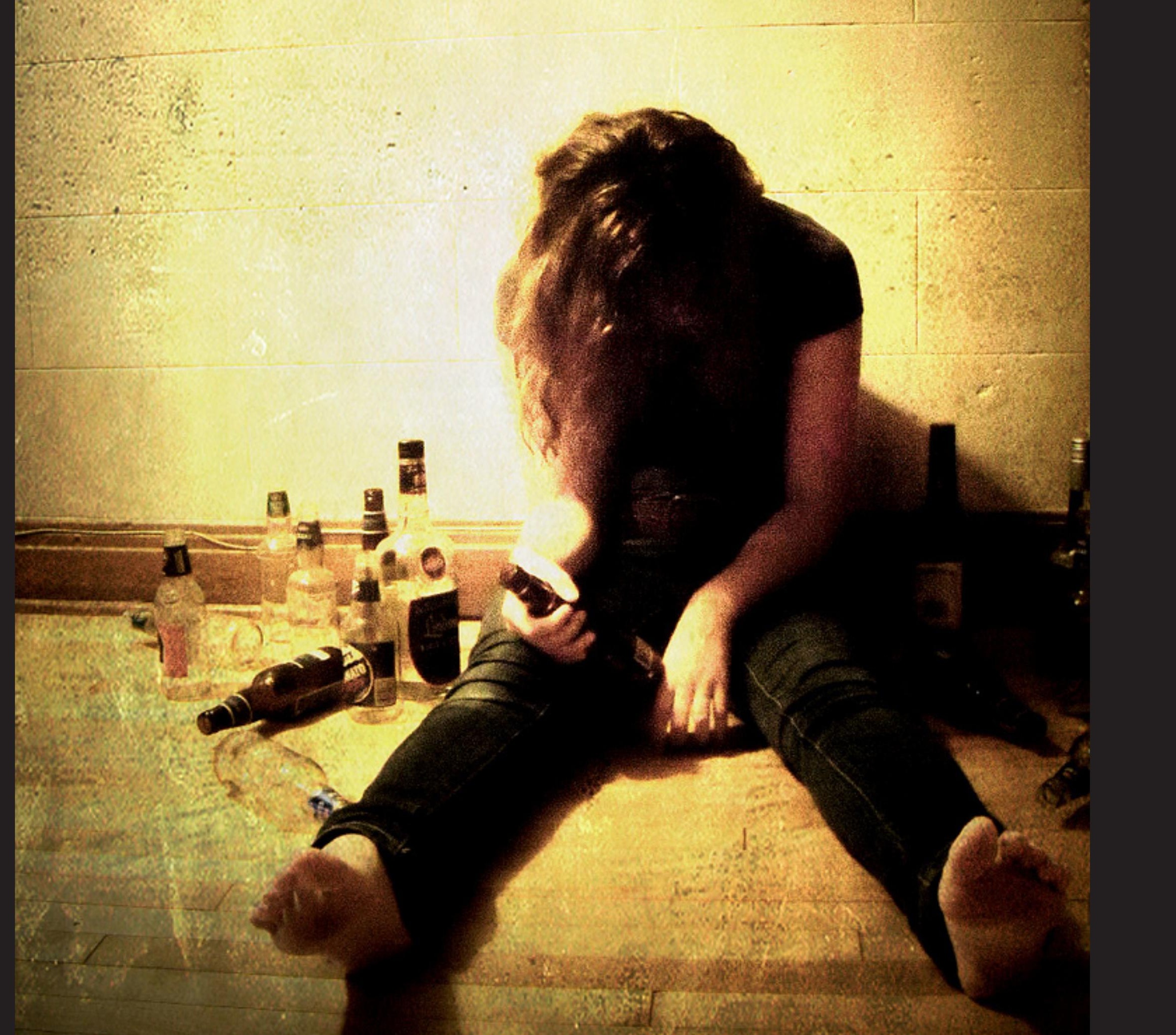


My early research on this topic began with an interest in how the ancient Greek philosophy of Stoicism might be applied to contemporary architecture. Midway through the process of conducting this research my supervisor put me on the spot at one of our meetings and asked me to explain to him the why of my research: why I was personally interested in applying Stoicism to architecture. My immediate response was naturally quite inaccurate, so he kindly offered his opinion on what he thought my reasons were. Immediately I had a sense of déjà vu, having used almost the exact same explanation in a discussion with a very dear friend of mine only two weeks prior.

We had been intending to go for a walk in the Karori Wildlife Sanctuary, a picturesque nature reserve in a suburban area just outside of central Wellington. However, we opted to remain indoors, given the wintry weather, and our shared desire to remain fairly inactive that morning. Instead, my sister joined us and we sat around the fireplace, trapped in deep conversation. In response to my sister voicing her frustration at the loss of respect for the sanctity of the church, specifically during Sunday morning mass, I began to explain what I felt was an emerging desire among students and professionals alike that might be expressed in contemporary architecture.

There seems to be an attempt within the field of architecture to reclaim a sense of spirituality, which has been diminished by the secularisation of society. The inner city pockets of sanctity and retreat found in churches and cathedrals are becoming marginalised as the 
state distances itself from all religious associations. Simultaneously, as populations continue to increase and intensify the urban density, many people suffer a decline in access to the rural escapes of generations past. The combination of these factors leads to a living environment full of cacophony and lacking in opportunities for retreat.

Designing spaces to provide respite from emotional turmoil and mental stresses has been a reoccurring pursuit in the latter years of my architectural education. Fuelled by the aforementioned societal problems, increased responsibilities of adulthood, life as a student, and compounded by the circumstances of my family, it follows naturally that I continue to ask how architecture can ameliorate my personal troubles and those that I share with society.

\section{Acknowledgment}

Before continuing I would like to thank my very own "Stranger from Elea", Daniel K. Brown, for the immeasurable knowledge, inspiration and support that he has given me throughout my study. Additionally I thank all the friends and family that have supported me during what was undoubtedly one the greatest challenges I have faced so far. A special mention must go to my mother, Katrin Eickhorst and my sister, Tabea Squire, who had to live with me while I plumbed the depths of Stoicism, Plato and Kahn in search of retreat. 


\section{r}

This introductory section outlines the objective, structure and argument of the research. The objective of this thesis is to critically engage the analogous theories of Plato and Louis Kahn to establish how architectural form can provide an urban retreat for those who are temporarily vulnerable. The structure of the thesis comprises of six chapters.

\section{CHAPTER ONE}

This chapter introduces the ancient Greek philosophies of Stoicism and Plato. It outlines Stoicism as a model for the kind of retreat which this thesis seeks to engender in architecture. It examines Plato's dialogue Sophist, which is used by this thesis as a critical tool for defining retreat. It investigates Plato's theory of Forms, which is briefly addressed in Sophist, because of the way in which both

Plato's theory and Stoicism suggest that a sense of retreat - freed from overwhelming and irrational emotions - can be achieved through an enlightened understanding of the universe.

\section{CHAPTER TWO}

This chapter identifies the methodology of dialogue that Plato and Kahn both used by relating Plato's theory of Forms with Kahn's architectural theory of Silence and Light. It draws a parallel between Plato's 'sensible' and 'intelligible' realms, and Kahn's idea of the 'measurable' and 'immeasurable'. This parallel is consistent throughout the development of Kahn's theory of Silence and Light.

\section{CHAPTER THREE}

This chapter analyses the program and selected site between the St 
James Theatre and The Mermaid bar on Courtenay Place.

\section{CHAPTER FOUR}

This chapter converges Plato and Kahn's use of dialogues in order to critically examine the use of dialogues as a methodology for designing an architectural experience of retreat. It proposes that architectural dialogues leading people to a greater understanding of the inherent balances requisite to architecture can facilitate an experience of retreat.

\section{CHAPTER FIVE}

This chapter is a visual and written narration of the architectural dialogues as they are integrated within the design to form an architectural experience of retreat. The chapter is separated into three sections according to the time of day at which the visitor experiences the dialogue.

\section{CHAPTER SIX}

The final chapter critically discusses the conclusions of the architectural intervention and the theoretical research of this thesis. 


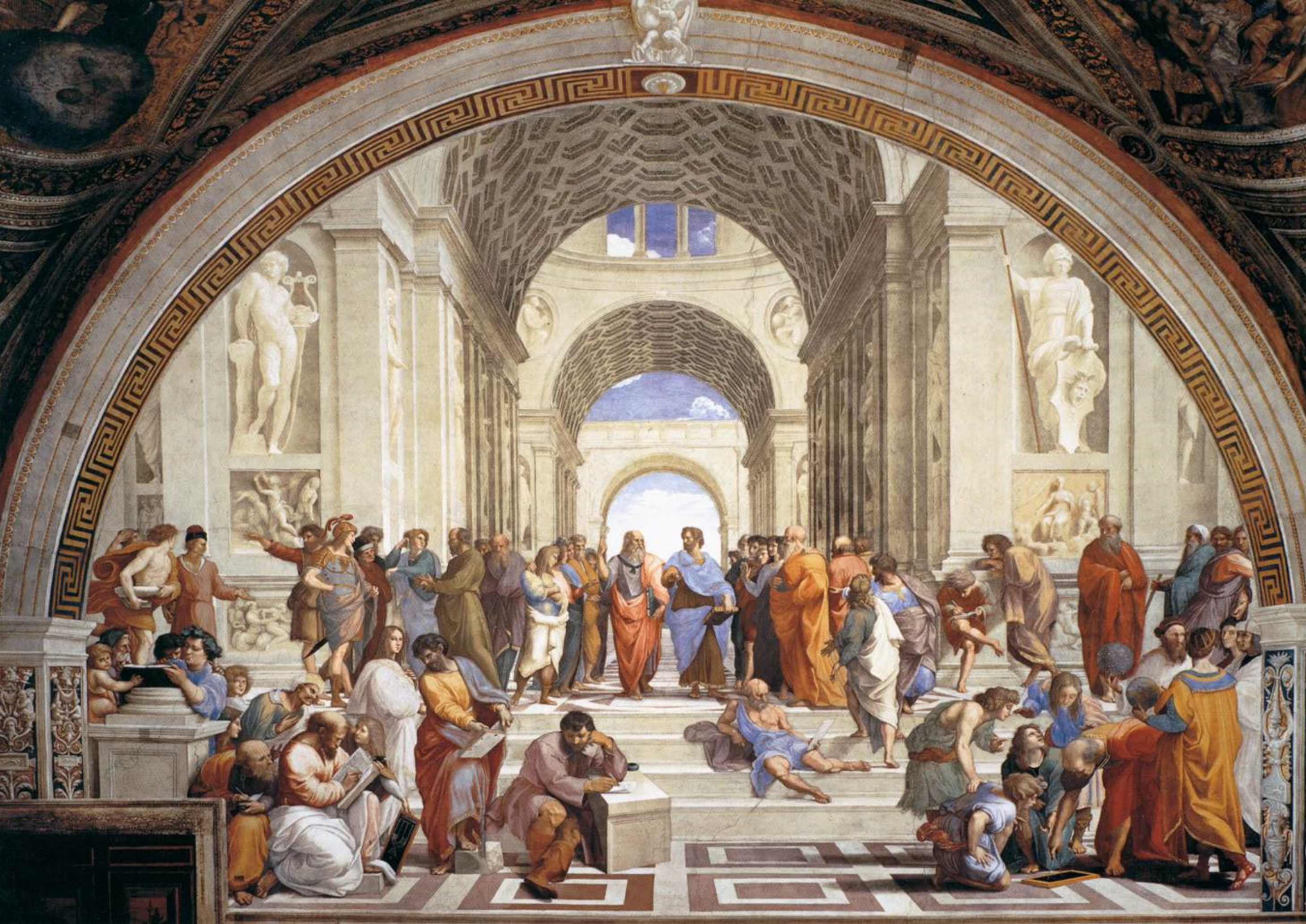




\section{VOLUME ZERO}

I have in my place, books about English history... I read only the first volume, and of that only the first chapter, in which each time I see something else. But really, I am interested only in reading Volume Zero, which has not been written. And then volume minus one. History could not have started in the places they speak of. History preceded this; it just is not recorded.

Louis Kahn, architect (1902-1974) 
The preceding quote of Louis Kahn resides in John Lobell's book: Between Silence and Light: Spirit in the Architecture of Louis I. Kahn (54). I have used it to begin this introduction because if it were possible for Kahn to read this, I think it would be important for me to begin with Volume Zero of my research. While the relationship between Louis Kahn's 1961 essay "Form and Design" and Plato's theory of Forms (discussed in Plato's "Dialogues") developed into the fundamental driver of the research to establish a new approach for architecture of retreat, it was important to first establish the model of retreat to which Plato's and Kahn's theories would ultimately lead. This introductory chapter describes the process by which that model was established and the ways in which Plato's "Dialogues" and theory of Forms became fundamental to establishing the methodology for this research.
In order to design architecture of retreat, it is important first to define the kind of retreat that the architecture is trying to create; as such, Volume Zero begins with an investigation into the ancient Greek philosophy of Stoicism (early $3^{\text {rd }}$ century BC). This particular philosophy suggests a way in which to become detached from the chaos of irrationality and emotions, representing an ideal form of rational retreat. The thesis sets out to translate this philosophy into an architectural experience because of the way Stoicism presents itself as a useful tool in challenging architecture to create a space of detachment and retreat amidst the cacophony of an urban centre.

Volume Zero also includes a discussion of Plato's dialogue Sophist and its principal character the Stranger from Elea (Eleatic Stranger), the namesake of my thesis. The importance of this character is that
Fig. 4 (pg. 12)

"Stanza della Segnatura The School of Athens" by Raphael (1509), featuring Plato in the centre surrounded by other great Greek philosophers, including Zeno of Citium, the founder of Stoicism (second from left). 
he acted as a guide, leading the second character (a Student) to an understanding of truth. In terms of taking a philosophical approach to translate Stoicism into an architecture of retreat it is important to begin with a fundamental understanding and definition of this kind of stoic retreat. Sophist offers a methodology for establishing philosophical definitions and as a result this method and the dialogue itself become central tools for defining retreat.

Prior to committing to the final approach to this thesis investigation, Minimalism was examined as an existing example of architecture that perhaps may be considered stoic, thereby representing a potential vehicle for establishing an urban retreat. However, ultimately Minimalism leads to an unsatisfactory definition for stoic architecture, as it is merely comprised of a list of shared characteristics. The dialogues of Plato such as Theaetetus and Euthyphro explain that this kind of list does not represent a true definition; Louis Kahn similarly expressed this in "Form and Design" when he was attempting to define Order. This is one of the many parallels Kahn shares with Plato and an example where both theorists felt that a list of superficial characteristics was insufficient for giving a true definition of something.

Volume Zero concludes with an evaluation of Plato's theory of Forms in order to understand what the essence, or Form, of stoic architecture might be. It is at this point that the parallels between Plato's and Kahn's theories about form become most apparent. The thesis investigates how the integration of these theories could replace a superficial list of stoic characteristics as the primary methodology for designing an architectural experience of stoic retreat. In Chapter One - Volume Zero, the thesis introduces an "ideal" model for retreat as conceived within the context of Stoicism. The first step is to introduce a method for defining Stoicism by turning to Plato. 



\section{Fig. 5}

Stoicism derives its name from the Greek word stoa (porches) because the philosophy was taught and developed in the stoa poikile (painted porches) in Athens.
Stoicism is a philosophy founded by Zeno of Citium in Athens during the Hellenistic period - a period in Greek history that started with the death of Alexander the Great (323 BC) and ended with the fall of Greece to the Romans (146 BC). Stoicism was one of four major schools of philosophy to develop from Socrates' ideas, the others being the Cynics, Skeptics and Epicureans. Stoicism presents itself as a way of life through which an idealised Stoic sage can remain detached from destructive emotions such as grief, anger and lust. It holds that maintaining a rational agency will allow a sage to understand the universal reason, or logos. It was believed that an understanding of the logos left the sage able to rationalise his place in the universe and thus become freed from the pain of any situation in which he found himself. Its appeal lies in the freedom it gives. This thesis will test whether the implementation of stoic philosophy in architecture could remove inhabitants of a building from the discordance and turmoil that we experience in the sensible realm, rehabilitating or returning us to a state of mind detached from the things which cause us to suffer. 


\section{THE SOPHIST}

The thesis begins with the search for a definition of stoic architecture, to test how an architectural retreat can be designed which offers a similar sense of detachment and isolation to what a stoic sage strives to experience. In two of Plato's dialogues, Sophist and Statesman, he establishes his methodology involving dialectic, which is used by the student Theaetetus and by the Eleatic Stranger in order to come across the concise definition of two types of people: sophist and statesman respectively. These two related dialogues suggest he was planning a third dialogue in which the Stranger uses dialectic to define a third kind of person, the philosopher; but this was never written by Plato. According to Brown University Professor of Philosophy and Classics, Dr Mary Louise Gill, this might indicate that Plato - having established the methodology by which a definition can be reached - expects that we, the readers, are now able to define the philosopher ourselves, without the Stranger's help. Sophist becomes important as a dialogue for this thesis because it provides an example of a methodology for finding or establishing a definition beyond a list of superficial characteristics. This is necessary in order to establish a working definition for stoic architecture.

The dialogue in Sophist begins with an example to test the method of definition: the Eleaetic Stranger starts by establishing the definition for an angler. The Stranger and the Student (Theaetetus) agree that the angler shares certain similarities to the sophist and define him through successive divisions and collections, as follows:

One half of all art was acquisitive - half of the acquisitive art 
was conquest or taking by force, half of this was hunting, and half of hunting was hunting animals, half of this was hunting water animals - of this again, the under half was fishing, half of fishing was striking; a part of striking was fishing with a barb, and one half of this again, being the kind which strikes with a hook and draws the fish from below upwards, is the art which we have been seeking, and which from the nature of the operation is denoted angling or drawing up (Sophist 221b-221c).

Having agreed upon this definition for the angler, the Student (Theaetetus) and the Stranger continue by repeating the process in order to define sophist. However, upon reaching the sixth division they encounter a problem whereby they seem to have come across a definition of the sophist that is in disagreement with their initial impression. The first five divisions all defined the sophist within the acquisitive arts, whereas the sixth had him located in an art of separation, whereby the sophist purified the soul of false beliefs that prevented learning. This definition is of a noble art whereas the sophist previously had been a person frowned-upon as a trickster and deceiver by those present in the dialogue. They have not stumbled upon the definition of sophist but have instead discovered a distinct kind of sophist. Dr Mary Louise Gill explains that this definition "merely has the same name owing to a superficial resemblance." In the dialogue, the Eleatic Stranger explains that this definition is to the real sophist like a dog, the gentlest of animals, is to a wolf, the fiercest (Sophist 231a). The result of their pursuit is a false definition for sophistry with five preceding divisions. These collectively describe characteristics of sophistry, but do not answer 
the question of what sophistry itself is. In order to achieve this, the Student and the Stranger start again several times, before finally agreeing upon a series of successful divisions that lead them to the final definition of sophistry.

This problem of definition is encountered frequently in Plato's dialogues, where Socrates will often approach an interlocutor and ask him to define a particular word. In Euthyphro the main character is asked what holiness is and, believing to know the answer, responds by suggesting that, "holiness is doing what I am doing now, prosecuting the wrongdoer who commits murder or steals from the temples or does any such thing" (Euthyphro 5de). Similarly, in Theaetetus the main character Theaetetus is asked what knowledge is and explains that knowledge is what one might learn from his teacher Theodorus: geometry, arithmetic, astronomy, music and cobbling (Theaetetus 146c-d). Their responses frustrate
Socrates because they are merely giving him lists of examples, while he is actually seeking what the examples all have in common (Gill). $\mathrm{He}$ is not interested in all the things that demonstrate holiness or knowledge but in holiness or knowledge itself: his interest lies in their essences.

In Sophist, the false-definition and preceding five divisions are merely lists that describe characteristics of the sophist; Socrates might point out that this is why the first set of divisions was unsuccessful in producing a definition because it did not pursue the essence of sophistry. As has already been established, this thesis searches for a definition of stoic architecture in order to design an architectural retreat derived from these principles. What Plato's Sophist and Socrates both demonstrate is that a collection of characteristics is not enough to reveal the definition itself, and that the search must begin with the desire to uncover the essence of stoic 
architecture.

The difficulties that the Student (Theaetetus), the Eleatic Stranger, and Socrates's interlocutors encounter in their pursuit of definitions are paralleled in this thesis investigation and in the approach to the final design research intervention. The definition of stoic architecture begins with an initial hypothesis: that Minimalism and Stoicism have something in common. The assumption is not incorrect, for Tom Spektor's article, "The Morals of Modernist Minimalism", identifies a "strong philosophical affinity" between the two (85). The Eleatic Stranger's methodology was then tested in relation to this initial hypothesis, which led to the identification of a primary characteristic: the counterpoint. In a dialogue, which was written in tandem with the research of this thesis, one character points out the dilemma in this characteristic of Minimalism:
This may be true, but the dilemma in your statement is that the counterpoint to which Minimalism responds is 'something'. Therefore, with great frequency the perfect solution is to create a space that is 'nothing'. For how could 'something' be more perfectly counterpointed than by 'nothing'?

Not only does the comparison of Minimalism and Stoicism simply lead to a shared list of superficial characteristics, but one of those characteristics, the counterpoint, is directly counter-productive to the design of architecture.

The following section turns to Plato and his theory of Forms in order to understand his method for understanding the essence, or true definition of something so that this might replace the superficial list of stoic characteristics as the primary methodology for designing an architectural experience of retreat. 


\section{THEORY OF FORMS}

In this section, the thesis introduces Plato's theory of Forms, after which the section discusses Plato's ideas in relation to the stoic idea of "retreat". Plato's theory of Forms is only briefly mentioned in Sophist in relation to the discussion the Stranger has with the Student about the Paremenidian paradox of 'being' and 'notbeing'; however, the theory of Forms is examined in great depth and detail in Plato's greatest work, The Republic. The significance of Plato's theory to this thesis is in the link it offers between Plato's dialogues - which ultimately become a critical tool in establishing the methodology of the thesis - and architecture. The link is present in the theory's pursuit of true knowledge in order to free the mind from the deceptions and illusions of the sensory realm, making both detachment and retreat a possibility. It is present in similar ways in the design and philosophy of architect Louis Kahn. The parallels between Kahn's and Plato's philosophies become critical in relating the theory of Forms to architecture and will be examined in greater detail in Chapter Two.

The meta-physics of Plato are heavily dependent on his theory of Forms, whereby the universe is separated into two realms: an intelligible realm and a sensible realm. All objects that exist in the sensible realm - perceivable to us by our senses - are merely imperfect shadows of their essences or Forms. These Forms exist in the intelligible realm, and are only perceivable through cognition. Plato's theory of Forms will be examined using three allegories that Plato employs in his greatest work, The Republic: the allegory of the divided line, the allegory of the sun and the allegory of the cave.

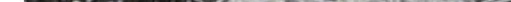




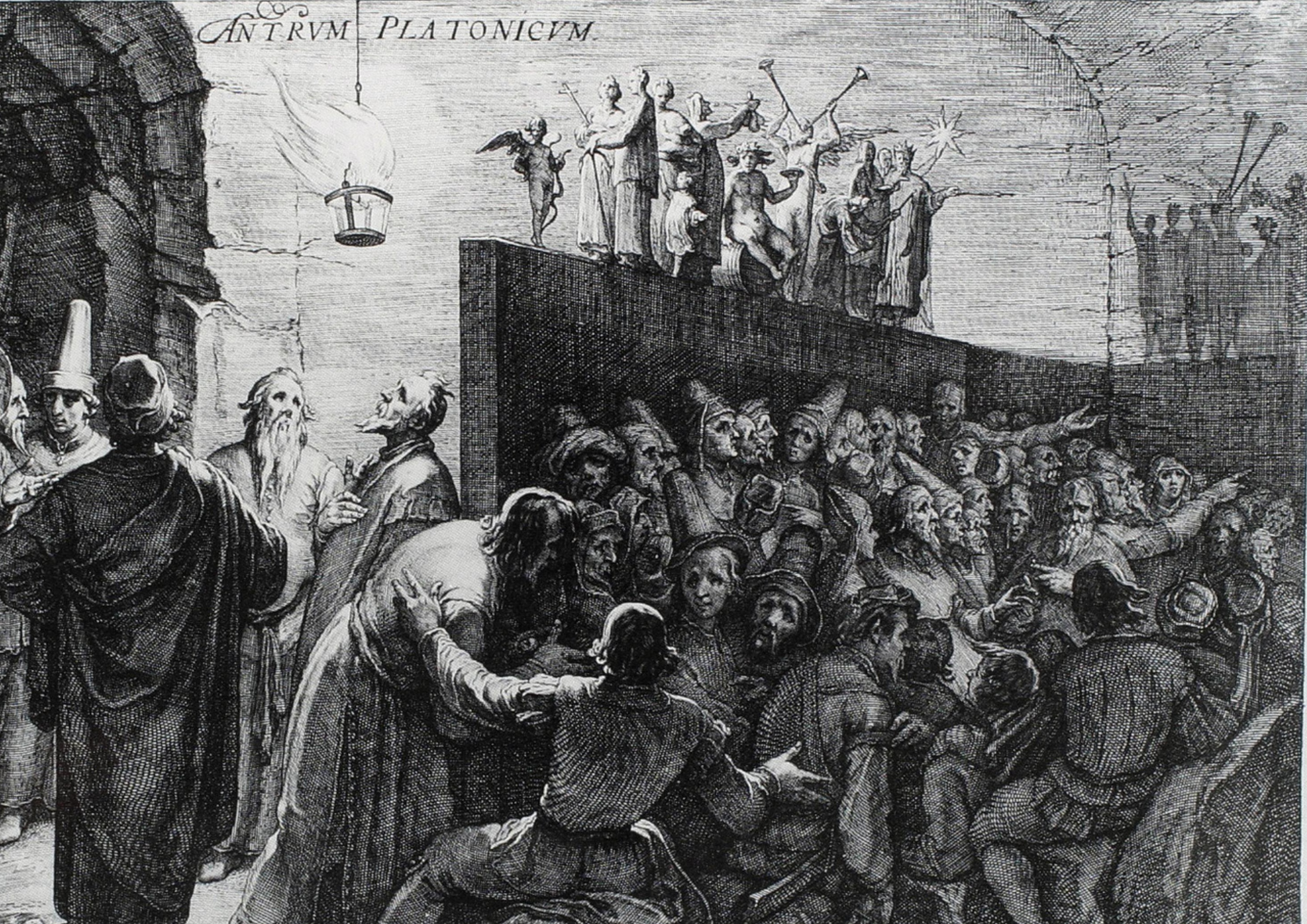




$\begin{array}{ccccc} & \text { objects } & \text { mathematical objects } & \text { ideal forms } \\ \text { A } & \text { B } & \text { C } & \text { D } & \text { E }\end{array}$

\section{ALLEGORY OF THE DIVIDED LINE}

Although the allegory of the sun preceded the allegory of the divided line, the latter will be explained first because of its diagrammatic depiction of Plato's two separate realms. The allegory begins with Socrates asking those present to imagine a line divided into two unequal segments, the smaller representing the sensible and the larger the intelligible. Each of these segments is then divided again by the same unequal ratio. As shown in the diagram (see fig. 6) the second segment represents all physical objects that we can perceive with our senses and the first represents the images that these objects create, like shadows and reflections.

The third and fourth segments represent the intelligible realm of knowledge, the third representing mathematical knowledge such as hypotheses and theories, and the fourth representing the philosophical knowledge of Forms. The fourth segment relates to the third in the same way that the second relates to the first. Just as the first segment contains mere shadows of the objects of the second segment, so the abstract and mathematical knowledge in the third segment is merely a shadow of the true philosophical knowledge of Forms in the fourth segment. Plato uses the example of mathematics for the third segment because it is accepted that there are odd and even numbers, from which other mathematical knowledge is based, yet it has never been questioned why numbers are odd or even to begin with. The odd and even numbers represent the images and shadows in the sensible realm which are created
Fig. 6

Plato's allegory of the divided line 
by the objects that cast or project them. In the same way, there is a reason why numbers are odd and even but mathematics are unable to explain this, so there must be something else causing this to be true: an intelligible Form.

\section{ALLEGORY OF THE SUN}

Before the allegory of the divided line, Plato uses the sun as a metaphor for illumination in the intelligible realm. He explains that our perception of objects in the sensible realm is dependent on the illumination provided by the sun, without which we would be unable to see or understand anything. He suggests that the same occurs in the intelligible realm, that one particular form exists as a source of illumination (The Good) and grants cognition of the lesser forms. The Good is Plato's supreme form of knowledge - though not knowledge itself - an understanding of which was the ultimate pursuit of Plato's theory of Forms.

\section{ALLEGORY OF THE CAVE}

The final allegory used to describe Plato's theory of Forms is the allegory of the Cave. In Plato's dialogue The Republic, Socrates describes a cave in which a row of prisoners has been chained their entire lives, forced to face the rear of the cave and unable to turn their heads to see each other. Behind them is an elevated road with a low wall between the road and the prisoners. On the other side of the road is a fire, which casts shadows on the rear of the cave; these shadows are all that the prisoners are able to see, so when a person walks along the road or stops and creates shapes with puppets or other objects, the prisoners cannot see the true object, but only its shadow. Having been in the cave their entire lives, the prisoners are in the firm belief that the shadows cast on the cave wall are the entirety of reality. They have attributed names to various objects through conversation with one another and associated the sounds of the passers-by above them with the shapes and symbols they see 

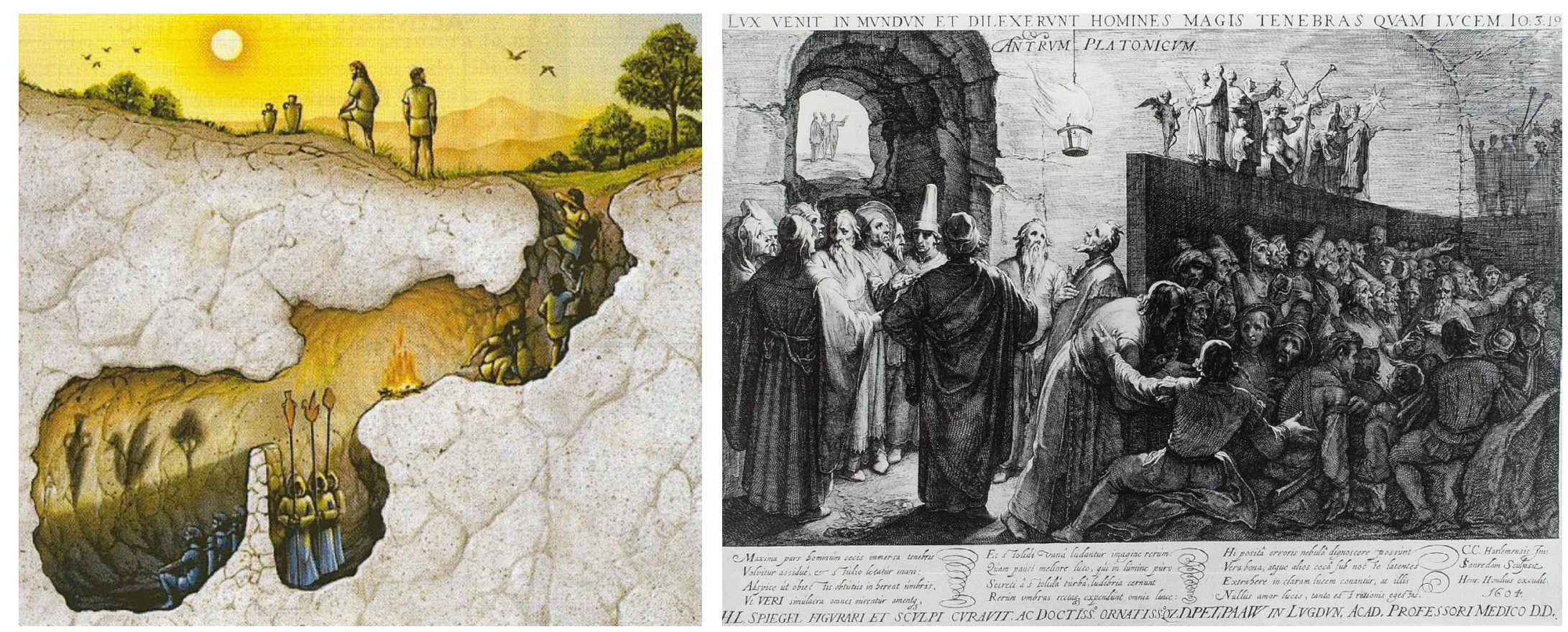

Fig. 7 (far left)

An illustration of Plato's allegory of the cave.

Fig. 8 (left)

An engraving by Jan Saenredam (1565-1607) of a painting by Cornelis Corneliszoon van Haarlem (1562-1638) representing Plato's allegory of the Cave (also on pg. 21). 
on the wall. Plato uses the cave and its prisoners as an analogy for the relationship between the sensible and intelligible realms.

Plato continues by having Socrates explain what might happen if a person from outside the cave were to descend and free one of the shackled prisoners, leading him up to the outside world. Immediately the prisoner would suffer a great deal of discomfort in moving, walking and in looking at the fire directly; it would take time for him to adjust to the brightness of the fire and the clarity of the objects and people which he had formerly only known as existing in the form of shadows on a wall. Additionally, the prisoner would be at a loss to explain to a passer-by what a particular object he is looking at might be, for he has only ever seen its shadow. As the prisoner is led past the fire and towards the cave entrance the blinding light from outside would only increase his discomfort causing him to turn back and seek the comfort of the darkness in the cave. But if he were forced onwards and into the outside world it would be as if he were blinded, unable to see anything considered by us as real until his sight had adjusted:

And at first he would easily discern the shadows and, after that, the likenesses or reflections in water of men and other things, and later, the things themselves, and from these he would go on to contemplate the appearances in the heavens and heaven itself... And so, finally, I suppose, he would be able to look upon the sun itself and see its true nature, not by reflections on water or phantasms of it in an alien setting, but in and by itself in its own place (The Republic 516a).

The entire allegory of the cave is a description of the journey a man might take from understanding only the sensible realm, to first experiencing the illumination of The Good in the intelligible realm, 
onwards until he finally understands the entirety of the intelligible realm and is able to perceive The Good itself and the way in which it gives light to all things and yet is different from all things. Plato held that the only way one could achieve such an understanding was through dialectic and dialogue. The dialogue itself is therefore a method by which Plato believes he can achieve an understanding of the Forms and The Good. The following section will compare the similarities between the theory of Forms and Stoicism in order to gain a better understanding of the notion of retreat that this thesis will be testing, and the part that dialogues will play in achieving that retreat. 


\section{PLATO, STOICISM, AND NOTIONS OF RETREAT}

Plato's form of The Good and Zeno's stoic idea of logos have a certain commonality, despite being fundamentally very different philosophies - the stoics rejecting any notion of immaterial forms. The pursuit of either will lead in Plato's case to knowledge, and in Zeno's case to virtue. Once The Good and the logos are understood the philosopher and sage will be so dramatically transformed that they will no longer be able to return to their former states; in Plato's allegory of the cave were the prisoner to venture back into the cave he would be considered a madman by his former fellows, and even put to death. The commonality appears to lie in the desire to reach a form of enlightenment that leads to mental and spiritual freedom.

The term 'philosophy' comes from the Greek philosophia, which means 'love of wisdom'. This is true for Plato and his theory of Forms, in which he suggests that wisdom, or true knowledge, can be attained through an understanding of The Good. Here Stoicism differs from Plato's theory of Forms in that Stoicism suggests that wisdom can be attained through virtue, and that to live virtuously one must attain an understanding of the logos. The sage, knowing his place as part of the many systems that make up the logos, understands that the situation he finds himself in has a purpose, and in understanding the reason why he is in that situation, the sage is able to become detached from the pain and suffering that may result. The stoics believed that this form of enlightenment was achievable through the perfection of a rational agency, and Plato believed that it was achievable through dialectic and dialogue. 
In Stoicism, by practicing rationalisation and perfecting his rational agency, the sage is led to an understanding of the divine will of the universe; in Plato's theory of Forms (as most clearly evidenced in the allegory of the cave), a person is led up from ignorance into the sublime understanding of The Good. They each describe a transformation from a state in which a person is subject to the physical restraints of the body to a state in which the mind transgresses and retreats from those restraints, becoming detached.

\section{Architectural Implications}

The relevance of Plato's theory of Forms and Stoicism to architecture appears to be centred on the idea of the enlightened state of mind. This thesis argues that architectural experience can be designed to achieve a similar understanding of retreat, that architecture can create a spatial experience, which 'talks about' and offers an inhabitant this kind of retreat. The architectural experience can be conceived as establishing a dialogue with the inhabitant as he or she pursues or discovers this freedom of the mind. The thesis argues that the 'architectural dialogue' may in fact be a viable method by which an inhabitant achieves this detachment. Plato held that Forms could only be conceived through dialectic, or dialogue. The thesis therefore tests how introducing this as a methodology is appropriate not only for understanding stoic architecture, but more importantly for the pursuit of retreat through the enlightened state of mind. 


\section{LOUIS I. KAHN}

I only wish that the first really worthwhile discovery of science would be that it recognises that the unmeasurable, you see, is what they're really fighting to understand, and the measurable is only a servant of the unmeasurable; that everything that man makes must be fundamentally unmeasurable.

Louis Kahn, architect (1902-1974) 
Another motivation for pursuing Plato's theory of Forms as a tool is to test the relationship it has with architecture resulting from the parallels that can be drawn between it and Louis Kahn. These parallels are evident throughout Kahn's development of his theories of Form and Design and Silence and Light as portrayed most explicitly in his 1961 essay "Form and Design":

For to express oneself in music or architecture is by the measurable means of composition or design. The first line on paper is already a measure of what cannot be expressed fully. The first line on paper is less. (145)

Kahn's use of 'measurable' and 'immeasurable' in the essay is analogous to Plato's sensible and intelligible realms. If we continue by using Plato's terminology, what we are able to conceive with our cognition exists in the intelligible realm, whereas what we perceive is in the sensible realm and is a shadow of the more ideal intelligible realm. The preceding quote from Kahn's essay establishes that, like Plato, he believes that an idea is perfect, while the expression of it in the measurable realm is less; a perfectly straight line can never be drawn that way because it uses measurable materials such as paper and graphite in order to become perceivable. As a result it can never be a perfect line, but is rather a crushed trail of particles strewn across a fibrous surface.

\section{ORDER IS}

The second parallel between Plato and Kahn is in their shared search for beginnings and definitions. Kahn encountered the same problem
Fig. 9 (pg. 32)

Louis I. Kahn's "Salk Institute for Biological Studies", California, USA (1962).

\section{Fig. 10 (right)}

A matrix explaining the parallels between Plato's theory of Form and Louis Kahn's theory of Silence and Light, identifying each pairing as either oppositional or liminal. 


$\begin{array}{|cc|}\text { sensible } & \text { intelligible } \\ \text { (images / objects) } & \text { (mathematical objects / forms) } \\ \text { KAHN } & \text { 'immeasurable' } \\ \text { 'measurable' } & \text { Psyche } \\ \text { Nhought } & \text { "existence will" } \\ \text { Nature } & \text { desire to create } \\ \text { means to create } & \text { SILENCE } \\ \text { LIGHT } & \text { inspiration }\end{array}$


as the Stranger, the Student Theaetetus, and several of Socrates's interlocutors in searching for a definition. Like them, in his search for the definition of Order, Kahn begins by listing everything that Order is, but rather than leading him to a definition for Order, it simply creates an ever-increasing list of things that contain order but are not Order itself. Kahn's second daughter, Alexandra Tyng explains that in his exacerbation, it appears that Kahn inadvertently revealed the ideal definition itself:

The effort left him so mentally exhausted he finally threw out the definitions and kept the beginning of the sentence: 'Order is.' Amazingly, those simple words described order better than all the definitions put together. (29)
Kahn's pursuit of beginnings grew to later become a cornerstone of his theory of Silence and Light. The development of this theory and its similarities to Plato's theory of Forms will be examined in the following chapter. 


\section{THE DIALOGUE BETWEEN SILENCE \& LIGHT}

Alexandra Tyng studied Kahn's philosophy as part of her University of Pennsylvania Master's thesis in Architecture, which later formed the basis of her book Beginnings: Louis I. Kahn's Philosophy of Architecture. In it she explains that Kahn's interest in the notion of 'measureable' and 'immeasurable' continued throughout his theoretical development, resulting in the pairing of Silence and Light, with Silence being 'immeasurable' and Light being 'measurable'. The development of this theory continually described a pairing of ideas (see fig. 10), one of which related to the 'measurable' (and Plato's sensible realm) and the other to the 'immeasurable' (and Plato's intelligible realm). These began as oppositional dialogues and later transitioned into liminal dialogues as he began to refer to them as "auras" rather than "objects."
These pairings began with Kahn's ideas of Thought (measurable) and Feeling (immeasurable). Feeling is the inexpressible source of an idea that suddenly strikes a person. In "Form and Design" Kahn describes Feeling as without measure or language (145) and in Beginnings Tyng recalls that Kahn would often "return to here and now, having come to a realization without being able to articulate the process by which he had arrived at that point" (27). So, Feeling is an immeasurable force, the desire, and originates from a place that is similar to Plato's intelligible realm.

Thought is inseparable from Feeling. In "Form and Design" Kahn explains that it represents the process by which an idea can be transformed into a physical object: "Thought is Feeling and presence of Order" (145). Feeling is the desire to create and Thought 
is the means to create and so Thought is very much a part of the measurable realm. Thought and Feeling continue to parallel Plato's sensible and intelligible realms in a letter of Kahn's to the mother of his only son, Nathaniel: "So far I sense our own feeling and our own thought must reach out to the Realm of Feeling and the Realm of Thought" (Tyng 162). Kahn's idea that there exist realms separate to the physical universe would continue to develop through his theory of Silence and Light.

The parallels with Plato remain consistent as Kahn developed his theory of Thought and Feeling into a further oppositional dialogue between Nature (measurable) and Psyche (immeasurable). Through his use of the term 'Nature', Kahn refers to a force that unconsciously enacts a set of harmonious laws which are responsible for the countless variations present in the world: "the elephant and the man are different designs. But the same order created them..." (qtd.
McQuade 139). Nature, like the sun in Plato's allegory, brings all things into a perceivable existence. Psyche, on the other hand, is Kahn's way of referring to the collective soul of all living things, the "existence will" that gives rise to the force governing the laws of Nature. The relationship between the two is explained in an excerpt from one of his notebooks:

Nature is the maker of all things, the psyche desires things and challenges nature to make that which expresses the inexpressible, that which cannot be defined, that which has no measure, that which has no substance. (qtd. Tyng 162)

Psyche begins to transform away from a single word and towards the more abstract idea of "existence will" as Kahn continues to develop this dialogue. Kahn spoke of Nature and "existence will" in his 1969 lecture "Architecture: Silence and Light," saying that 
"The one is measurable. The one is completely unmeasurable" (473). Once again he refers to the ideas of 'measurable' and 'immeasurable' continuing to parallel Plato's theory of Form.

The change from the idea of Psyche to "existence will" marks a transition from the dualities being about oppositions to a more liminal relationship. The final duality of Silence and Light contains the conclusions to his development of the dialogue between the means to create (measurable) and the desire to create (immeasurable). The following passage from Tyng supports the way in which these dialogues appear to have developed in relation to Silence and Light:

In the 1960s, as Kahn pondered the relationship between nature and the psyche, he was also refining and articulating the two complimentary ingredients of creativity that he had originally identified as thought and feeling. Although Kahn consistently spoke of the dichotomy between the desire for expression and the means of expression, after 1967 he ceased to represent these components as things - thoughts and feeling, nature and psyche - and began to refer to the more abstract "auras" of silence and light. (130)

Silence, inheriting features from Feeling and Psyche, exists in an immeasurable realm, beyond the physical one we inhabit, and provides all things with the desire to be created: an "existence will" that is individual to each thing. Silence is analogous to Plato's intelligible Forms, and Light is the means by which the desire to be created (Silence) is fulfilled in the physical realm. The notion of "auras" is evident in his lecture "Architecture: Silence and Light" where he says, "In the aura of Silence and Light, the desire to be, to make, to express, recognises the laws that confirm the possible" $(1969,474)$. 
As Kahn's ideas developed, a consistent dialogue remained throughout. Though each iteration of his theory had different names and variations, they all developed from the dialogue between the 'measurable' and 'immeasurable'. This underlying theme is one way in which Kahn's theories can be compared with Plato's sensible and intelligible realms. The next section inspects a further parallel between Kahn's theory of Silence and Light and Plato's theory of Forms to test the usefulness of comparing Kahn's final dialogue between Silence and Light with Plato's idea of The Good.

\section{THE SUN AND THE LIGHT}

In addition to the parallel between Plato's sensible and intelligible realms and Kahn's theory of Silence and Light there is another way in which the two theories resemble each other. Dr Steven Fleming, of the University of Newcastle (N.S.W.), identifies the uncanny parallel between Kahn's use of daylight to reveal the structure of a space and Plato's allegory of the sun:

When coupled with the fact that Kahn sees his buildings as earthly manifestations of transcendent 'forms', his approach to daylight illumination suggests a striking accord with Plato's analogy. (32)

As noted previously, Plato's allegory of the sun holds that The Good illuminates the Forms in the intelligible realm in the same way that the sun illuminates the physical world to be perceived by the eye. Without the sun we are unable to perceive any objects or their images and so, from a philosophical perspective, nothing would exist. Kahn's description of Light as the means to create leads to the same conclusion. In his lecture, "Architecture: Silence and Light," Kahn says, "I sense Light as the giver of all presences, and material as spent Light" $(1969,472)$. Furthermore, Kahn wrote, "Light is really the source of all being" (Ed. Lobell 22). Without 


\section{Light, nothing could exist.}

Plato's theory is centred on the pursuit of an understanding of the intelligible realm, the intangible void from which all physical things receive their Form. In the following passage Tyng explains that Kahn sees Silence in a similar way:

In later conversations, Kahn indicated that he saw silence as a great void beyond the confines of time and space, a void without life of any kind. Yet out of such "emptiness" came galaxies, the stars, the planets - and life. Thus silence, although it is ostensibly a void, must contain the potential for life. (132)

While Plato pursues the sun's equivalent in the realm of Forms (The Good), Kahn's reverence for Silence was centred on the threshold between it and Light: the boundary between the two realms, which he believed was the point of inspiration. The dialogue was more important to Kahn than that which lies in the realm of Silence.

\section{THE RUIN}

The final step in Kahn's development of his theory on Silence and Light was to translate it from a meta-physical theory into an approach for the design of architecture. Since travelling to Rome in 1960, Kahn had become enamoured with the Ruin, and in 1964 he began to consider it as an integral part of a building's life. Kahn frequently refers to the spirit and essence of a building being revealed and freed when a building is released from 'bonds of servitude'. This is where the parallel between Plato and Kahn becomes most clearly manifested in architecture. In a 1964 letter to Harriet Pattison, the mother of Kahn's third child, Kahn wrote the following: 
The quiet ruin reveals again the spirit out of which it once stood as a proud structure. Now it is free of its bonds... The building standing complete has its spaces locked in unbending structure. Its bonds are the duties of use. The spirit is engaged and must answer... The quiet ruin now freed from use welcomes wild growth to play joyously around it and is like a father who delights in the little one tugging at [his] clothes. (qtd. Tyng 166)

No longer bound to fulfil the programmatic and habitational requirements of the measurable realm, the idealised Form of a building, its spirit, is most apparent in its ruined state.

The design for the Meeting House and central court of the Salk Institute for Biological Studies in California is the first example of Kahn's fully developed concept of "wrapping ruins around buildings". Though the design for the Meeting House at the
Salk Institute was never realised, the influence it had on his later work is extensive. The National Assembly Building (1962-1974) in Dhaka, Bangladesh and the Kimbell Art Museum (1966) both drew inspiration from existing ruins (see fig. 11-14). Kahn's use of ruins as inspiration culminated with his design for the Hurva Synagogue (1968-1974), where the building itself is conceived as a ruin, set amidst many other ruins in Jerusalem.

As previously stated, Kahn was continually searching for a beginning - having expressed his desire to read "Volume Zero" of history - and the beginning to all things existed in his realm of Silence. However, Kahn realised that the true beginning, existing in the immeasurable realm of Silence, was unattainable. Tyng explains Kahn's realisation: "the closer one gets to unravelling the mystery of the beginning, the farther the knowledge recedes from one's grasp" (132). There is always another "Volume Zero" behind the one that
Fig. 11

A plan of the Domus Aurea in Rome which Kahn drew inspiration from to design the National Assembly in Dacca.

Fig. 12

A plan of the National Assembly in Dacca, Bangladesh (1962-74) featuring a central octagon surrounded by an array of rectangular spaces, like the Domus Aurea. 

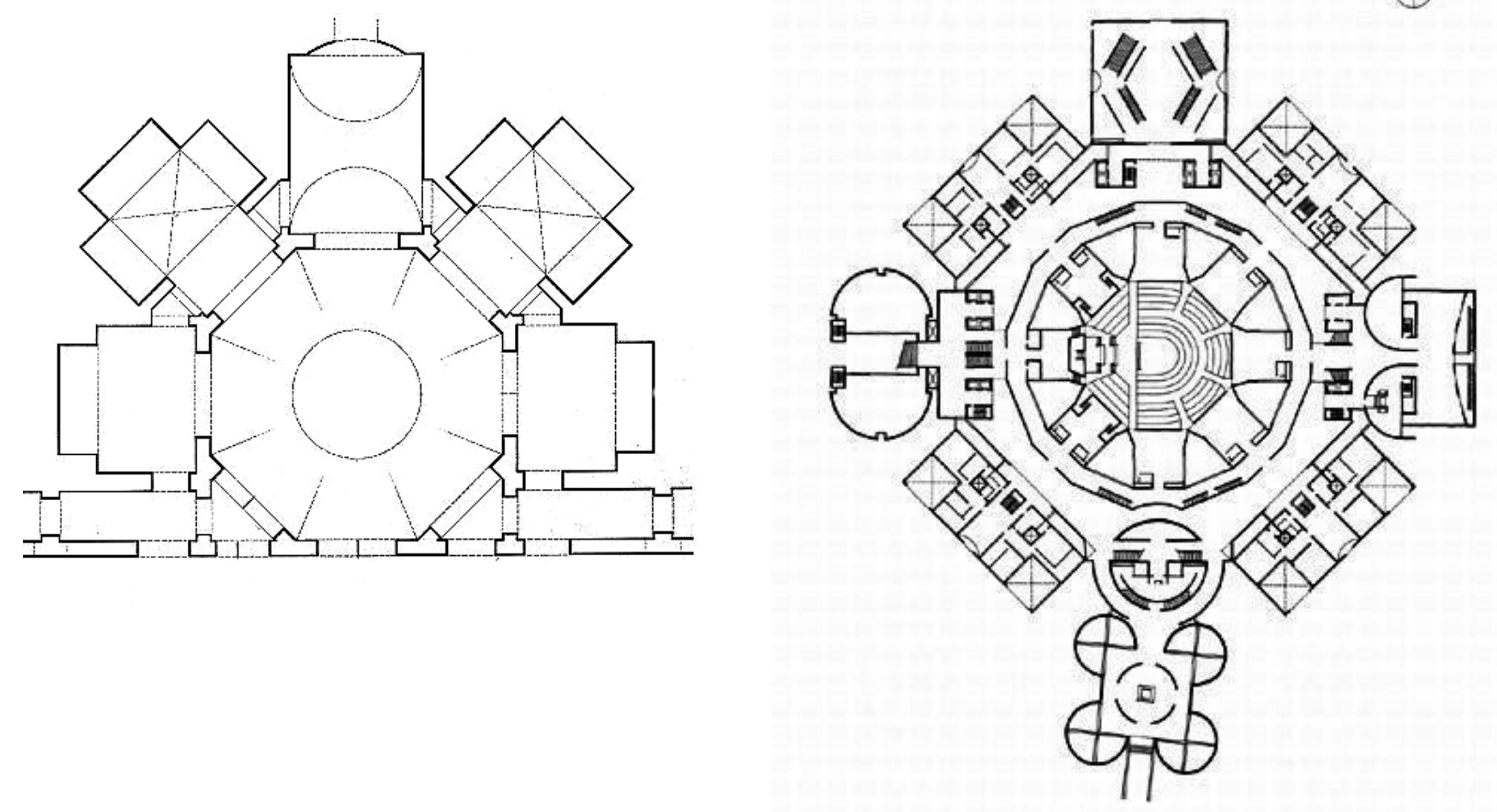

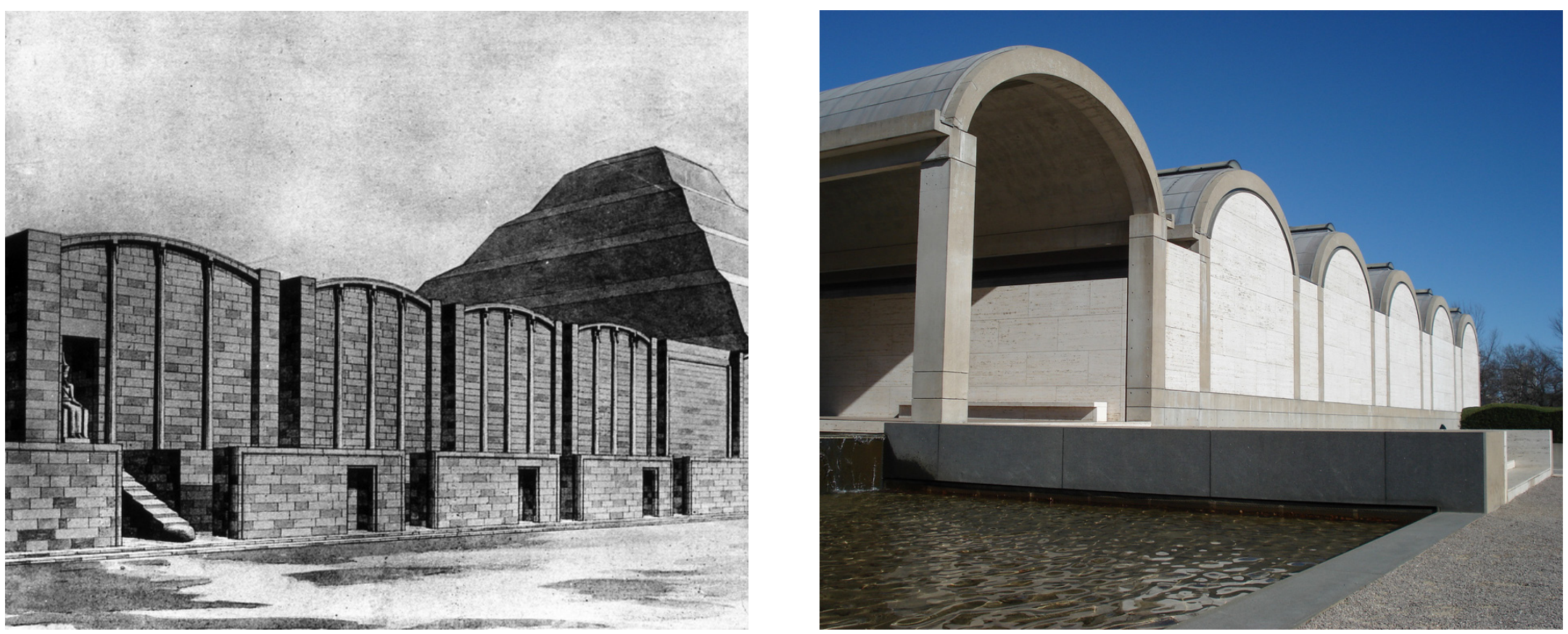


\section{Fig. 13 (far left)}

A lantern slide of the Step

Pyramid (background) and

Chapels (foreground) at Sakkara, Egypt.

\section{Fig. 14 (left)}

Exterior of Louis Kahn's

Kimbell Art Museum,

Texas (1966) which

clearly demonstrates the

inspiration Kahn drew

from Sakkara. has just been found. As a result, Kahn's interest in an immeasurable realm again favours how it interacts with the measurable realm what occurs at the meeting point between Silence and Light, where they engage in dialogue. This interest in the threshold is exemplified by the following passage from a lecture by Kahn:

I sense a Threshold: Light to Silence, Silence to Light - an ambiance of inspiration, in which the desire to be, to express crosses with the possible. $(1969,473)$

\section{CONCLUSION}

Plato held that the only way to understand or attain true knowledge - thereby removing yourself from the cacophonous illusions of the measurable realm - was through dialogue. The use of dialectic allows two opposing positions and viewpoints to reach an understanding, detaching both from the emotional conflict their opposite causes.
Kahn showed interest in a multitude of dialogues that stemmed from his ideas of 'measurable' and 'immeasurable' (dialogues between Nature and Psyche; Thought and Feeling; Silence and Light) and these led him to develop his theory of Silence and Light. His interest in these dialogues (both oppositional and liminal) was due to their nature as a point of inspiration at the threshold between the desire and the means to create. This thesis progresses from Kahn and Plato in order to test Oppositional and Liminal dialogues as a methodology for designing in a site featuring many oppositions. 


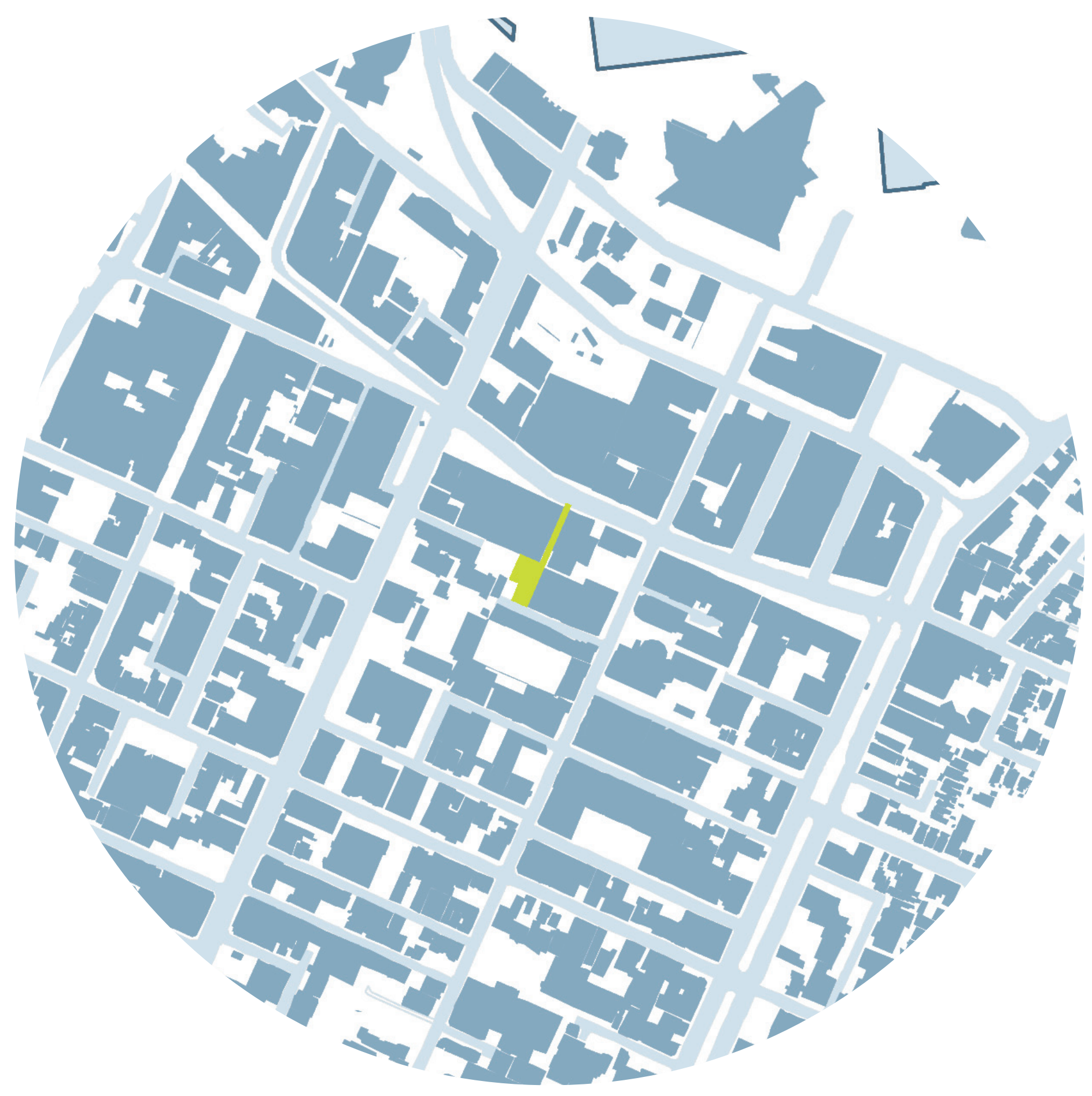




\section{CONTEXT - THE DIALOGUE OF THE SITE}

The fact that we are accompanied by a limited range of perception makes it seem plausible that, where our vision stops, existence stops as well, and the world comes to an end. Here the world of imagination and memory begins. 
The selected site for the thesis's design research intervention is a dark and narrow unnamed alleyway leading south from Courtenay Place, the centre of Wellington nightlife, to an isolated car park with two services lanes: Holland Street (leading to Tory Street) and York Street (leading to Taranaki Street). Further south, beyond these service lanes, the city block is comprised almost entirely of residential apartments.

In the evening, Courtney Place on the northern entry of the site is vibrant and filled with noisy bar and nightlife, while the car park at the southern end is usually dark and deserted. This unnamed alley is flanked on the west by the historical St James Theatre and on the east by The Mermaid and The Splash Club a strip club and brothel respectively. It represents a liminal threshold separating the faces of a building of culture and a building of vice. As mentioned in the previous chapter, the liminal dialogue of Silence and Light was extremely important to Kahn as the threshold between them represented the point of inspiration to him. The site is appropriate for testing this research question because it represents the threshold between two opposing programs. The site is also in close proximity to a temporary triage service that the Wellington Free Ambulance provides on Friday and Saturday nights, which cares for people who succumb to the frenetic nightlife. The Accident Compensation Company (ACC) and Wellington Free Ambulance are finalising a deal to create a permanent triage facility off Courtenay Place (Hunt A3), which makes the selected site an ideal location for the design of a permanent facility which provides vital retreat and care to those who are vulnerable.
Fig. 15 (pg. 46)

Site plan within the greater context of Te Aro, Wellington.

\section{Fig. 16 (right)}

Site plan showing the alleyway and carpark in light blue. 


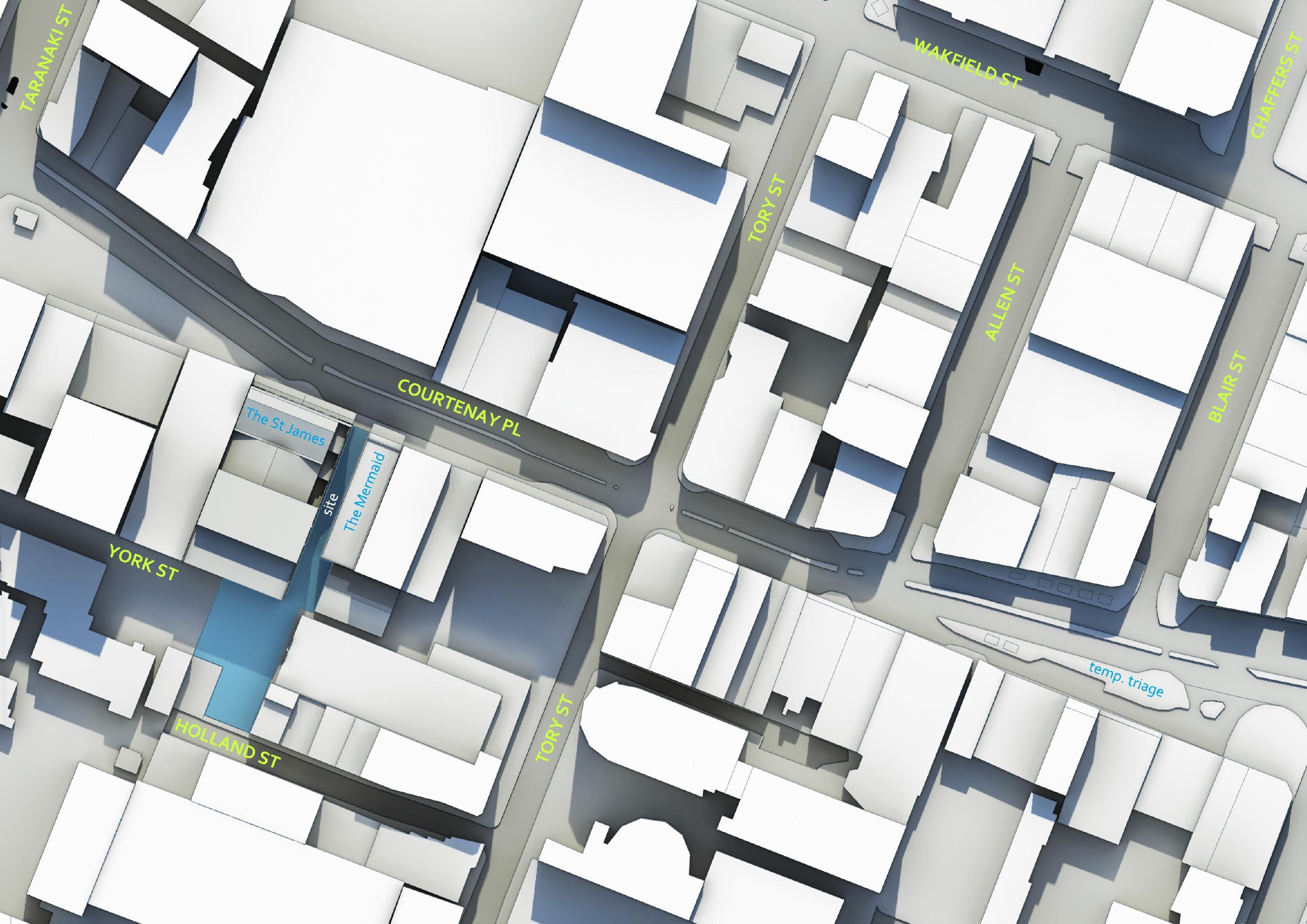



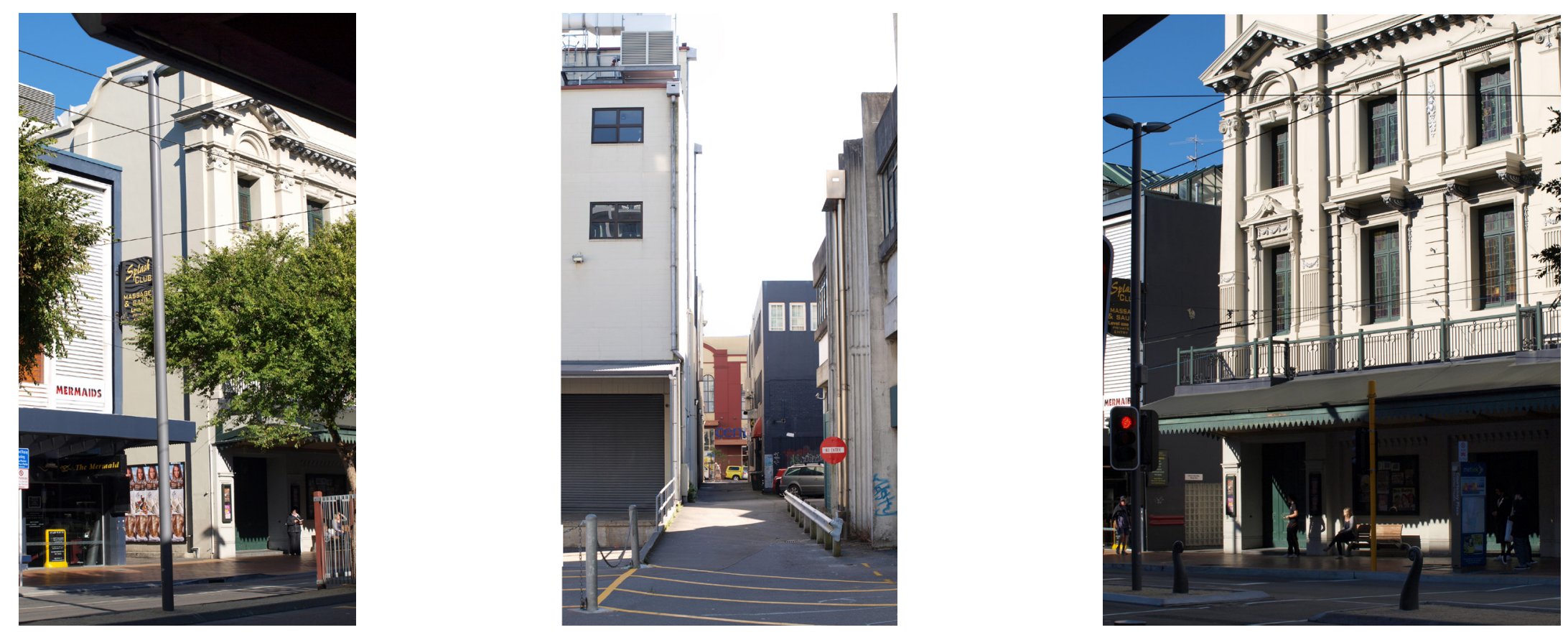

Fig. 17, 18, 19

Photographic studies of the site during the day. 


\section{CULTURAL AND CARNAL EXCESS}

Until 2003, prostitution was illegal in New Zealand, and remained hidden or on the outskirts of the central urban environment. Now, with the backing of women's rights groups, human rights groups and the public health sector, prostitution has been made legal, creating a previously non-existent condition in the urban centres of New Zealand's cities.

Prior to the Prostitution Reform Act 2003, prostitution was illegal but effectively permitted in New Zealand, with the restriction of having to be conducted indoors behind a façade. Sex-workers advertised their services as "escorts" and brothels were known as "massage parlours". The Massage Parlours Act 1978 was replaced with the Prostitution Reform Act 2003, which legalised prostitution and brothels in New Zealand; the first brothel to be licensed in
Wellington was Il Bordello, in the traditional red-light district of Vivian Street. Its owners had also been operating The Mermaid strip club since 2001 on Courtenay Place, above which is now a licensed brothel called The Splash Club. The addition of a brothel in the heart of Wellington's nightlife district caused a great deal of controversy, with other businesses fearing the possibility of Courtenay Place becoming a red-light district (Giblin). The City Council intervened by changing planning laws to prevent any further sex businesses from entering Courtenay Place; however, this came too late to prevent The Mermaid and The Splash Club from establishing themselves.

The alleyway selected as the site for this thesis's design intervention runs north-south, and on the western side lies the St James Theatre, 
previously known as His Majesty's Theatre, which was built in 1912 At the time it was one the largest theatres of its kind in Australasia and was used for vaudeville and cinema. One hundred years later, it is the home of the Royal New Zealand ballet and hosts a wide variety of dance and theatrical events.

The St James Theatre and The Mermaid (on the eastern side) are both oppositional in their program as well as their demographic, but they each contribute to the need for retreat. After a ballet performance or theatrical event, the patrons of the St James Theatre move out into Courtenay Place, entering the nightlife alongside the patrons who visit The Mermaid and those who visit the neighbouring bars. By the end of the night the distinction between these people becomes blurred. It is no longer important whether they came from The Mermaid or the St James Theatre; each demographic will have people in need of retreat and triage.
In addition to the oppositional nature of The Mermaid's and the St James Theatre's programs, the site experiences an oppositional shift in the type of occupants from night to day. During the daytime the alleyway's main usage is as a pedestrian thoroughfare, connecting the residential apartments to the south with the Courtenay Place precinct and waterfront to the north. While this is also its main use during the night, the people making use of this thoroughfare change from students and business people during the daytime to drunken, loitering revellers at night.

The nature of retreat desired during the daytime is very different to that required during the night. The daytime retreat being sought is one of sanctity and spirituality, free from the stress and noise of city life, and addresses the mental and spiritual wellbeing of the vulnerable inhabitant. The night-time retreat, however, is a retreat from self-induced excess, which may have occurred in an attempt 
Fig. 20, 21, 22

Photographic studies of the site, including the night of a quarter-final of the RWC (far right) when Courtenay Place was

closed to vehicular traffic.
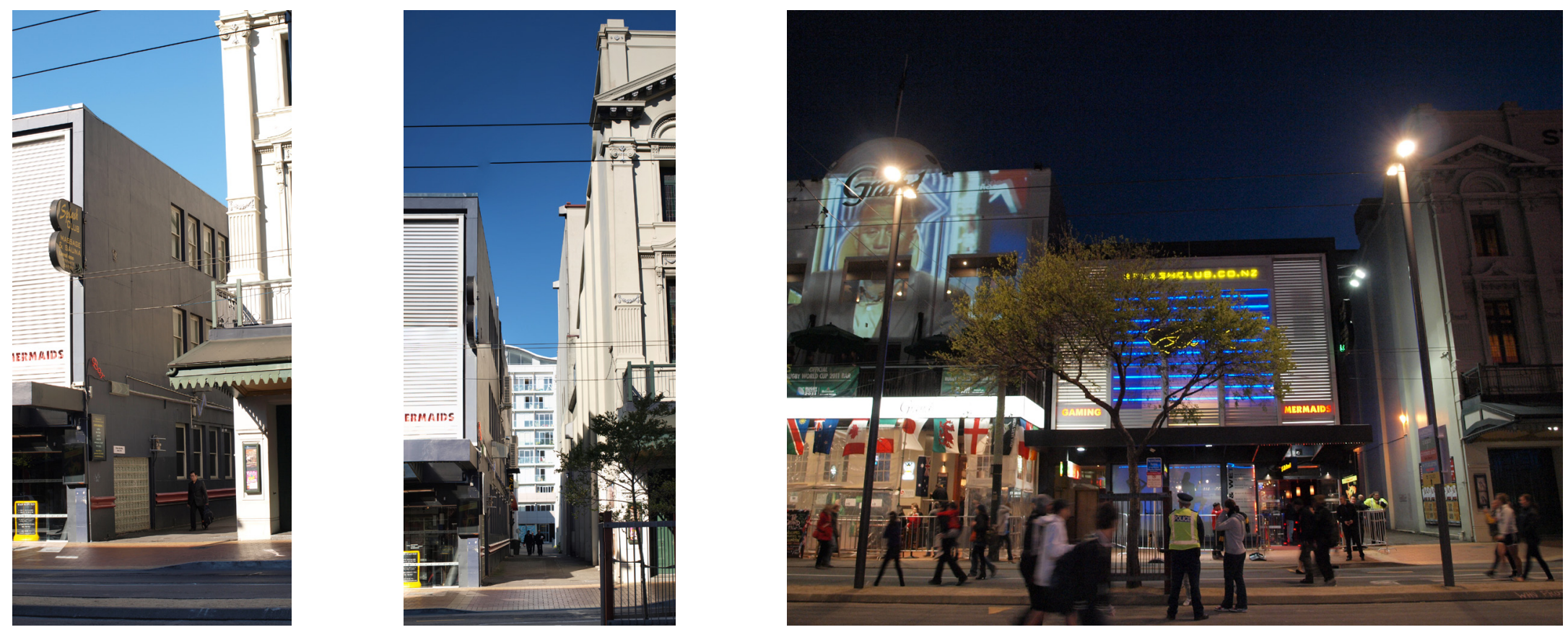

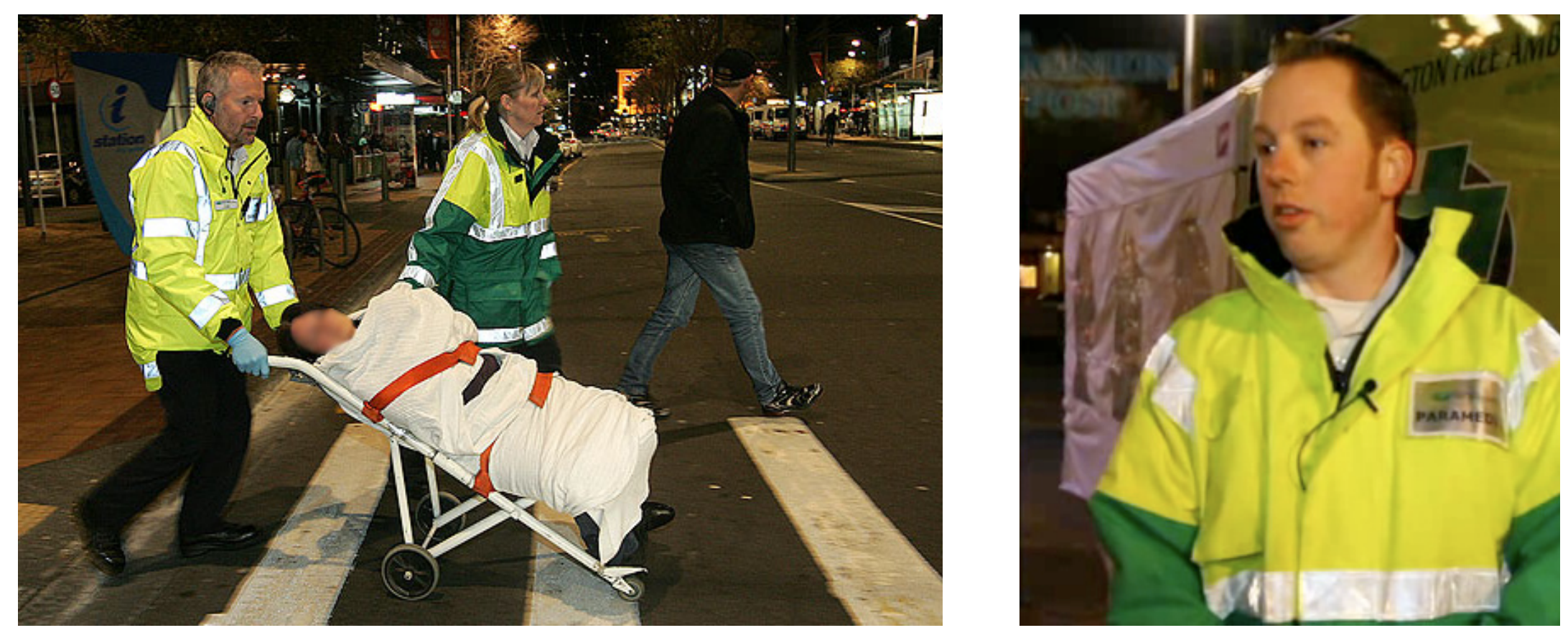

Fig. 23 (far left)

Paramedics from the Wellington Free Ambulance transport a patient to the nearby triage centre.

Fig. 24 (left)

Robert Ives, Community Care and Patient Delivery manager, is interviewed in front of the temporary triage tent and ambulance. 
to escape from the stress and emotional turmoil experienced during the day; it addresses the mental and physical wellbeing of the vulnerable inhabitant.

Emergency services can expect to receive up to 20 call outs to Courtenay Place on any given Friday and Saturday night. In August 2011 the Wellington Free Ambulance and Accident Compensation Company (ACC) began an 8-week trial service as part of the preparations for the 2011 Rugby World Cup (RWC). A temporary triage centre was set up on Courtenay Place for intoxicated and injured revellers on Friday and Saturday nights, and the trial was extended through the RWC itself, becoming a regular weekend service. The Wellington Free Ambulance's triage tent is intended to relieve this pressure on emergency services and the Wellington Hospital's Emergency Department. With the success of the trial, Wellington Free Ambulance (represented by
Robert Ives, Community Care and Patient Delivery manager) is interested in ensuring that the service is continued. The inaugural night of the service was interrupted by two cars occupying the reserved area intended for the ambulance and tent, forcing the medics to move further along the street (Duff). Disruptions like this highlight the importance of finding a permanent location if the service is to continue. Ives stated that: "If there was [sic] an old shop or something we could use, that would be brilliant" (Newton A3). This creates an excellent opportunity for the site to provide a permanent triage centre for the busy nights on Courtenay Place. Such a building would provide a safe environment for the medics and patients, and offer the vulnerable people of the night a place to recover from their intoxication or injuries. 
The architectural component of this research deals with resolving a site that represents the threshold between two contrasting programs (The Mermaid and the St James Theatre), as well as the differing requirements for retreat during the night and the day. These are the conditions to which the architecture must respond programmatically, and the following section will detail the intended program for the design research intervention.

The mental, emotional and physical vulnerability of people in the Courtenay Place precinct not only occurs on Friday and Saturday nights, but throughout the week. For this reason, the program will address two principal imperatives. In tandem with the program catering for "Triage of the Night", there will be a collection of spaces catering for "Triage of the Day" where it is possible for people requiring respite from a stressful day at work or other such trials to find retreat. This program will cater for both flexible forms of retreat, i.e. simply finding a quiet place to read a book or relax in the sun (a challenging condition in a narrow alleyway), as well as more institutional services. The dual program includes consultation spaces for counselling, as well as semi-permanent accommodation for volunteers or patients.

"Triage of the Day" offers a community centred approach to retreat. On July $17^{\text {th }} 2011$ a fridge was placed on the corner of Kilmore and Barbadoes Street in Christchurch and filled with books. The "Think Differently Book Exchange" is a part of the "Gap Filler" initiative in Christchurch, which seeks to regenerate the vacant sites left over after the September $4^{\text {th }} 2010$ earthquake. The fridge did so by 
Fig. 25

The "Think Differently

Book Exchange" on a vacant site in Christchurch (2011).

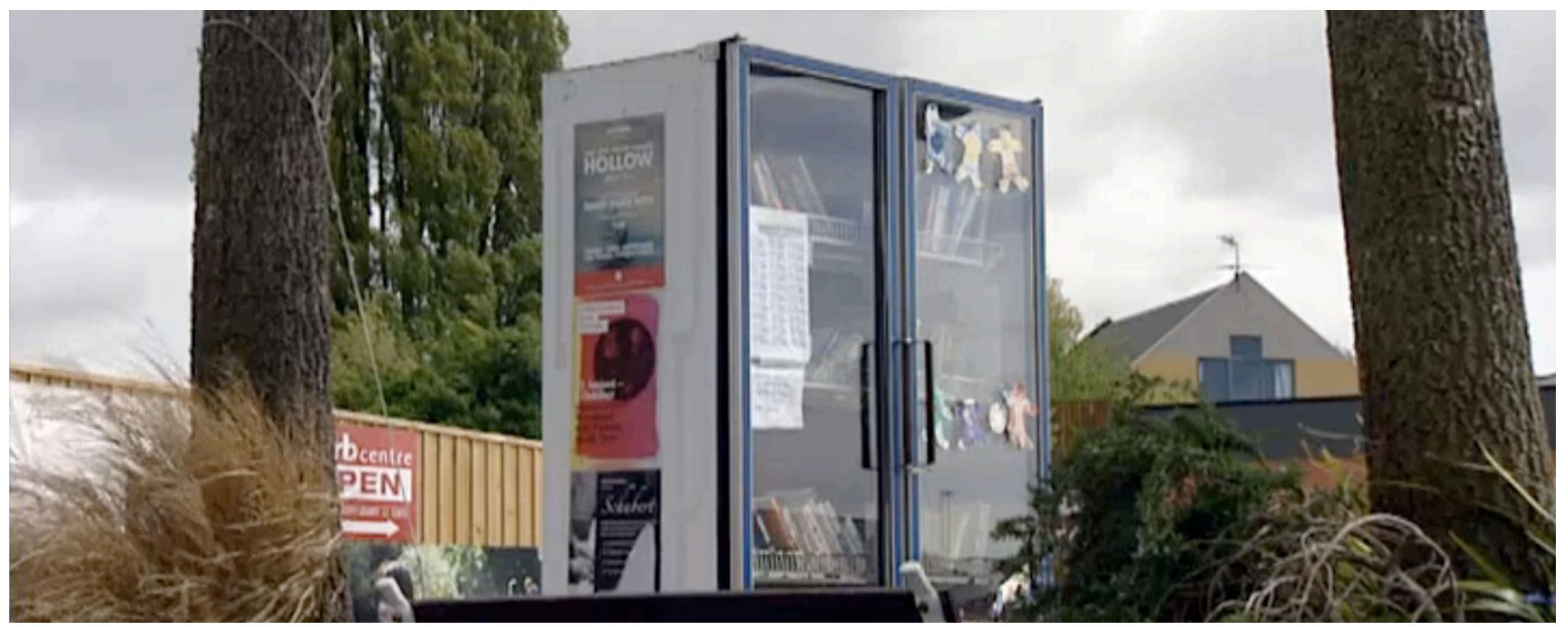


being a place in which books could be left for other people to find and swap. This kind of community activity is ideally suited to the "Triage of the Day". A person seeking retreat can come into the building and find an interesting book, swapping it for another that they would like to share. This creates a way for the inhabitants to become engaged in each other's plight. The storage space used for collecting used books can additionally be used by the Wellington Free Ambulance to keep the medical supplies they require for the "Triage of the Night", although with requisite safeguards added. This has the added effect of providing a secure store of supplies should a large emergency such as an earthquake occur in the Wellington area. Storing Civil Defence supplies within the building can further augment this facility, so that in the immediate aftermath of a Civil Defence emergency, the Triage Centre can be used as a vital inner-city base.
The following table identifies preliminary figures for the areas used for each element of the program and to which time of day it relates. They are based on current practice in triage centres and related emergency departments of hospitals. 
Fig. 26

Program

\section{TRIAGE OF THE DAY}

consultation spaces

$2 \times 18 \mathrm{~m}^{2}$

community library

200 books

retreat spaces

as many as possible

kitchenette

$1 \times 15 \mathrm{~m}^{2}$

accommodation

$1 \times 18 \mathrm{~m}^{2}$

\section{TRIAGE OF THE NIGHT}

treatment facility

$>26 \mathrm{~m}^{2}$

based on existing temporary triage centre

storage space

based on Civil Defence Cabinets

$>4 \times 1 \mathrm{~m}^{2}$

recovery spaces

based on an average of 5 patients per night over the 12 week trial period

\section{SHARED}

toilets

$4 \times 4 \mathrm{~m}^{2}$

circulation/sevices

$+15 \%$ 


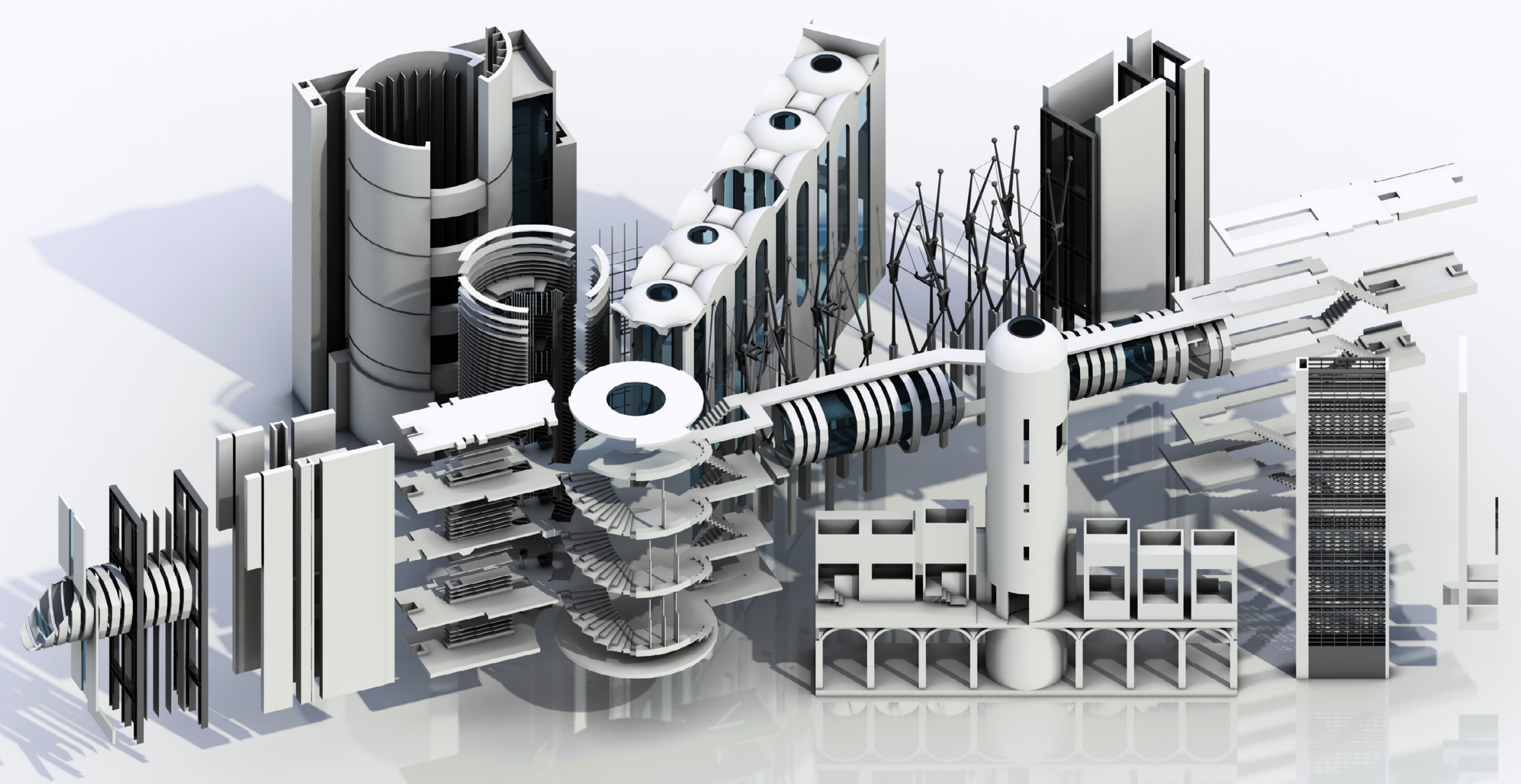




\section{DIALOGUES AS A METHODOLOGY}

The beauty of architecture is that it deals with the recessions of the mind, from which comes that which is not yet said and not yet made. 
In Chapter One, Plato's theory of Forms was analysed to demonstrate his belief that understanding and "true" knowledge can be achieved through dialogue. The Greek philosophy of Stoicism also suggests that an understanding of the logos (universal reason) can lead the stoic sage to an enlightened state of understanding. This chapter tests whether the strategic use of architectural dialogues can lend inhabitants of a space a sense of logos by unveiling the balance inherent in the built environment. This chapter proposes that architectural dialogues, leading visitors to a greater understanding of the inherent balances essential to architecture, can facilitate an enlightened state of understanding. This experience itself is a form of retreat, for the balance in architecture reflects the balance of universal reason, or as the stoics refer to it, the logos.
Stoicism claims that the stoic sage's understanding of his place within the universe, as part of the logos, can lead him to the ultimate form of retreat. So for a non-sage, the security of understanding one's place within a building environment based on the visible sets of balanced forces (dialogues) can offer a similar kind of retreat. The inhabitants' awareness of their position within the balanced systems and the dialogues of the architecture can create a sense of stability or security, because it represents something that is known and intuitively understood. The dialogues become the method by which an understanding of balance and the logos of the architecture are possible, leading to the sense of retreat.

The implementation of these dialogues also invites the author to propose a visual 'manifesto' on the nature of architecture, and like
Fig. 27 (pg. 60)

Exploded axonometric view of the design intervention,

\section{Fig. 28}

A matrix of the different dialogues that are investigated in this thesis, both theoretically and through design research. 


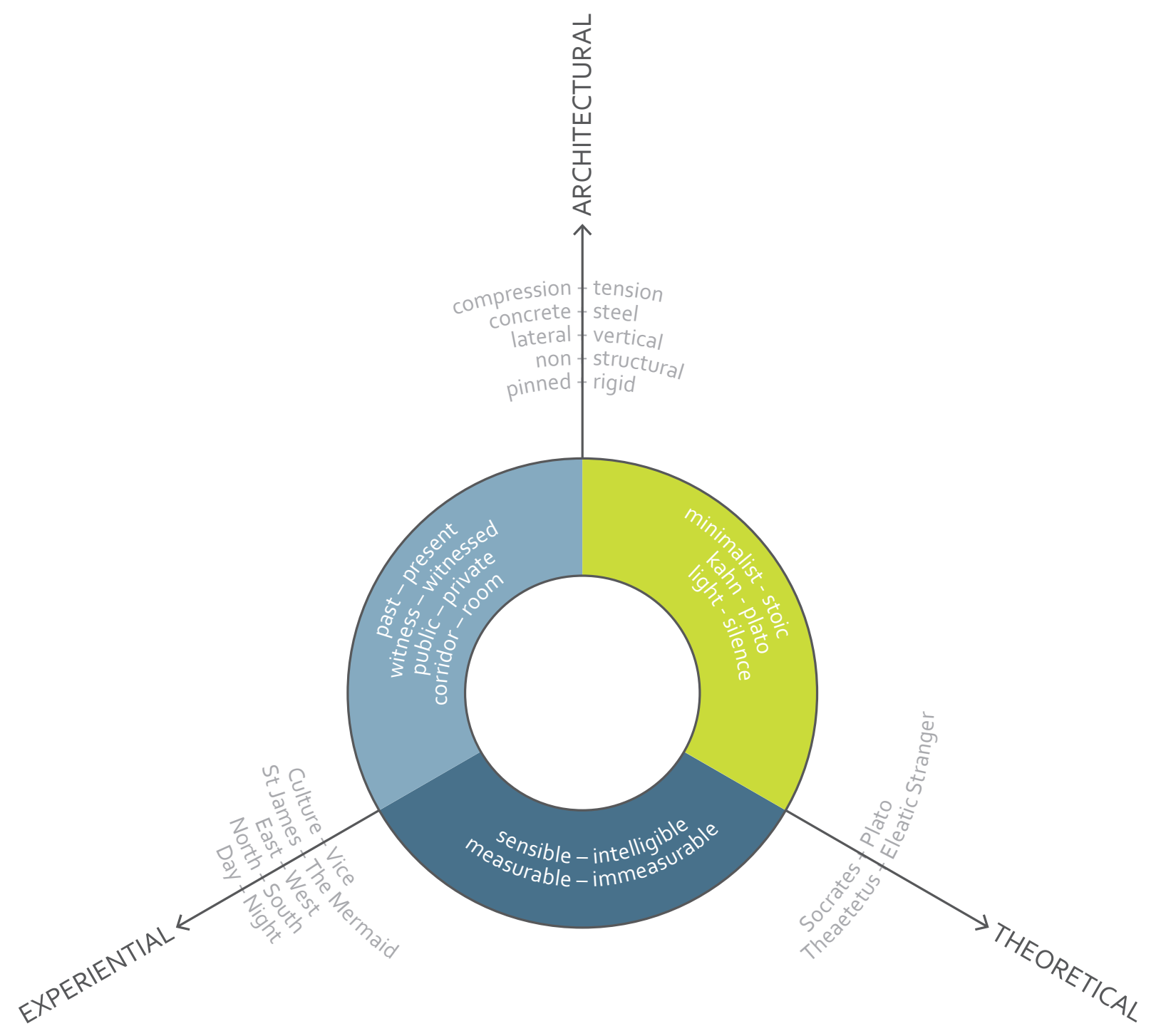


Plato, unveil 'truths' at their most fundamental levels.

In Chapter Two, the dualities (dialogues) within Kahn's theory of Form and Design (Silence and Light) were examined and compared with those relating to Plato's theory of Forms. Each was described as being either a duality about opposition (Sensible and Intelligible, Measurable and Immeasurable, Thought and Feeling, Nature and Psyche) or a liminal duality reflecting two sides of a single threshold (Nature and "existence will", desire to create and means to create, Silence and Light). The dialogues that the thesis tests as part of the design research are also divided into these two groups, Oppositional dialogues and Liminal dialogues. The following section introduces architectural "characters" through which the "dialogues" will occur within the thesis's architectural design research intervention. The dialogues reveal the balanced systems and relationships inherent in architecture so that the sense of balance within architecture can be conveyed to the inhabitant.

During the sequential dialogues, the architecture will periodically provide spaces of reflection or an individual element in a dialogue to point out how far the visitors have come in their journey towards retreat since first entering the building. This will give the visitors a renewed appreciation of the sense of retreat that they experience within the stability of the architectural dialogues, compared with the lack thereof in the outside world. 
Fig. 29

A collection of images documenting

the

development of the design research from initial site selection through to final design. The second row features the point at which dialogues were introduced as a methodology and the third row demonstrates the addition of Louis Kahn's architectural theory.
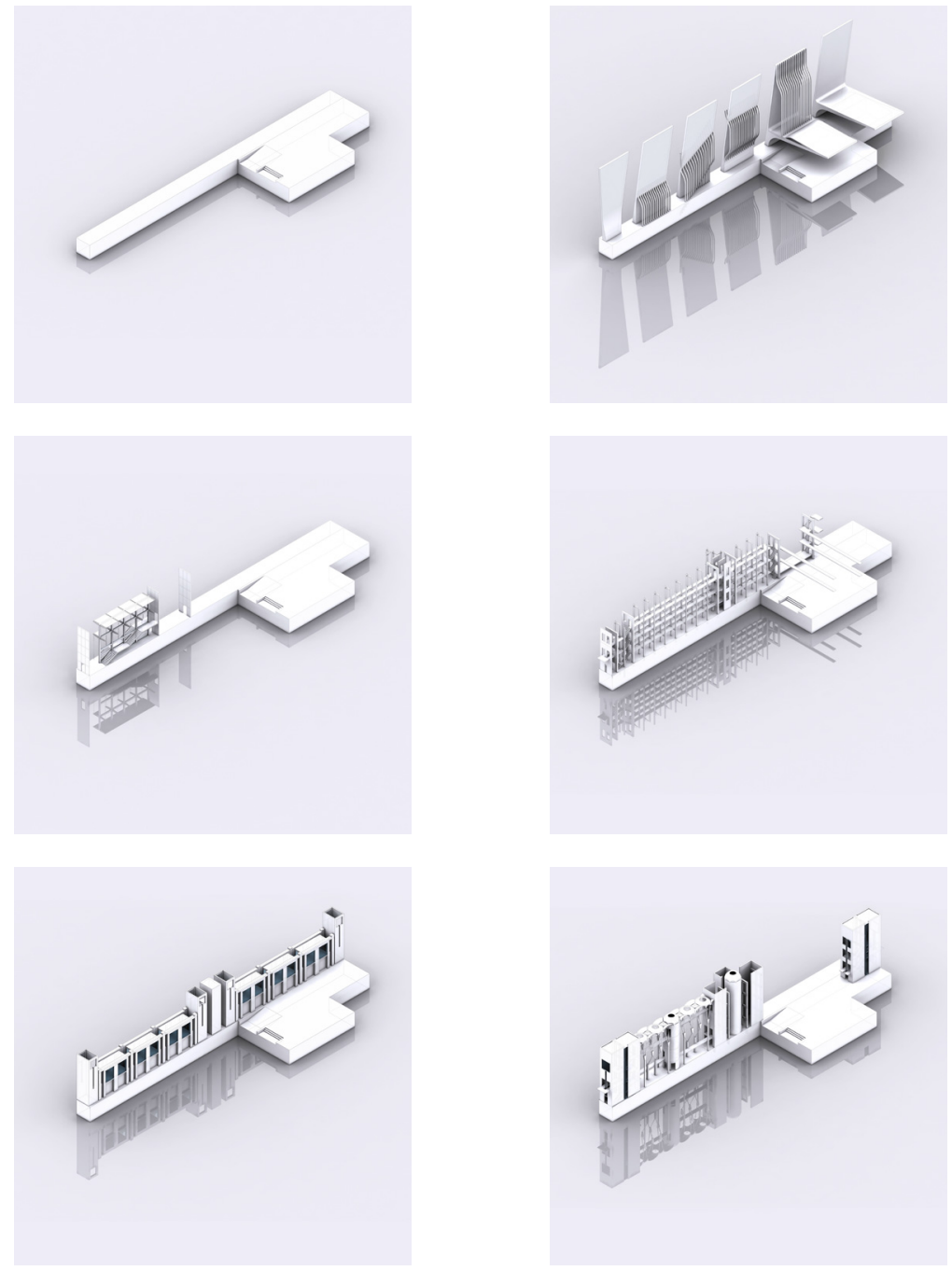
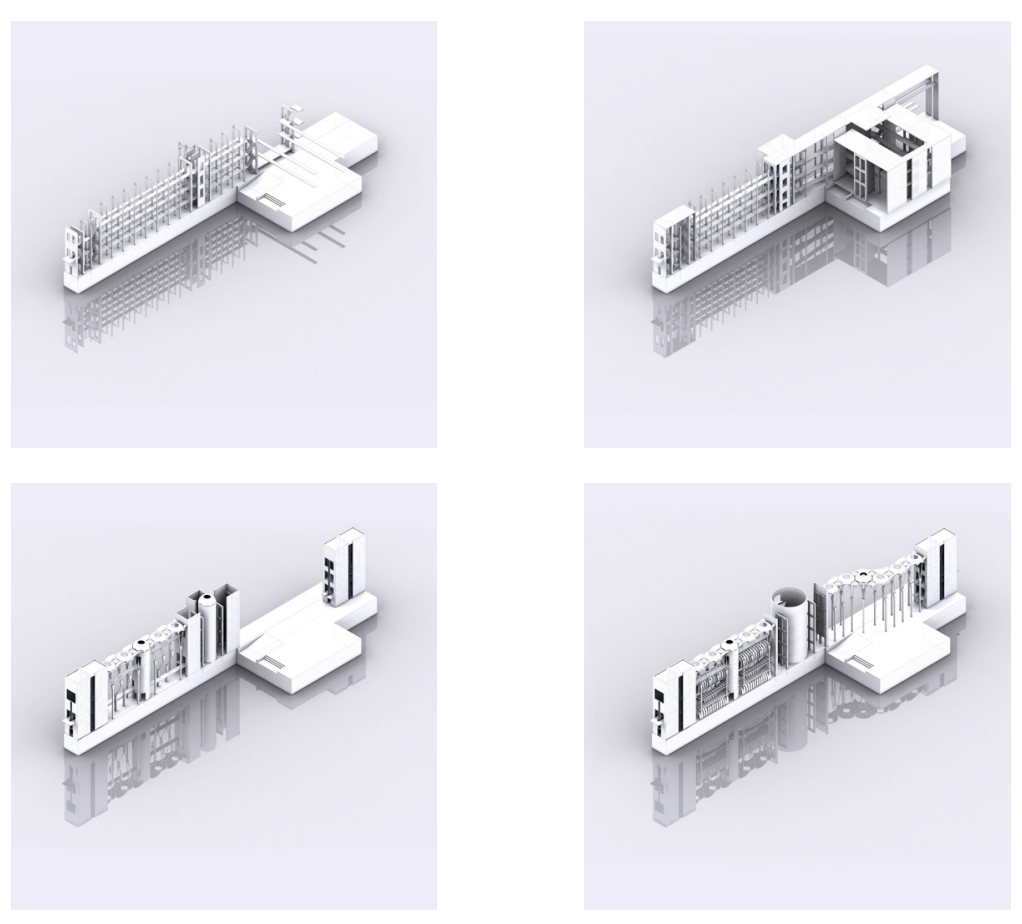
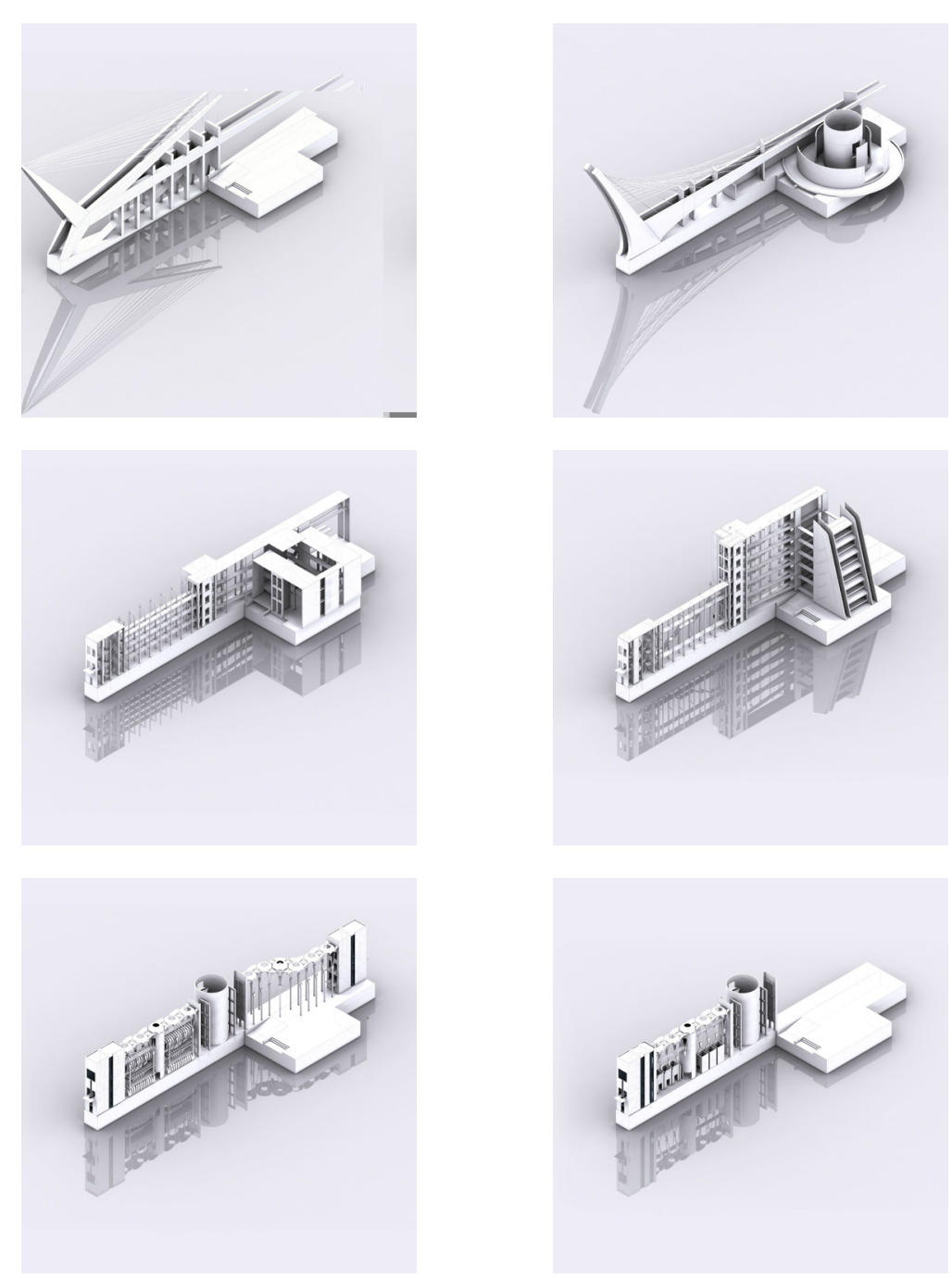

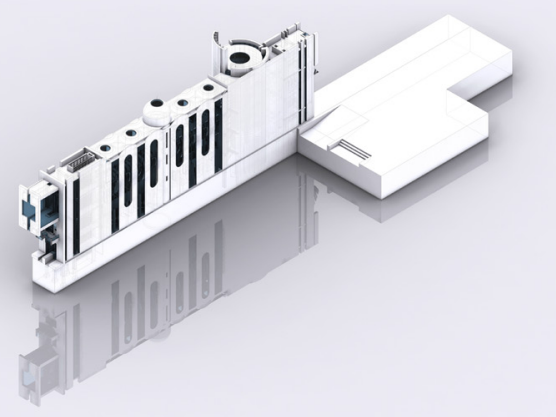




\section{THE STRANGER}

For the true philosophers, and such are not merely made up for the occasion, appear in various forms unrecognised by the ignorance of men, and they 'hover about cities,' as Homer declares, looking from above upon human life; and some think nothing of them and others can never think enough; and sometimes they appear as statesmen, and sometimes as sophists; and then, again, to many they seem to be no better than madmen.

Socrates, in Plato's Sophist (216c-d) 


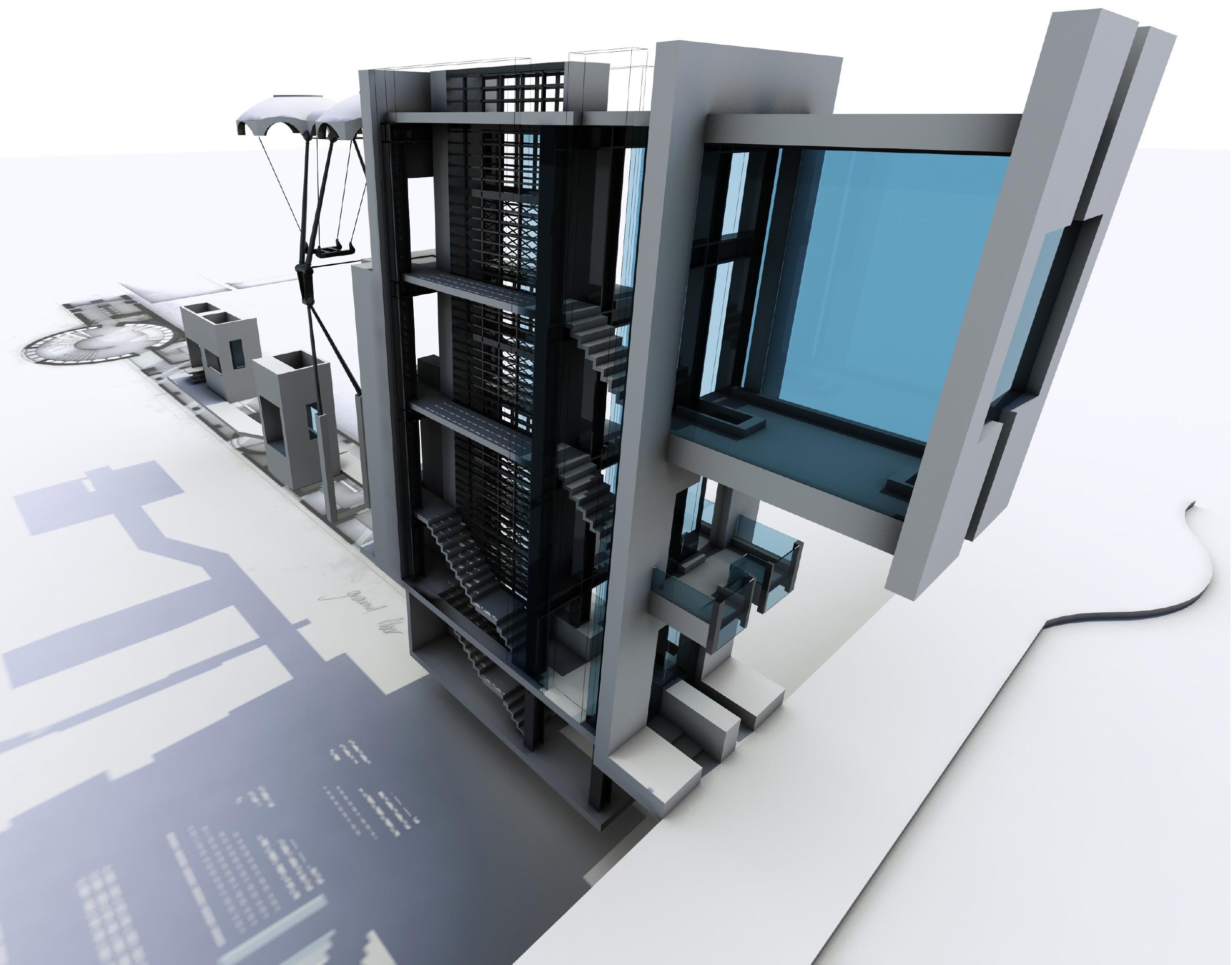




\section{THE STRANGER, STUDENT, WITNESS AND SOCRATES}

The characters in Plato's dialogues were just as significant as the discussion that occurred between them. Their education, place of origin, and roles in the dialogue all provide a rich context within which Plato sets his discourse. This thesis uses Plato's Sophist as a theoretical model. The following section investigates the characters Plato used in Sophist in order to examine their usefulness as participants in the architectural dialogue of the design.

The title of this thesis (An Architectural Dialogue with the Eleatic Stranger) refers to the central character in Plato's dialogue Sophist. The other characters in Sophist are: Theodorus, Theaetetus (the Student), Socrates, and a young man also named Socrates. The dialogue is chronologically set one day after Plato's dialogue Theaetetus in which Theaetetus, a promising young student of
Theodorus is first introduced to Socrates. In both dialogues, Theaetetus takes on the role of the Student, but his relationship with the teacher - Socrates in the first dialogue and the Stranger in the second - differs greatly between the two. In Theaetetus the dialogue is typically Socratic, with Theaetetus suggesting what knowledge is and then discussing each suggestion with Socrates. The method of dialogue that the Stranger uses in Sophist is much more one-sided than Socrates's method in Theaetetus. The Stranger is much more leading in his discussion than Socrates, and often asks if Theaetetus is keeping up with his argument. Theaetetus's contribution is only to ask for clarification when he does not understand something, so the Student's relationship with the Stranger (teacher) is much more submissive in Sophist than it was in Theaetetus.
Fig. $30(\mathrm{pg} .67)$

Exploded perspective of the design intervention showing parts of the Stranger's dialogue along with a number of spaces for reflection. 
The Stranger is also significant in Sophist because of where he originates from. The Italian town of Elea was famed for the Eleatic school of philosophy, which was founded by Parmenides (early $5^{\text {th }}$ century BC), under whom the Stranger is presumed to have studied. Plato chose to use a Stranger from Elea as the main character in Sophist because the Parmenidian idea of 'non-being' needs to be addressed in order to reach the definition of sophist. Had the Stranger come from somewhere else, he may well have been less able to challenge the teachings of Parmenides.

Other than Theodorus, Socrates, the Eleatic Stranger and their Student (Theaetetus), there is only one other character in Sophist. The younger namesake of Socrates, who never speaks a word during the whole dialogue acts as a silent witness to the proceedings.
In both Theaetetus and Sophist, the main discussion occurs between a teacher and a student, with the teacher attempting to lead the student to understand knowledge (in Theaetetus) and sophistry (in Sophist). This relationship is significant and forms the basis for the experimental methodology proposed by this thesis. The architectural intervention of this thesis similarly attempts to lead its inhabitants to an understanding of the relationships of balance in architecture; therefore, the thesis will test the use of metaphorical characters in a similar way to Plato, in order to help with the reading of the architectural dialogues.

The architectural dialogue of the design research intervention makes use of four characters: The Stranger, The Student, The Witness and Socrates. The Stranger's metaphorical role, like the Stranger from 
Elea, is to act as a teacher and guide by engaging the Student in dialogue. Each of the aforementioned dialogues represents the Stranger teaching the Student; in fact the visitor represents the Student, and the Stranger (and therefore his dialogue) is represented by the architectural experience. At night, the Student represents the inhabitant of the Triage centre who is in need of retreat. During the day, the Student represents urban residents passing through the site as well as visitors to the "Triage of the Day". As the Student enters, the Stranger begins the dialogue, slowly leading him or her towards retreat. The Witness takes on the role of the younger namesake of Socrates in Sophist; in the design he is represented as a tall narrow tower that silently observes the dialogue from the middle of the building. Socrates himself is silently represented by a larger tower (the repository) to the south end of the building.
The dialogues are structured to unveil the inherent balance within architectural oppositions, such as those arising from Tension and Compression, Concrete and Steel, Pinned and Rigid etc. As the Student (visitor, patient, paramedic or counsellor) witnesses the Stranger's dialogues (the architectural experience), a sense of intuitive understanding is achieved in relation to the forces and oppositions from which the built environment finds balance.

The nature of the dialogues, which the design intervention tests, is not simply to make the architecture visible, but rather to enable it to be understood. Once the Student (the visitor) enters, the Stranger (architecture) engages the visitor in critical dialogues about architecture that invite an intuitive sense of understanding of the built environment, a sense of truth, and therefore retreat. The dialogues occur as the visitor passes along the linear corridors, and periodic resting spaces allow for moments of reflection. 


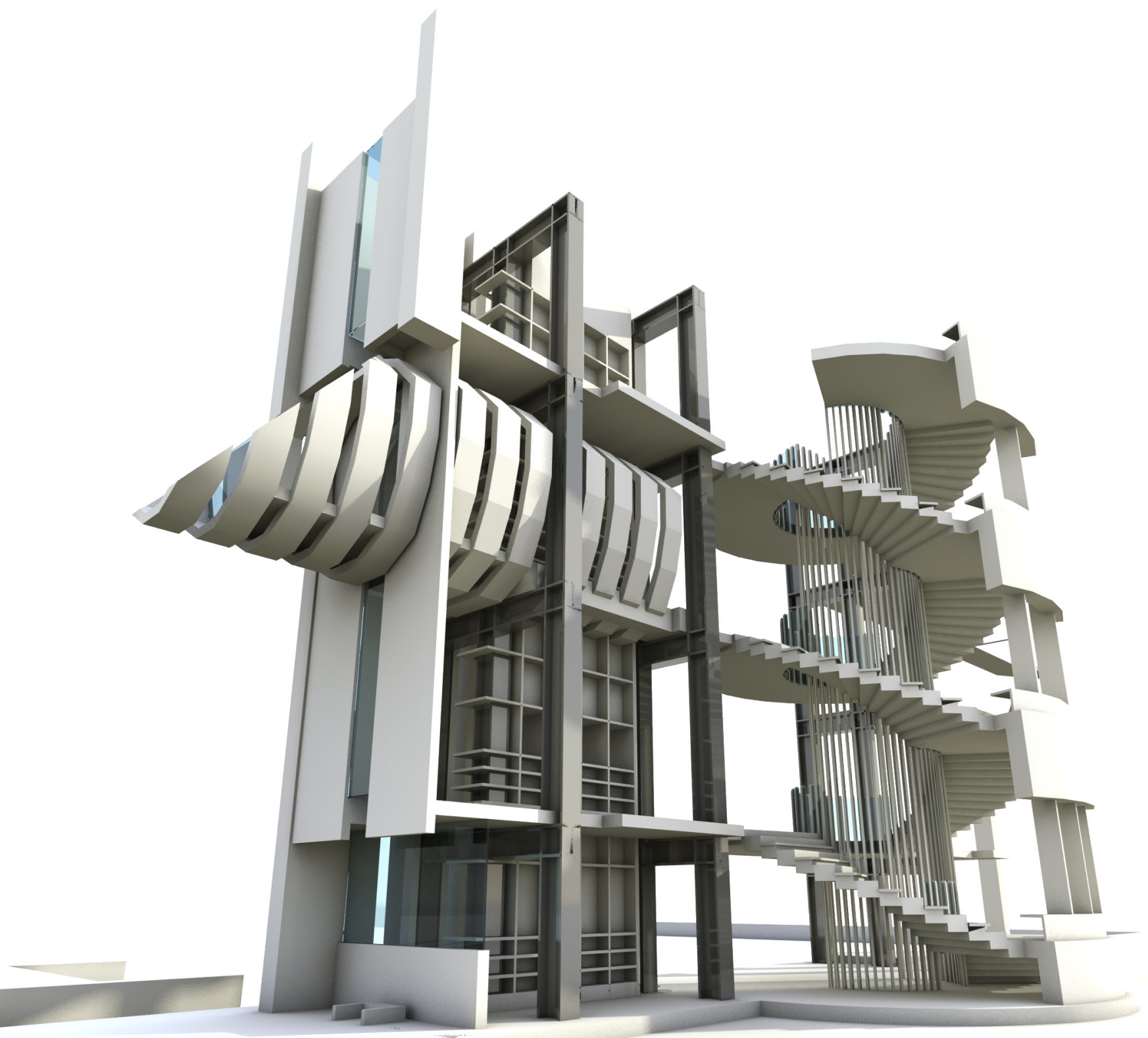




\section{SOCRATES}

And so, finally, I suppose, he would be able to look upon the sun itself and see its true nature, not by reflections on water or phantasms of it in an alien setting, but in and by itself in its own place.

Socrates, in Plato's The Republic (516a) 


\section{DAY AND NIGHT}

As Day shifts to Night, so the demographic shifts from those seeking a quiet place to read during the day, to those requiring medical attention at night. In the evening, and even during the Night, there will still be people wishing to use the building as a quiet refuge and not simply for the medical service it provides.

The patients of the triage centre are just as much Students to the Stranger's dialogues as any visitor seeking retreat during the day. Even though they circulate through different spaces within the building, due to their different programmatic requirements, the patients (Students of the night) and the visitors (Students of the day) both share the same architectural experience, witnessing the balance of forces and conditions in architecture. The fifth chapter will examine in detail the different sequential dialogues that the
Stranger uses to engage each of these types of Student across the different floor levels of the building.

The following section examines each of the Oppositional (internal and external) and Liminal dialogues which the architectural experience (the Stranger) will engage. 


\section{Fig. 31 (pg. 72)}

Exploded perspectives of the repository (Socrates) and its associated anchor.

\section{OPPOSITIONAL DIALOGUES [external]}

\section{EAST AND WEST}

The first dialogue begins outside, along the footpath of Courtenay Place, and it sets up the introduction of the Stranger to the Student (pedestrians). A hovering concrete panel wall beckons the Student to enter. It seems almost to float, appearing otherworldly, and creating a threshold from the light into the darkness, from the noise into the silence, from the public into the private. This initial outdoor dialogue occurs as the Student walks east-west or west-east along Courtenay Place. Even if the Student does not accept the Stranger's invitation to enter, the dialogue has still been engaged because the externalized form of the architecture is derived from the nature of the internal dialogues. The structure supporting the extended concrete panel is exposed as it cantilevers from within the building, providing passers-by an intuitive understanding of the balance within the architecture's structure as they walk beneath it.

\section{NORTH AND SOUTH}

In Chapter Three it was identified that the nameless alleyway that has been selected in order to test the design intervention of this thesis connected a residential area (to the south) with the commercial Courtenay Place (to the north). This connection is retained and creates the axis along which the second external dialogue is initiated. As Students (urban residents) walk along the alley to and from Courtenay Place, they pass through the design intervention and are engaged in dialogue by the Stranger. The Students are able to recognise a sense of retreat by experiencing the Stranger's dialogues along the ground level. 


\section{OPPOSITIONAL DIALOGUES [internal)}

\section{CONCRETE AND STEEL}

This dialogue reveals the role materiality plays in creating balance and stability within the architecture. An image from Viollet-leDuc's Entretiens sur l'architecture in Robert McCarter's book Louis Kahn (see fig. 33) presents an excellent example of the architectural dialogue between Concrete and Steel, and its role in revealing the dialogue between Compression and Tension (although in Violletle-Duc's image Concrete is replaced by masonry). Viollet-le-Duc allows masonry and steel to act in their natural ways, with each supporting the other to create balance. The masonry forms domes and arches, with steel ties resisting the inherent spreading of these. Normally, thick masonry columns would support the archways; however, Viollet-le-Duc's use of steel trusses removes the need for such an invasive structure, creating a column-free floor space below.

\section{COMPRESSION AND TENSION}

The purpose of this dialogue is to reveal the nature and workings of the structure as an integral and participatory part of the architecture. The dialogue is about permanent balance because in order for the architecture to exist, the forces of Compression and Tension must be brought into equilibrium by the structure. The dialogue is oppositional because of the nature of Compression and Tension, one is opposed to the other; without one the other cannot exist and only when they are both engaged in dialogue can the balance between them be revealed. In Viollet-le-Duc's drawing (see fig. 33), the spreading of the compressive domes is resisted by tension ties. Each of the trusses in the drawing uses a combination of compression and tension in order to prevent the exterior walls from experiencing any of the spreading from the domes. These thick masonry walls are only able to resist compression and 
Fig. 32, 33

Images of from Viollet-

le-Duc's Entretiens sur

l'architecture (1858-72).

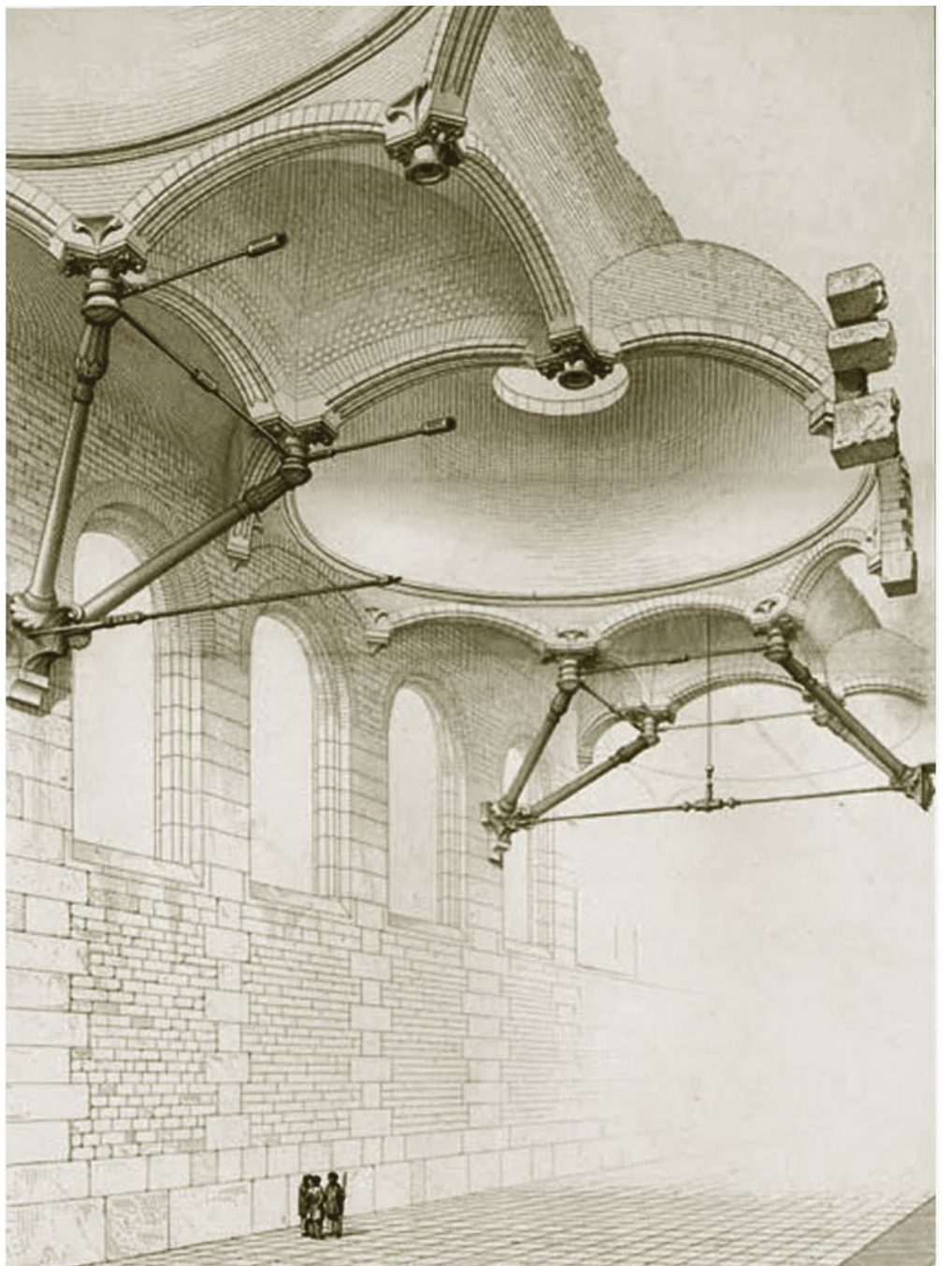

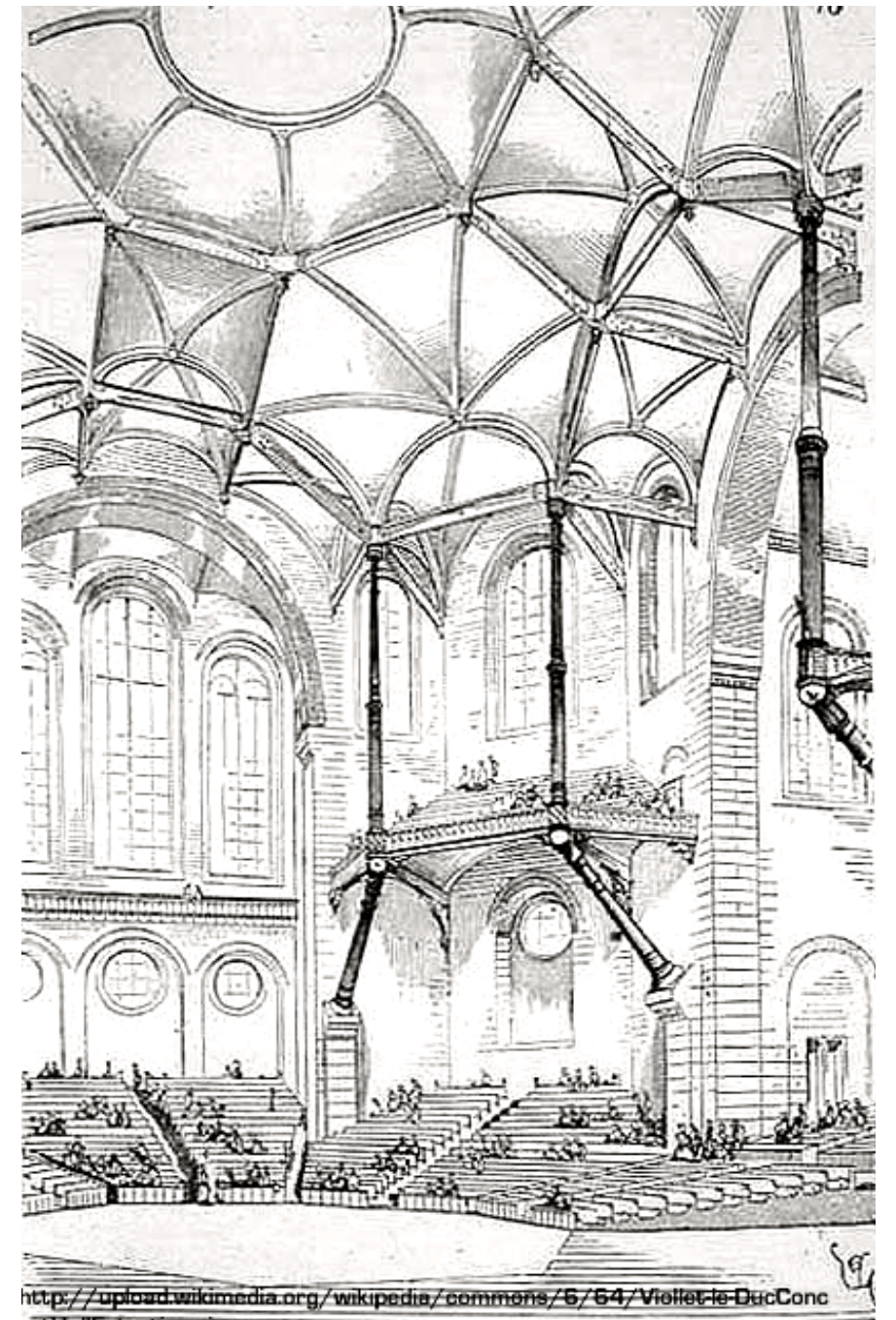


would be unable to resist such lateral loads (from the spreading). Furthermore, the steel in these trusses is able to articulate the type of force it is resisting through the thickness of the structural member: slender ties for tension and thicker struts for compression. As a strong expression of the dialogue that can be evidenced between Steel and Concrete, and Compression and Tension, this relationship was exposed in this thesis design intervention.

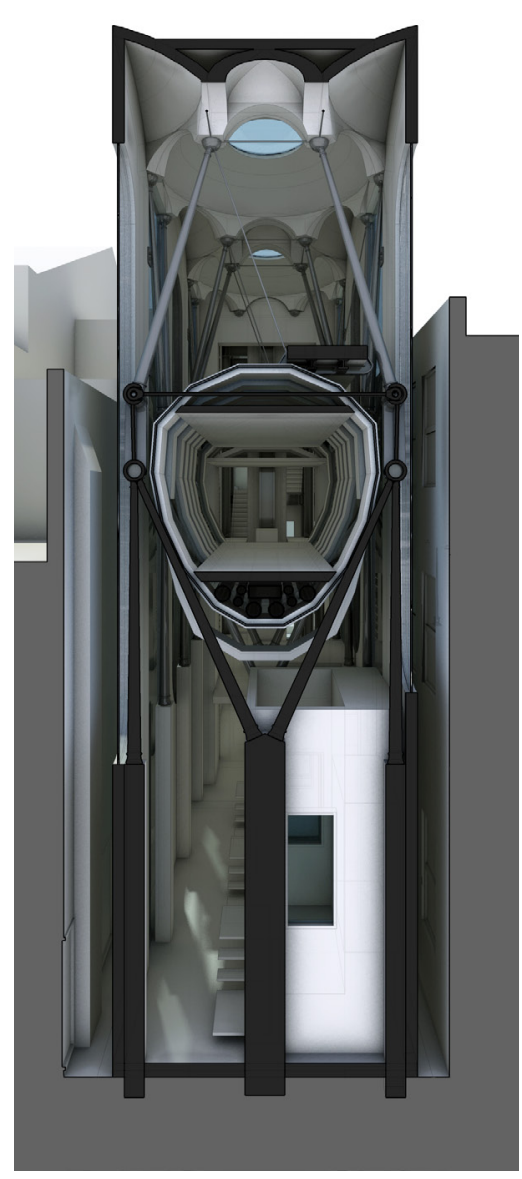

Fig. 34

A transverse section of the design intervention

showing part of the dialogue between Stee and Concrete, and Compression and Tension. 


\section{LIMINAL DIALOGUES}

\section{PINNED AND RIGID}

A further structural dialogue that results from the preceding two occurs in the connections between Compression and Tension and Concrete and Steel. The nature of these connections, either Rigid or Pinned, is determined by the nature of the forces being resisted and transferred by the structural members. A Pinned connection can visibly show the column's ability to rotate freely, as opposed to a Rigid connection which is intended to resist this rotation. This visibly demonstrates to the Student the way in which two structural components interact with each other (in dialogue) to transfer Lateral and Vertical loads to the ground.

\section{LATERAL AND VERTICAL STRUCTURE}

The dialogue between the Lateral and Vertical structure occurs in a liminal fashion, because structural elements designed to resist lateral loads are equally intended to resist vertical loads. The participants in the dialogue also contribute to other dialogues (Compression and Tension, Concrete and Steel, Pinned and Rigid) and in doing so represent both sides of the discussion rather than only representing one. In the Lateral load resisting structure, steel moment frames resist forces in the transverse direction, while concrete sheer walls resist forces in the longitudinal direction. Due to the nature of earthquake forces and the design of lateral load resisting structures, these never change position; concrete sheer walls will always remain in the longitudinal direction and steel moment frames in the transverse. The clear separation between the moment frames and sheer walls plays an important part in the way in which the Stranger (architectural experience) is able to enlighten 
the Student (the visitor) about the necessary equilibrium between the Lateral and Vertical structure.

\section{PUBLIC AND PRIVATE}

In addition to creating a threshold between the Public realm of Courtenay Place and the Private realm of the retreat, the dialogue then questions this threshold through the differing levels of 'public privacy' in the retreat. The building contains areas ranging from those that are completely open to the public to areas that are deeply private. Semi-private nodes (such as the pods) are visible from the public spaces, making the thresholds between these 'publicly private' spaces another focus of the Stranger's dialogue.

\section{WITNESSING AND WITNESSED}

The semi-public nature of the retreat establishes a dialogue in which the metaphoric Stranger and Student are simultaneously
Witnessing and being Witnessed. The ground floor of the site retains a thoroughfare for the urban apartment residents to the south; thus each level moving upward engages a different hierarchy of security between the different occupants, both external and internal, ensuring a sense of safety and stability remains constant for everyone in the retreat.

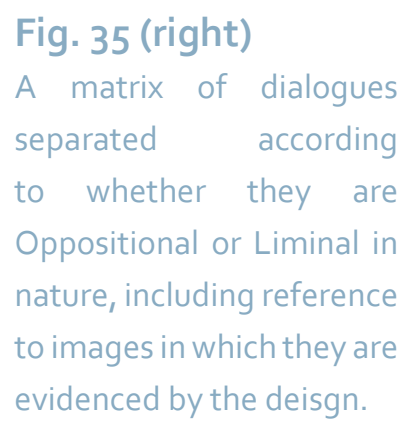




\section{OPPOSITIONAL}

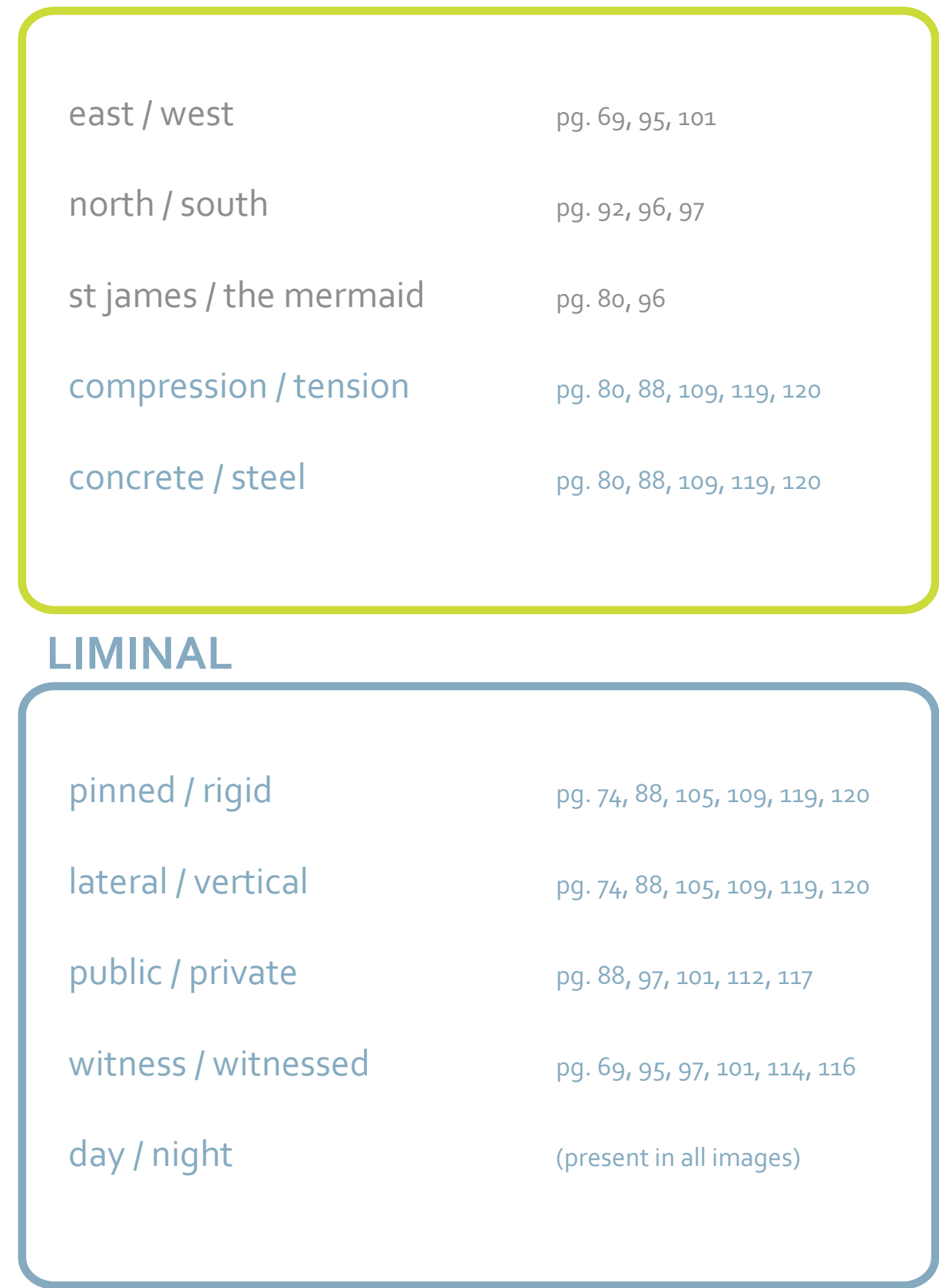

externally intiated

internal 


\section{THE SETTING OF THE DIALOGUES: KAHN’S RUIN}

The setting in which a dialogue occurs plays an important part in conveying the message of the dialogue itself. It provides a context within which the characters can be placed and to which they can respond. The following section examines Kahn's literal use of the Ruin and its potential for being tested as a metaphorical context within which the architectural dialogue between the Student and the Stranger can occur.

For Louis Kahn the Ruin was the closest architecture could get in representing the ideal and immeasurable spirit of a building. $\mathrm{He}$ pursued this idea throughout his later works, culminating with the design of the Hurva Synagogue in Jerusalem. According to Kahn, the ideal Ruin achieves equilibrium between the 'measurable' and 'immeasurable.' On the threshold between Silence and Light it expresses equally the intangible desire and the tangible means by which it was created. As such it represents an appropriate test for the notion of creating a sense of retreat through an understanding of the balances within architecture and the built environment. In the design research component Kahn's interest in an ideal form of architecture (the Ruin) can be tested metaphorically as the setting within which the Stranger and the Student conduct their dialogues.

The selected site is in fact the threshold between two opposing programs: the cultural function of The St James and carnal function of The Mermaid. Kahn perceived the Ruin as existing on the threshold - between Silence and Light. The liminal nature of the Ruin, Kahn's metaphorical context upon which the architectural dialogues in the thesis design intervention occur, parallels the 


\section{Fig. 35 (pg. 85)}

An exploded perspective portraying the Witness (slender tower) and the Ruin in the design. liminal nature of the nameless alleyway, the literal context of the architecture. In this way, the site itself is yet another dialogue in which this thesis engages. 


\section{THE RUIN}

It was small wonder that this place had fallen into disuse, its roof gone, weeds growing through the rotting pews. But on nights like this, when she felt that she must get out of the Jade Pagoda or go mad, this was where Oenone came to calm herself.

Philip Reeves, author (1966 - ) 


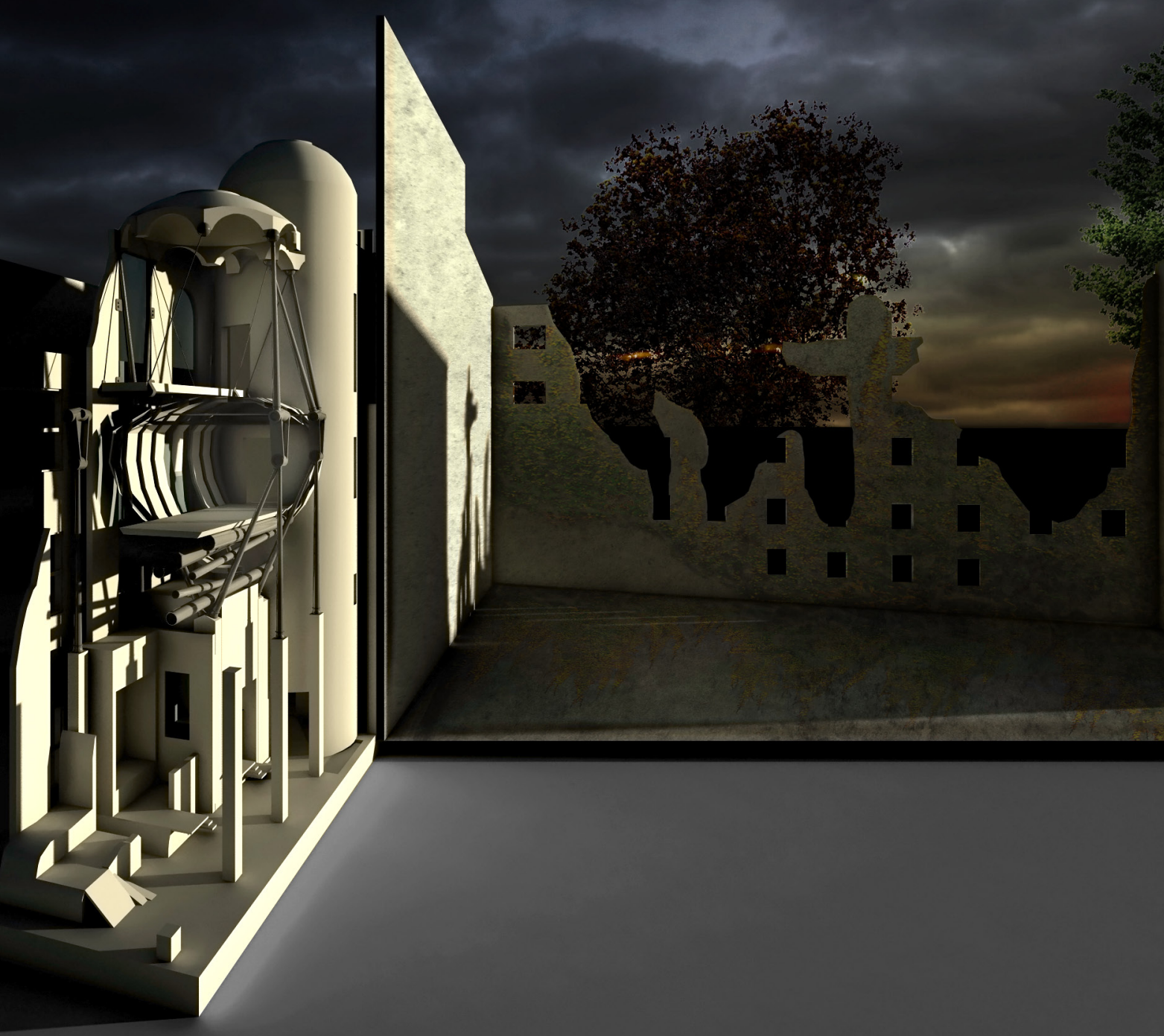




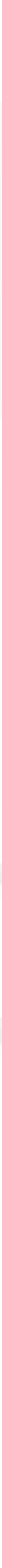




\section{THE ARCHITECTURAL DIALOGUES}

Kahn held that a work of architecture must start with the immeasurable, must be realised through the measurable means of construction, and when completed must allow its inhabitants to experience the immeasurable of its beginnings.

Robert McCarter 
In the following chapter the separate dialogues described in Chapter Four are integrated into a holistic description of the architectural experience. This chapter follows the journey of a Student seeking retreat during the Day, and then during the Night. The chapter describes the experiential dialogue sequences of Day and Night as a visitor engages the ground floor, and then moves to the levels above. 


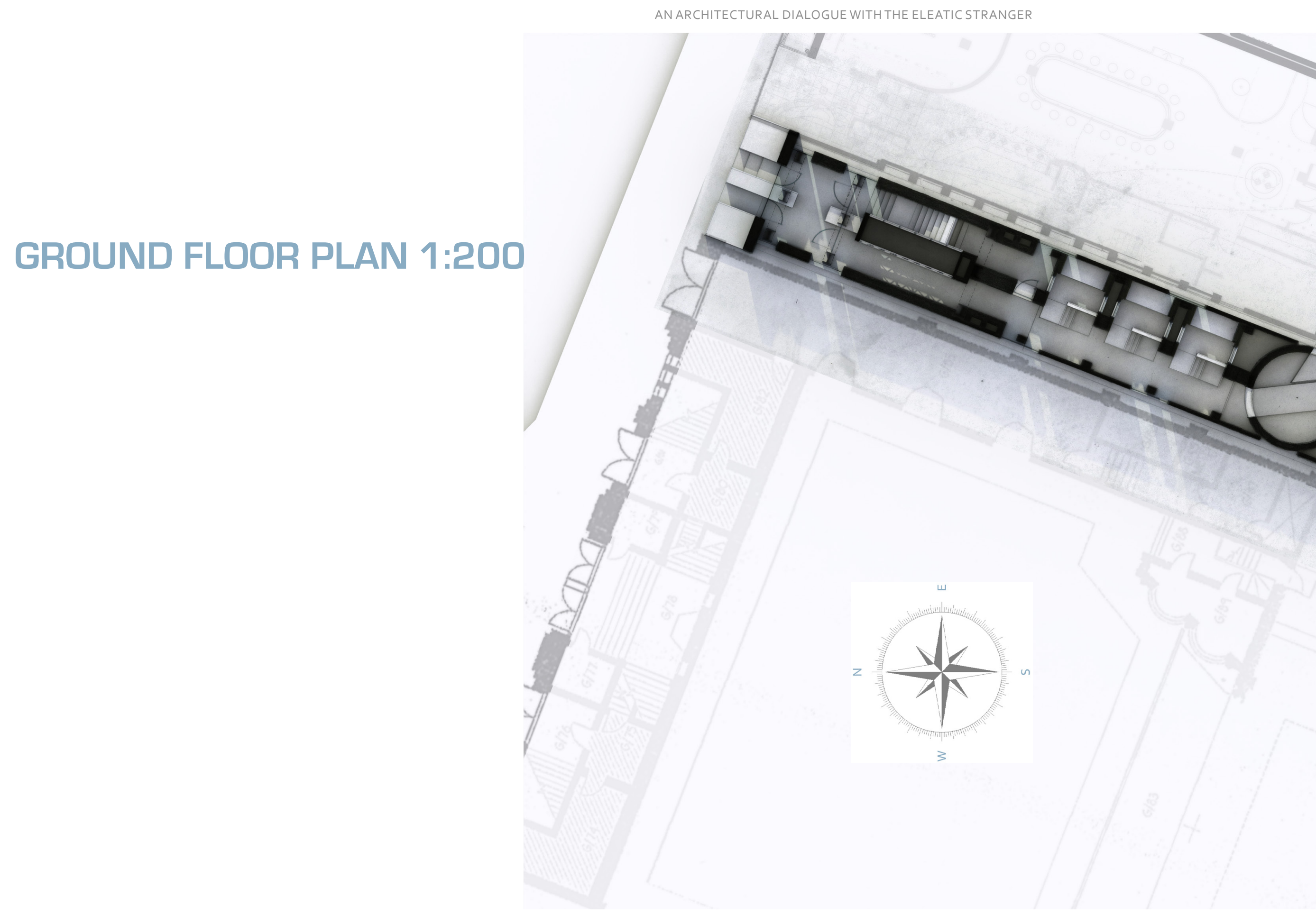




\section{T}

\section{GROUND FLOOR}

The Stranger first "beckons" the passers-by on Courtenay Place when they perceive the "floating" cantilevered façade. Upon entering the building, visitors (the Student) become integrated into the Stranger's internal dialogues, which progressively enable them to reach an understanding of retreat.

Once inside, the Stranger introduces the architectural 'moment resisting frame'. Its exposure unveils the connections it makes with each floor and the roof, enabling it to be understood by the Student; it is through these exposed connections that it is able to transfer the lateral loads from each floor level downwards to the ground. Additionally its exposed separation from the sheer walls on either

side, emphasised with floor-to-ceiling windows, helps the Student understand the relative roles that the moment frame and sheer wall play - one dealing purely with transverse lateral loads, and the other with longitudinal lateral loads. The windows are there to highlight these structures and to remove any visible elements that might mask the nature of the structural relationships. They also reveal the opposing alleyway facades of the St James and The Mermaid, identifying them as playing a critical part in the dialogue of the site (culture and vice).

If visitors (the Student) remain on the ground floor they will be led past the first two moment resisting frames and the lift, from where they can then retreat further into the building. 


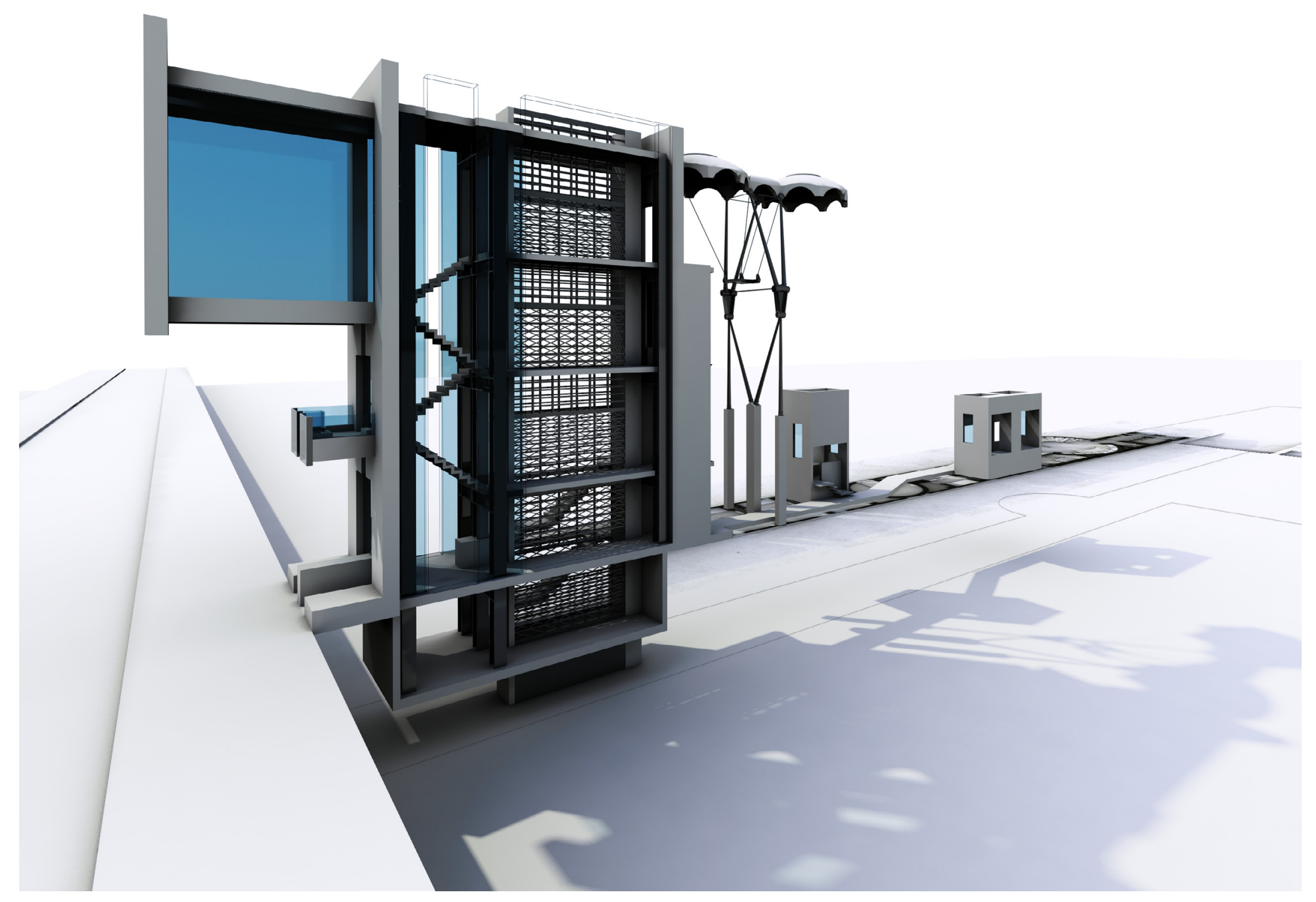


Having walked past the lift on ground level, visitors (the Student) enter a corridor leading towards a slender tower (The Witness). This space contains three enclosed spaces in which visitors can pause and reflect upon the dialogues they have experienced so far and engage the next sequential dialogues present in the Vertical structure around them (Compression and Tension, Concrete and Steel, Pinned and Rigid). The visitors sit deeply recessed into the back of the 'pods', which are elevated above the level of the corridor outside. This ensures the 'Student' is always secure relative to the other visitors that pass by. The corridor repeats this process beyond the Witness as the visitors are led further south.

Beyond the 'pods' the Corridor narrows and leads on into the community book exchange (Socrates) at the far southern end. Here the visitors (the Student) can recline, read and reflect.
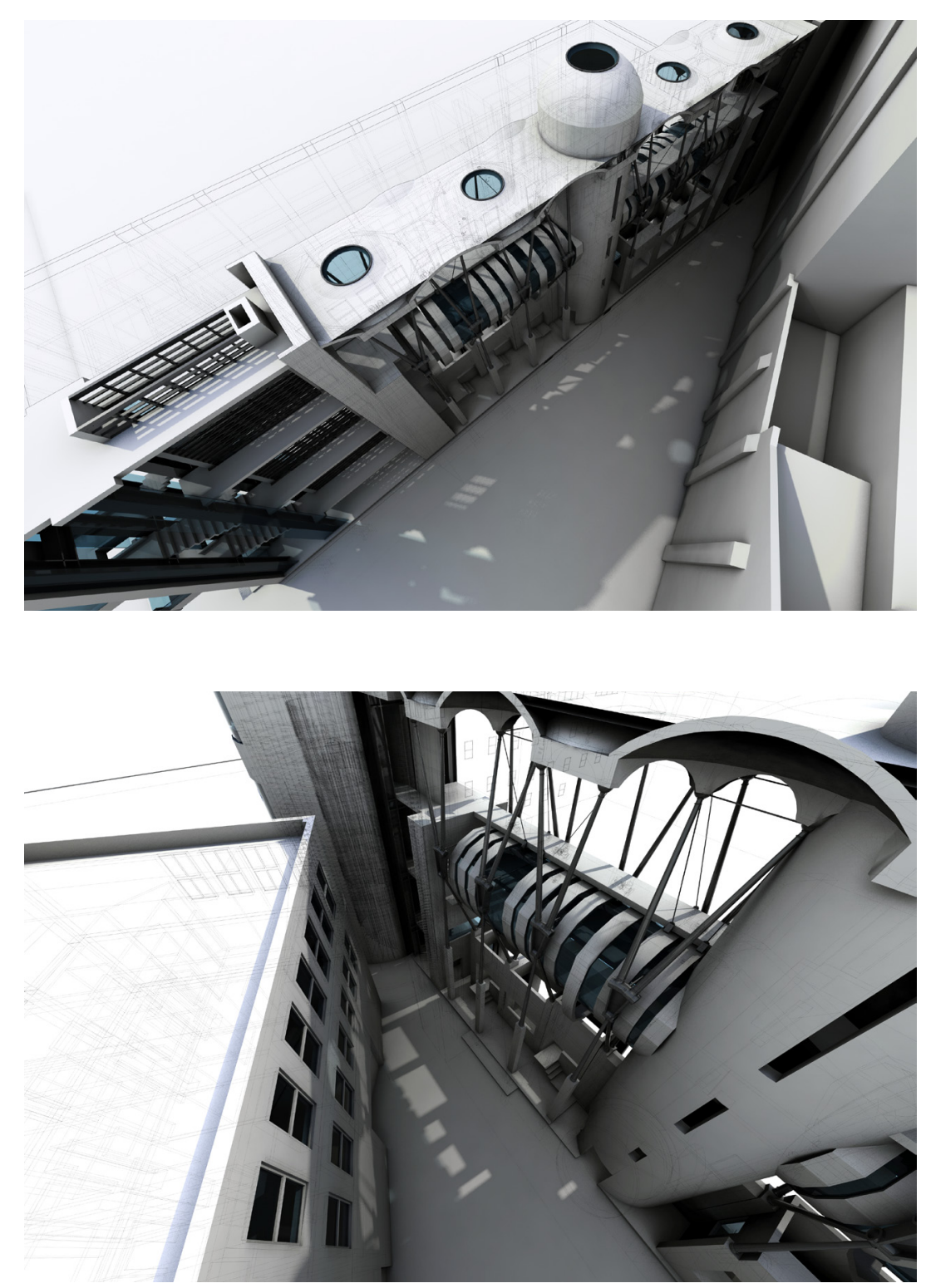


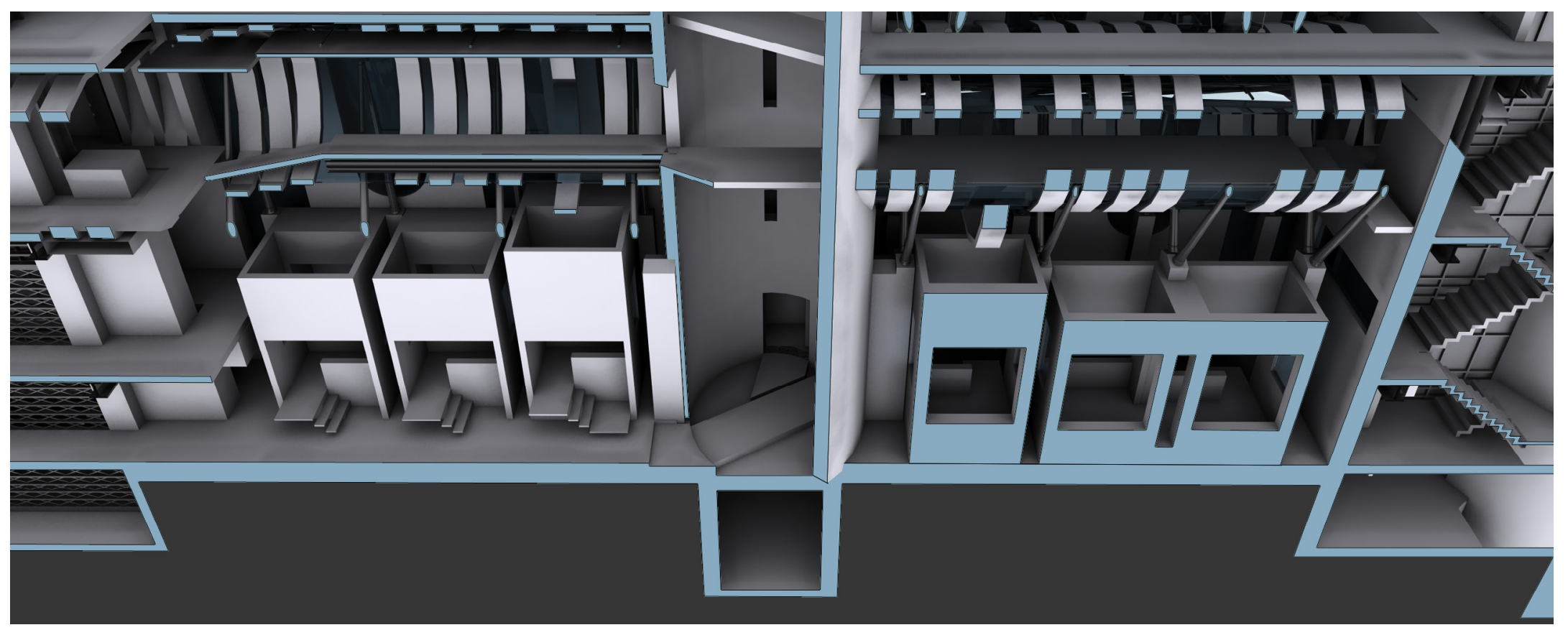




\section{FIRST FLOOR PLAN 1:200}

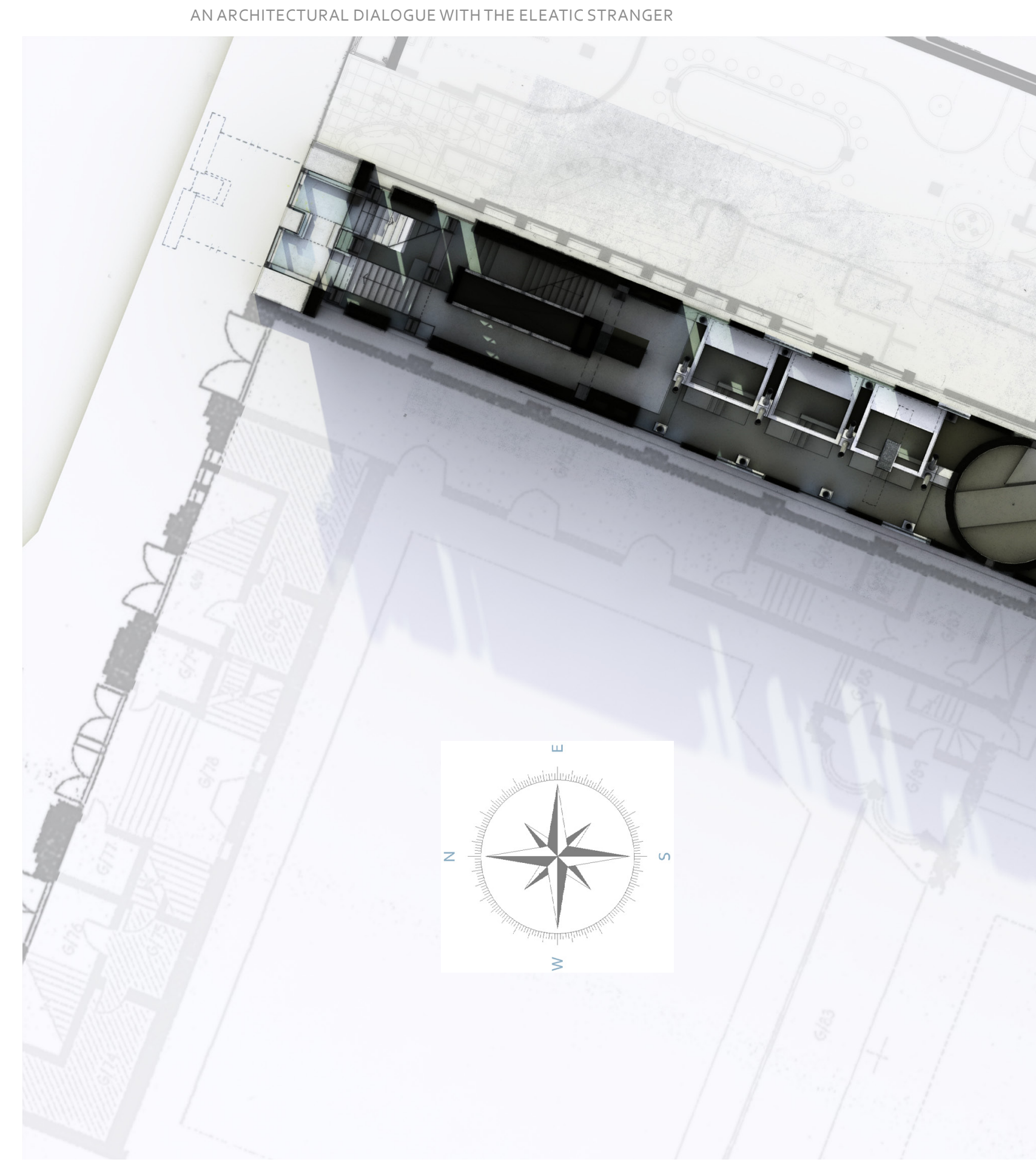




\section{FIRST FLOOR}

Near the main entry, a gurney lift and secure stair are available to lead the Student upwards to the upper floors. Upon initially ascending, the Student reaches an interior balcony on the south side of the gurney lift. From here the Student can partake in the dialogues occurring between the Stranger and other Students on the ground floor below by observing from the open balcony. Upon ascending further, the Student enters an exterior first floor balcony. Once visitors are outside, they are in a threshold between the Public and Private and become more aware of the liminal nature of this particular dialogue, having progressed from outside to inside, then inside to outside. From this exterior balcony position, visitors are reminded of the environment from where they have come, giving them a reference point by which to measure the level of retreat they have achieved so far. The Student then re-enters the building and the dialogue between Public and Private is continued in the therapeutic sunroom on the third floor.

From the ground floor within the community book exchange (Socrates), the visitors (the Student) are able to ascend to the first floor and read, reflect and relax in an elevated position within the central tower (Socrates) above the ground level of the community book exchange. Having taken part in the Stranger's dialogues, and reflected upon these within Socrates, visitors (the Student) can choose to further their retreat in dialogue with a counsellor in the consultation space behind the community book exchange (Socrates). A second consultation space is also available on the third floor. 


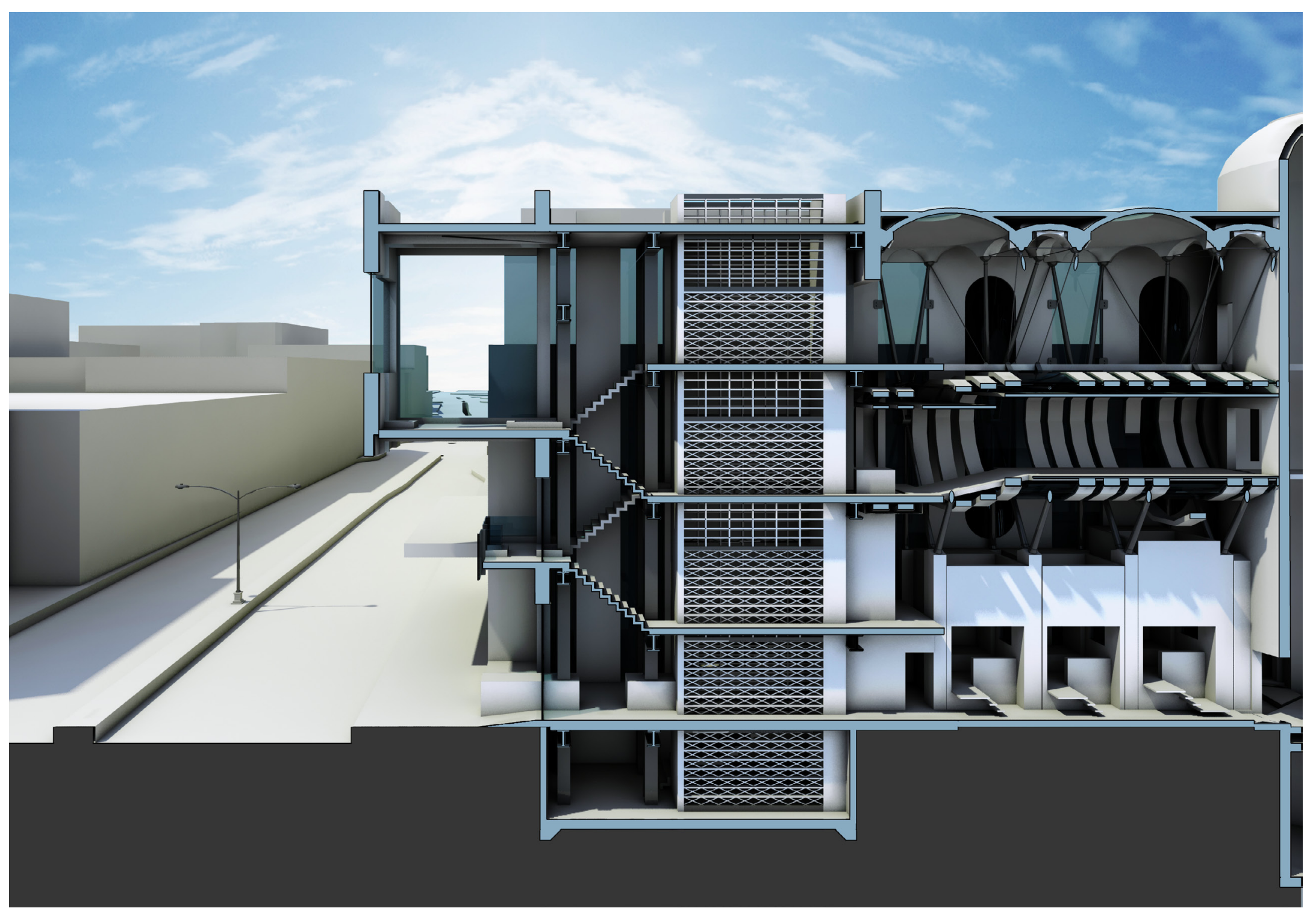




\section{SECOND FLOOR PLAN 1:200}

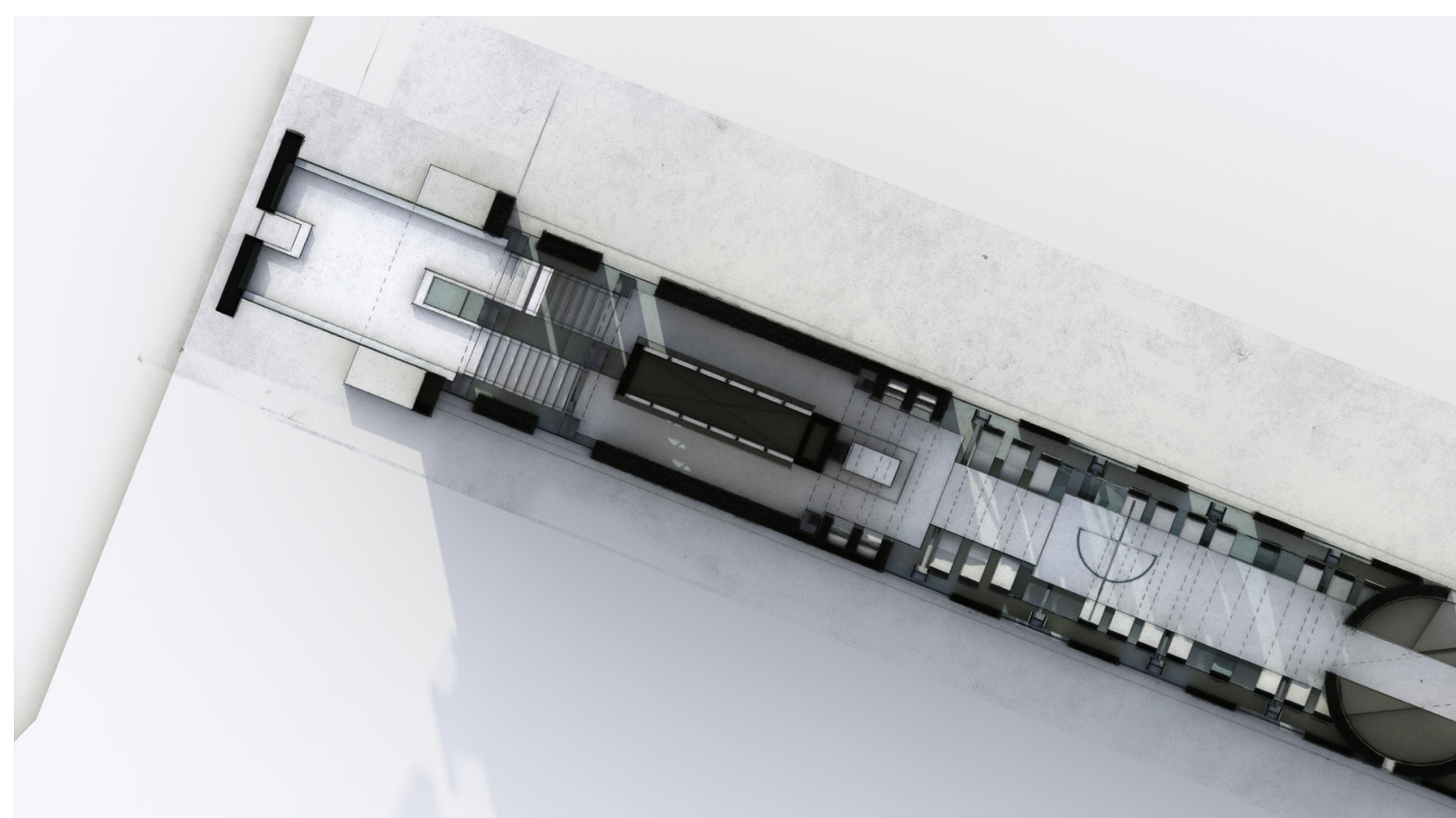




\section{SECOND FLOOR}

The second floor contains the medical treatment facility off limits to the general public. But above the main entry to the north on a mezzanine level between the second and third floors, the public has access to the therapeutic sunroom. This room stretches out above the footpath, sheltering the footpath from the rain and giving the Student an elevated east-west view along Courtenay Place. The dialogue between Public and Private is evidenced once again as the Student is now beyond the threshold wall separating the two, but still within the environment of the Stranger's interior dialogues.
Here, visitors are led to a space in which to reflect upon their journey towards retreat. Their elevated view of Courtenay Place offers them a reference point for how far they have come. Coupled with this elevated position, the visitors can appreciate that while they are outside the threshold, they are not in fact in the Public realm and can safely relax in the sunlight which streams in through large windows on each of the three exterior facades. As in the community book exchange (Socrates), the Stranger's sequential dialogue leads the Student to a space of safety and respite, in which the Student is able to retreat and reflect. 


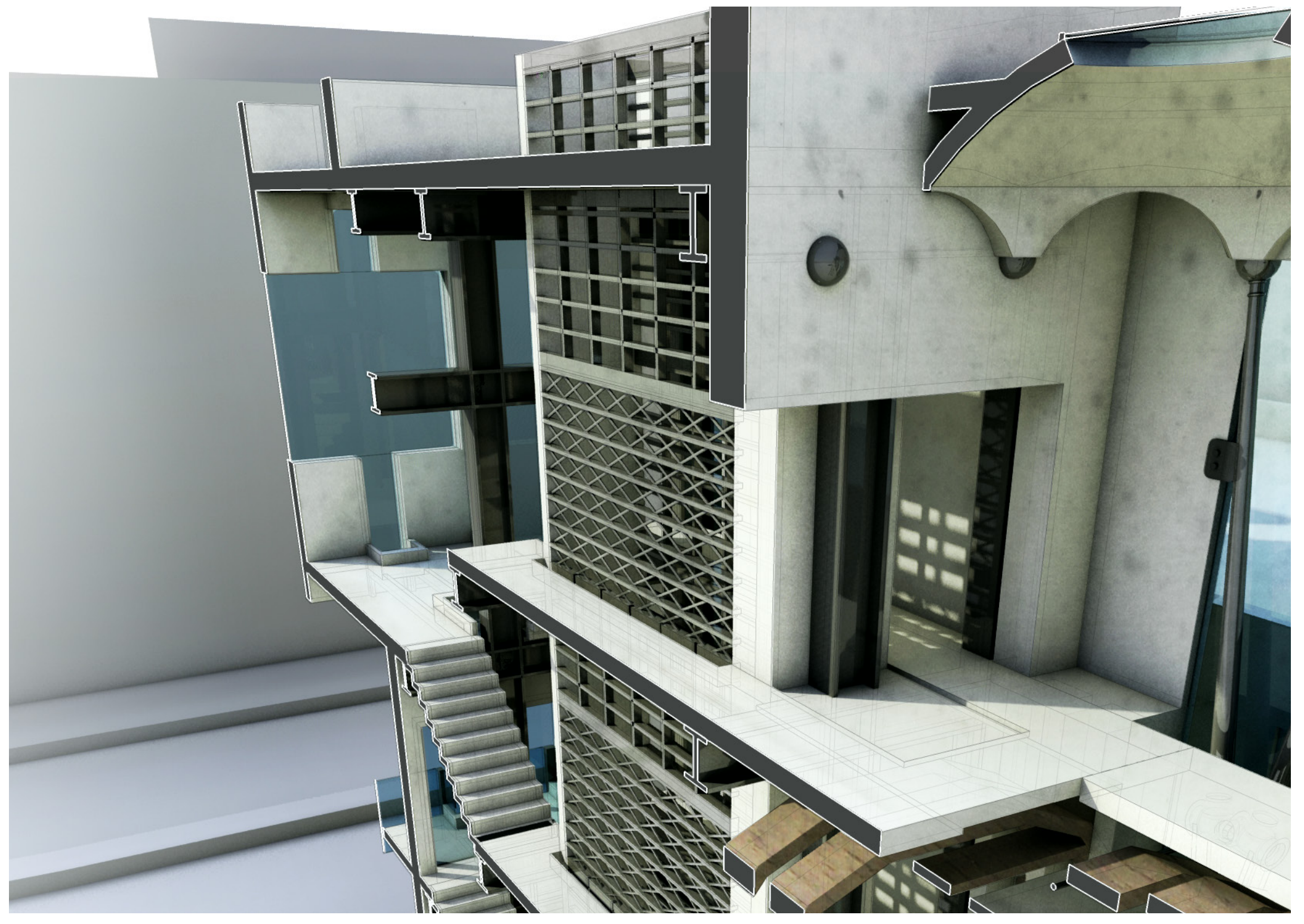


THIRD FLOOR PLAN 1:200

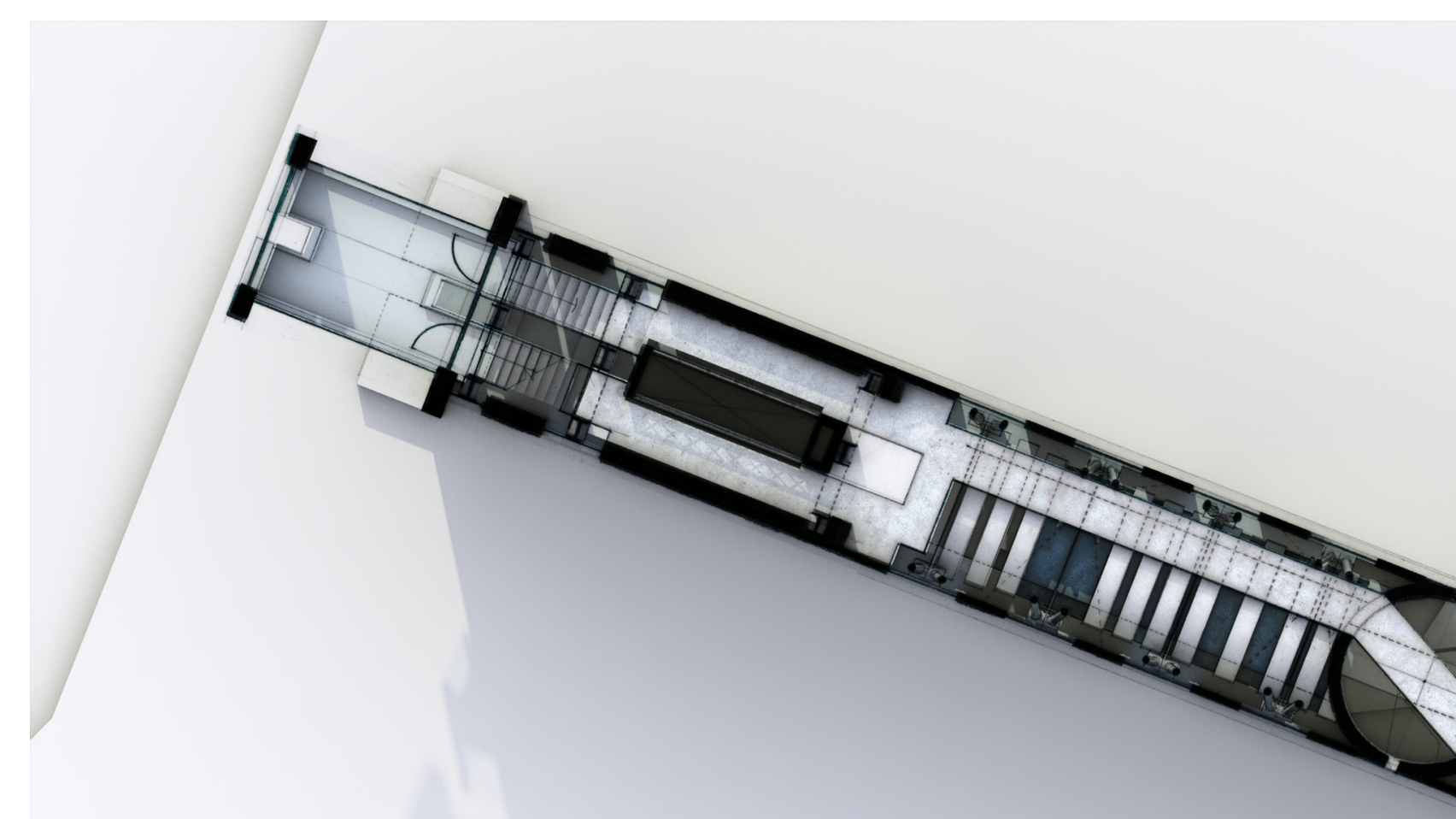




\section{THIRD FLOOR}

Once visitors (the Student) have finished their reflection in the therapeutic sunroom, the Stranger leads them up one final flight of stairs to the third floor. Each flight of stairs on the journey upwards has passed through two of the three moment frames in the northern anchor of the building. (The southern anchor engages Socrates.) The Vertical support that these steel frames give to the staircase is emphasised and evidenced each time the Student passes through the frame; in addition, the Lateral support the frames provide to the each floor level of the building is simultaneously evidenced. The concrete sheer walls that provide Lateral load resistance in the longitudinal direction are adjacent to each flight of stairs. This makes it possible for the Student to reach out and touch the bare concrete, gaining a sense of the mass and thickness of the material in comparison to the lighter steel frames through which the Student passes. This furthers the Student's appreciation of the dialogue between Concrete and Steel.

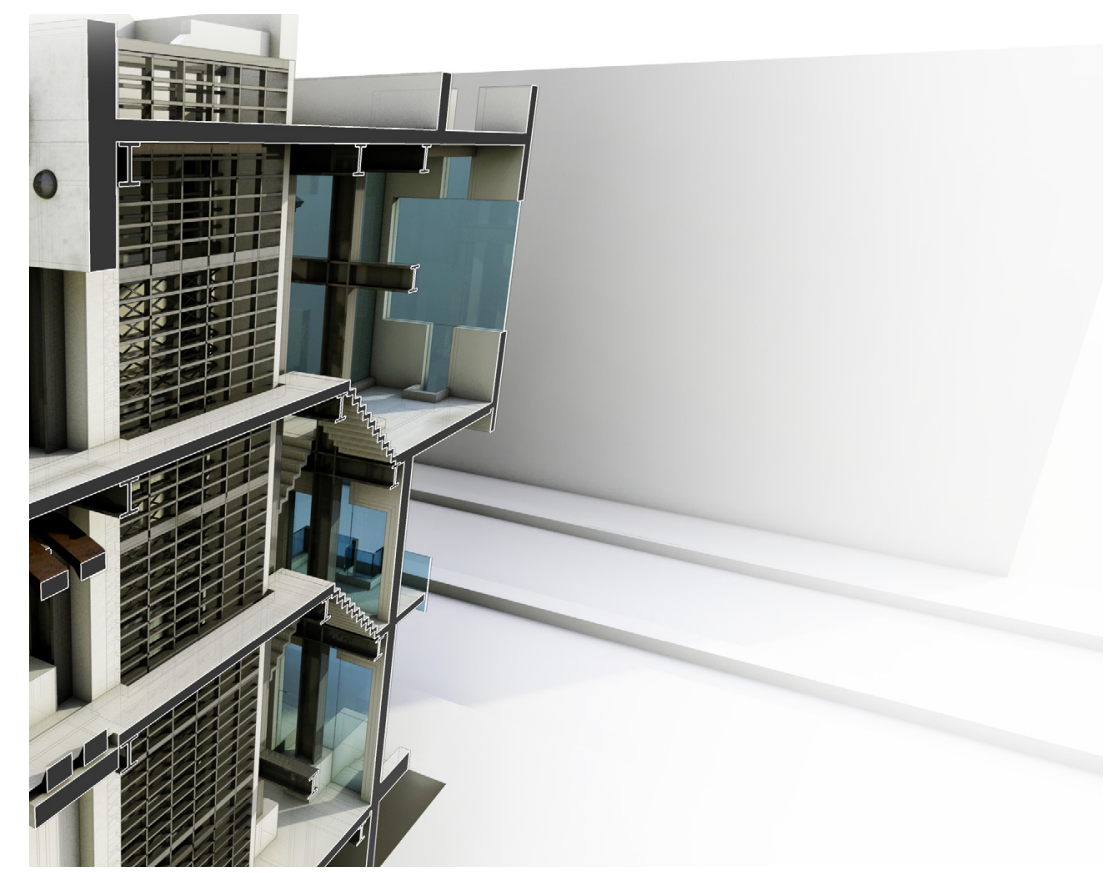


After the visitors have been led past the gurney lift and the final moment frame, they enter the third floor. The pathway on this floor mirrors the one on the ground floor, switching from east (adjacent to The Mermaid) to west beyond the slender tower (the Witness). As the Stranger leads the Student through this space, the Student is able to understand the conclusions of the dialogues between Concrete and Steel, Compression and Tension, and Rigid and Pinned. The pathway itself actively participates in these dialogues, being suspended via steel tension ties from the domed roof. The structure as a whole evidences a perfect balance between Compression and Tension, and Concrete and Steel - much like Viollet-le-duc's drawing.

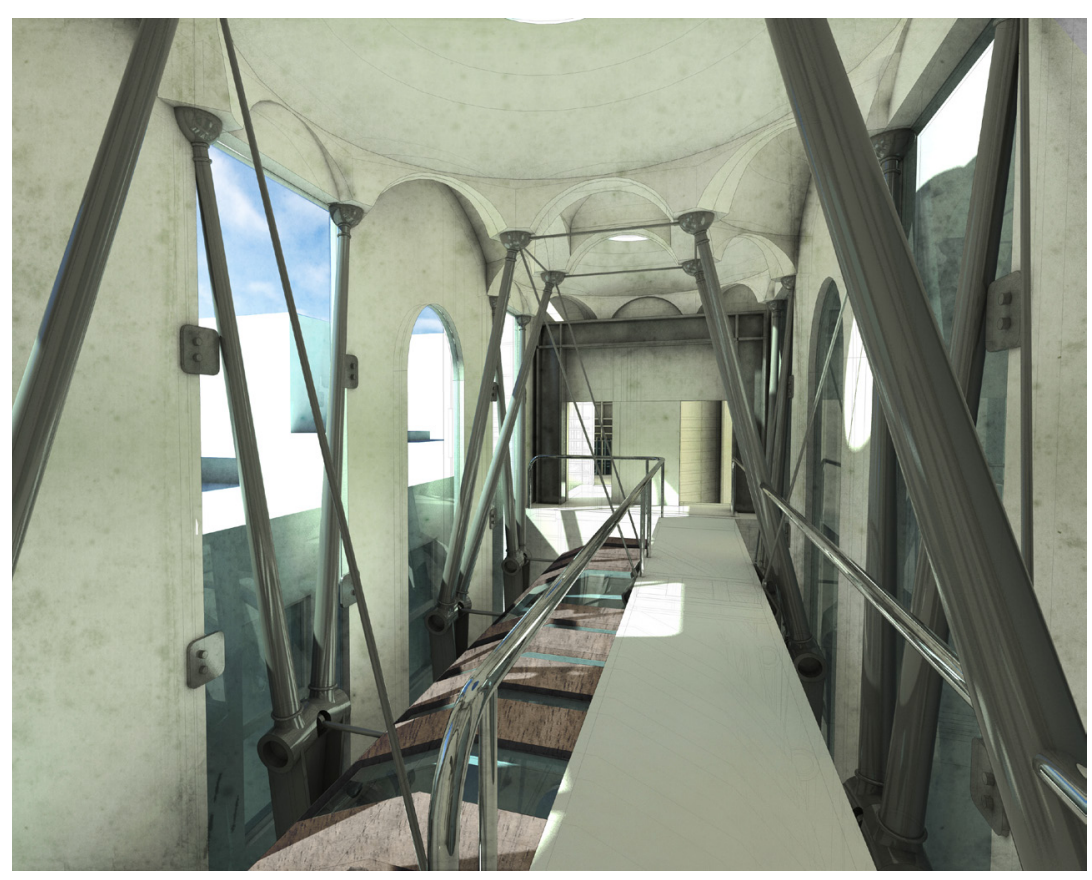


The Stranger concludes his dialogue with the Student with the introduction of the upper level of the community book exchange (Socrates), another space of reflection, which takes over in the process of directing the Student towards retreat. Once the Student chooses to leave the retreat and move towards the outside world, the whole dialogue repeats itself in reverse. The sequence reiterates the Student's awareness of the balance of forces within architecture and heightens the visitors' sense of this equilibrium, before they enter the apparently unstable environment outside. 


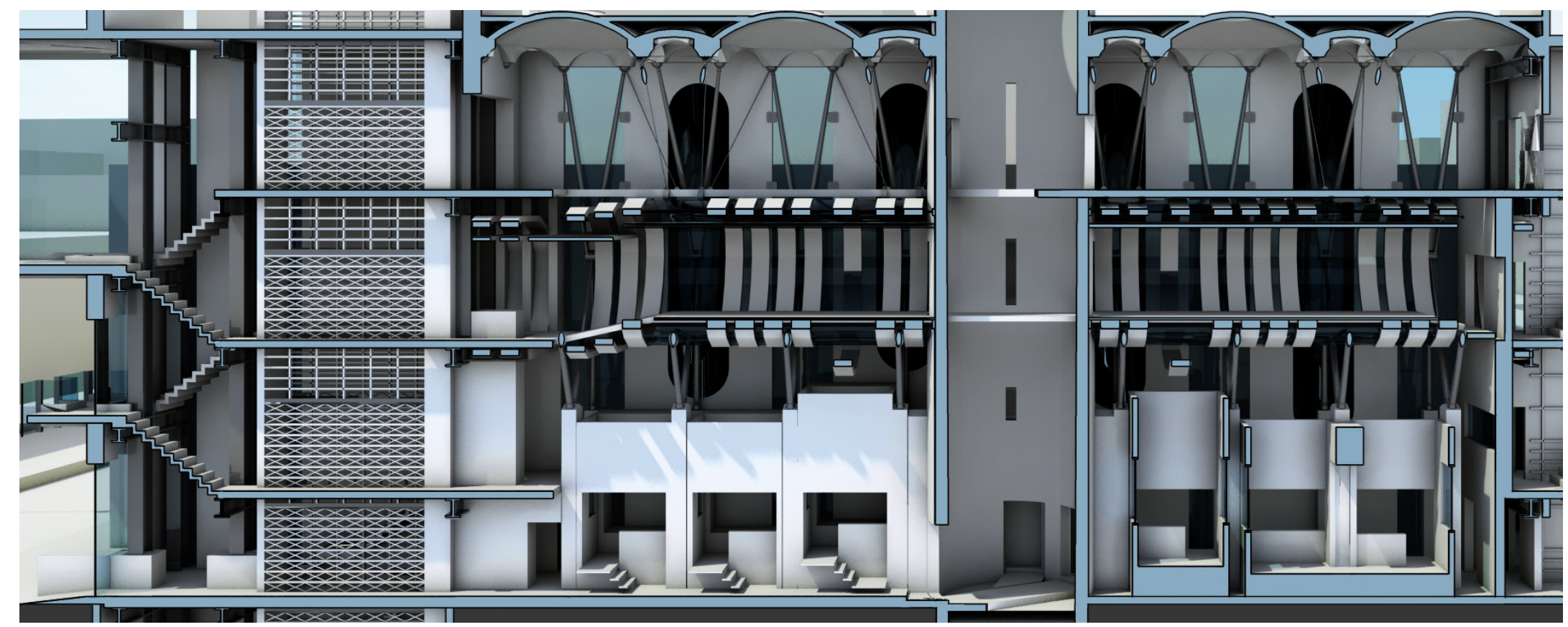




\section{TRIAGE OF THE NIGHT}

\section{GROUND FLOOR}

During the Night, the patient (the Student) also enters from Courtenay Place; however, these visitors might be entering on a gurney accompanied by paramedics. As patients are wheeled in, their reclined position makes their view of the dialogue between the steel moment frames and the concrete sheer walls even clearer.

The second moment resisting frame has a door in each of its ground floor bays, so that access to the different areas of the building can be restricted during the Night. This maintains a safe and secure environment within which the patient (the Student) can be treated by the paramedics, and be offered a sense of retreat through the architectural experience (the Stranger).
If patients (the Student) did not need to be transported on a gurney and were instead classed as 'walking wounded', they could be led past the gurney lift by a paramedic and into one of the reflection spaces, which double as treatment and recovery spaces for patients with only minor injuries. The stretchered patient (Student), on the other hand, would be taken up to the second floor treatment facility in the gurney lift. 


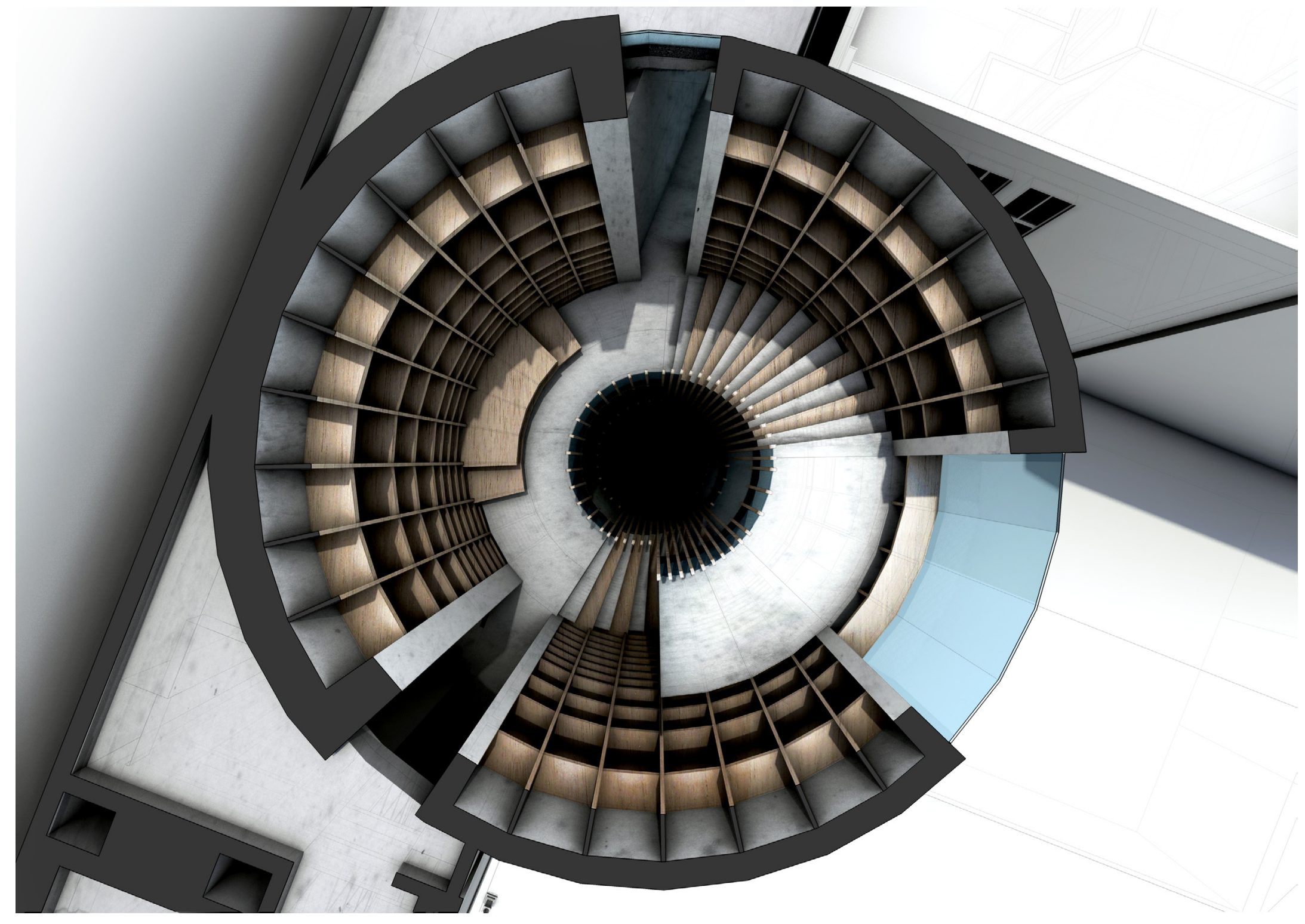




\section{SECOND FLOOR}

Upon arriving on the second floor, the Student arrives at a space that is encircled by two ribs that are recessed into the walls on either side. These are used by the Stranger to introduce a spatial ordering device within the treatment facility. As the Student is brought up the ramp and into the treatment facility, a large gap opens between the ribs: a point of reflection in the ordering device to enable the Student to witness the connections between the steel and concrete columns (Rigid and Pinned), as the columns branch below and continue on upwards to the third floor. This maintains the Student's appreciation of the interconnected nature and the balance of the architecture.

Once treatment is complete, the Student is transferred through a corridor into the recovery area at the southern end (Socrates). The corridor contains a full height window that looks east; during the Night it reflects the image of the Student, as did the windows on the ground floor when the Student first entered. The Stranger uses this to give visitors a new perspective on their situation, which has been changed for the better by the treatment and care provided by the paramedics. Visitors are able to see and appreciate how they have changed since entering the building, and with this knowledge they can move onwards into Socrates.

In the recovery area there are beds on which visitors (the Student) can lie down if they require more time to recover, or some muchneeded sleep before the morning. Once the Student is fully recovered and ready to leave the building, the Student can descend down the southern spiral staircase, past other recovering patients (Students) to the ground floor. From here the Stranger's ground floor dialogue is witnessed as the Student leaves, continuing to increase the Student's insight into the balance between the architecture's visible dialogues. 


\section{BETWEEN DAY AND NIGHT}

The experiential dialogues between the visitors during the day and the visitors during the night are not entirely isolated. There are points within each dialogue where each journey can be witnessed and understood by the other.

In the community book exchange (Socrates) at the far southern end, the circular staircase has a mezzanine level between each floor with an east-facing window. On the mezzanine level, just above the ground floor, this window is separated into four segments where up to four "Students of the Day" can sit, in close proximity, yet given separation and privacy with partitions. From this elevated position above the ground floor the "Student of the Day" is able to witness the last remaining patient (Student of the Night) recovering on a bed from the night before. This interaction repeats on each of the stairway mezzanine levels above, with the architecture offering

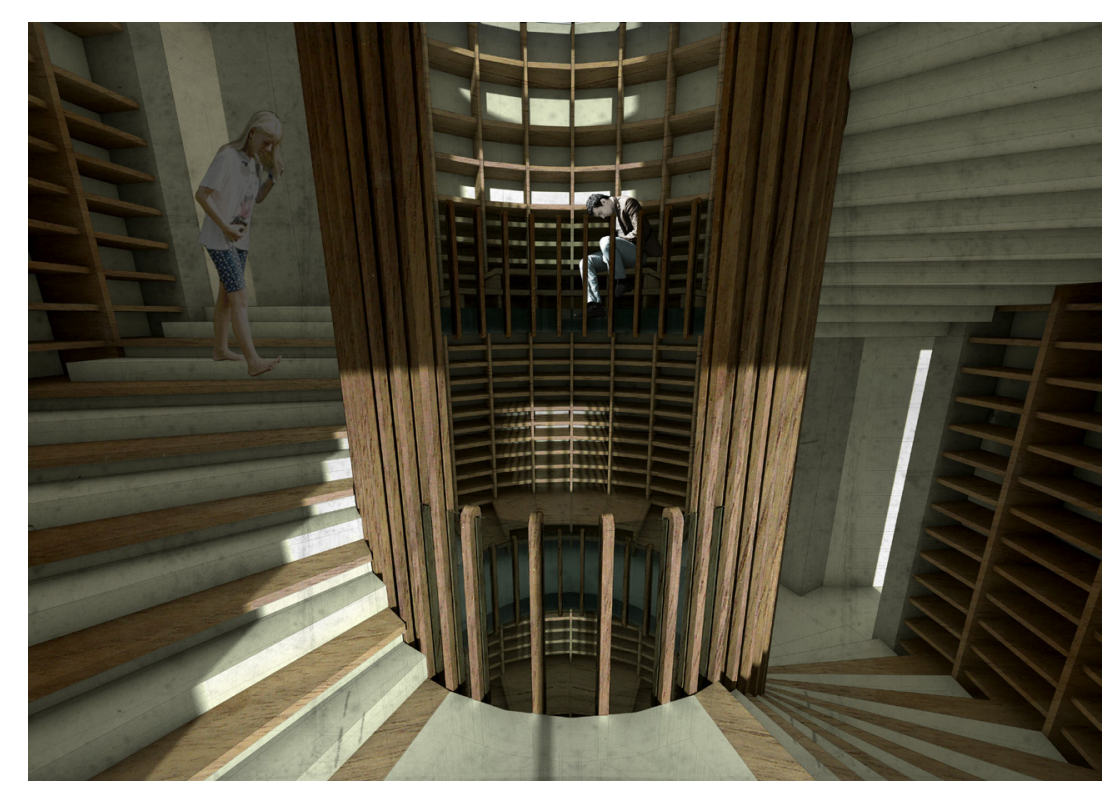




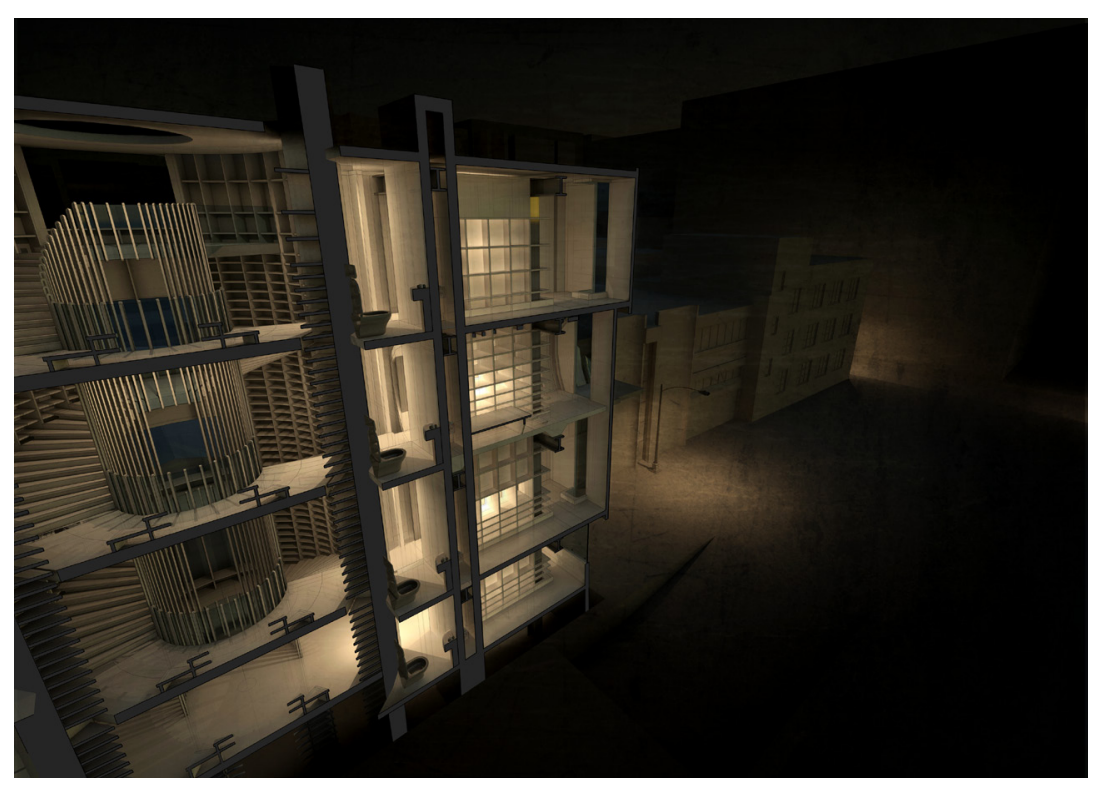

metaphorical protection to the vulnerable patients (Student of the Night) as they recover. The beds in the recovery area are integrated with the community book exchange and therefore further connect the Student of the Night (requiring medical triage) with the "Student of the Day" (requiring mental triage) in a shared architectural experience of retreat.

On the second floor, south of the community book exchange (Socrates) is a room that visitors (the Student) can use if they wish to stay and continue their reflection through the Night. It is contained in a similar way to the treatment facility. This places the "Student of the Day" in dialogue with the patients of the triage centre (Students of the Night). The Students of the Day and the Night gain an awareness of the similarities in their journeys into retreat. 
The unique proportion of the gurney lift (relating to the proportion of a gurney pushed by a paramedic) reveals a part of the building's night-time use to the "Student of the Day". The unusual shape of the lift makes the "Student of the Day" subconsciously aware of its unique purpose within the dialogue the Stranger has with the "Student of the Night". As the Stranger leads the visitors (Students of the Day) up from the ground floor in the evening, they walk around the gurney lift, continuing to gain a sense of the Stranger's dialogue with "Students of the Night", as patients ascend upwards in the gurney lift. During the day the second floor treatment facility is closed but the daytime visitors are able to look through glass windows into the facility. 


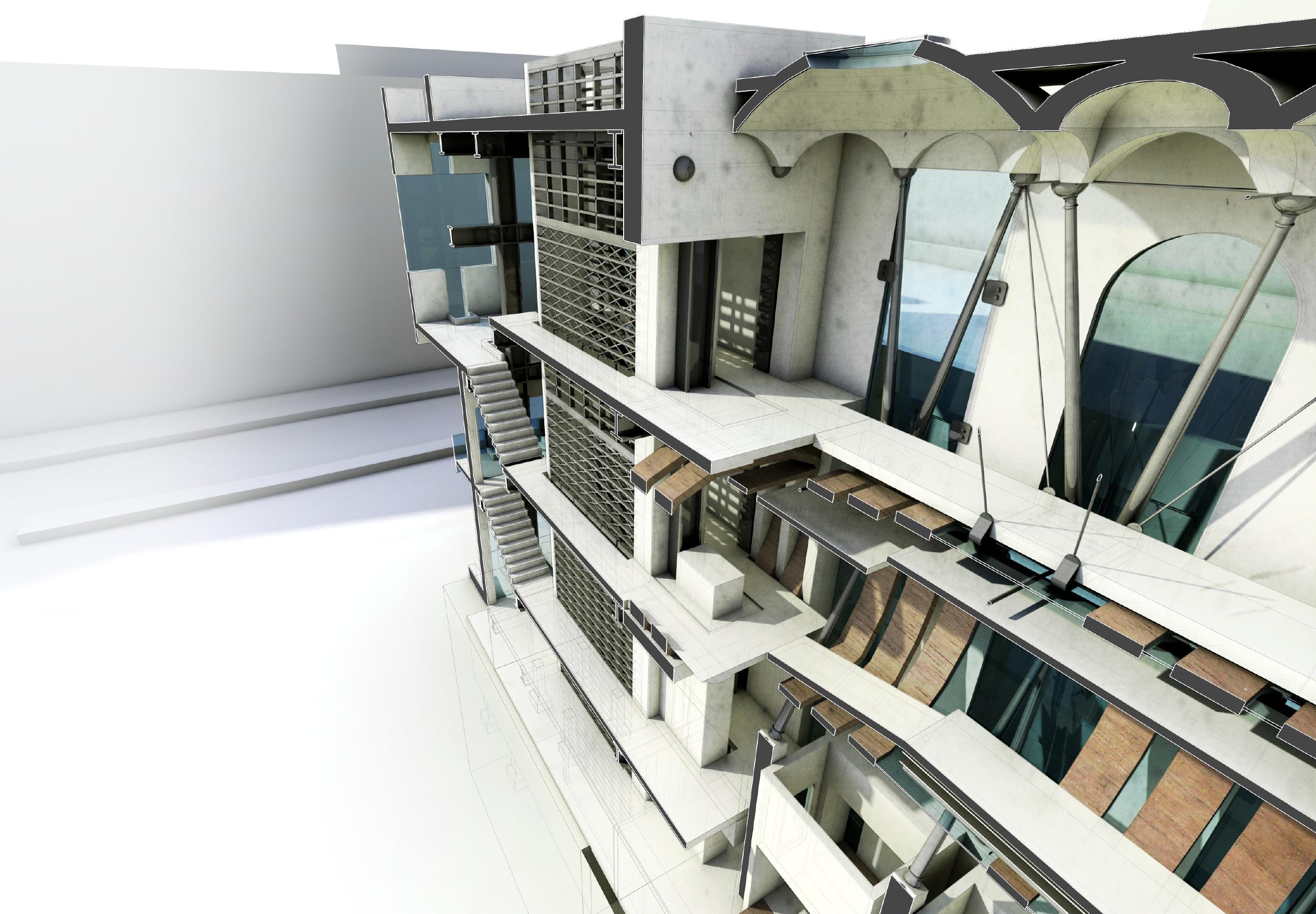




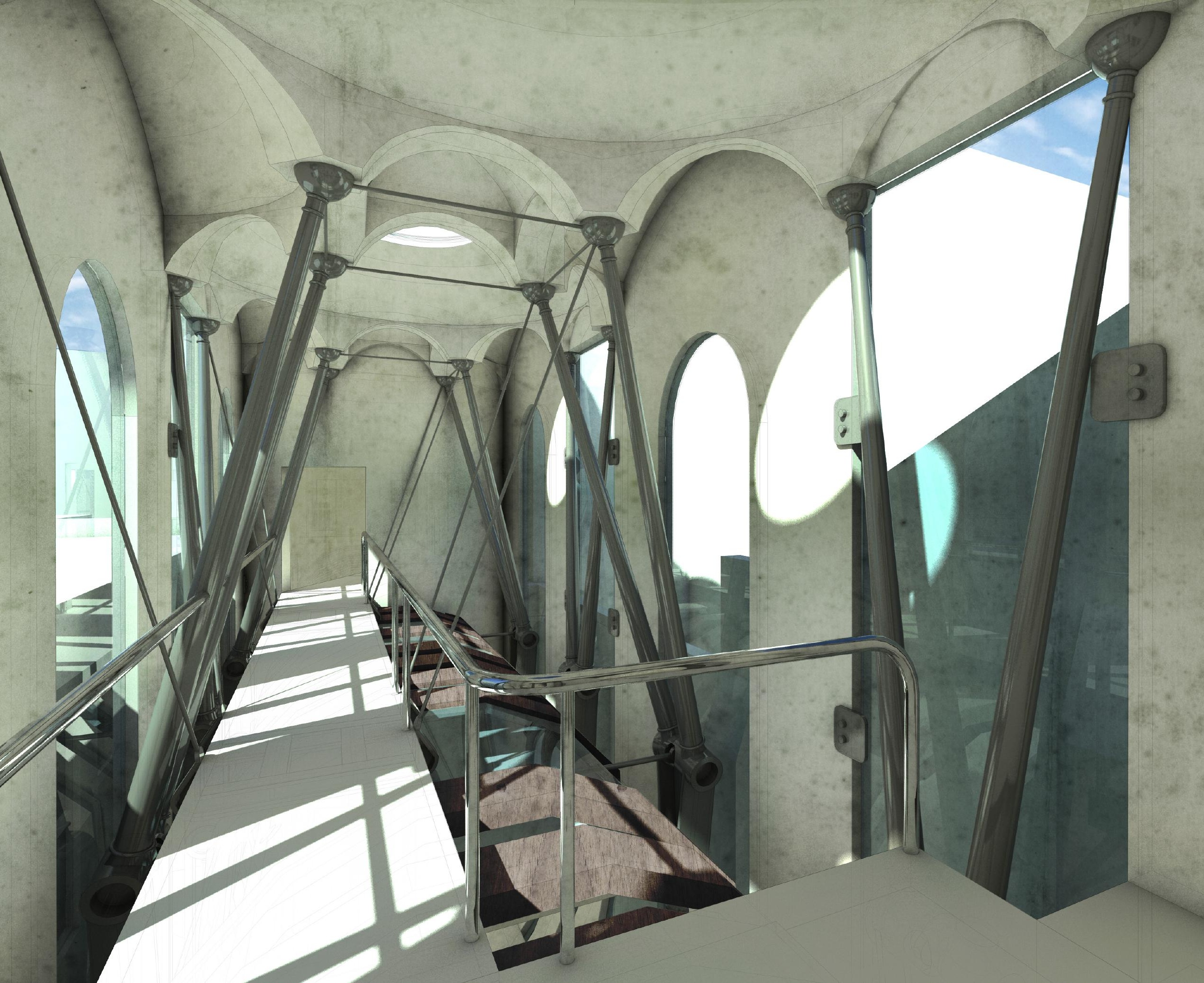




\section{CONCLUSION}

Silence, the unmeasurable, desire to be, desire to express, the source of new need, meets Light, the measurable, giver of all presence, by will, by law, the measure of things already made, at a threshold which is inspiration, the sanctuary of art, the Treasury of Shadow.

Louis Kahn, architect (1902-1974) 
Plato's theory of form (described in his Socratic dialogues, $4^{\text {th }}$ century BC) and Louis Kahn's theory of form (described in his 1961 essay "Form and Design") both engage dialogues to arrive at similar understandings of truth as evidenced by form. The main intention of this thesis was to test how Plato's and Kahn's theories could be applied to the design of architecture, to arrive at a work of architecture that could give its inhabitants a 'true' understanding of form and thereby a sense of retreat. The contemporary combination of an increasingly secular society and an intensifying urban density create an urban condition that is lacking in areas of sanctity and retreat. Coupled with the increasing vulnerability of New Zealand youth and a rampant binge drinking culture, the need for inner city pockets of safety and seclusion is becoming more and more necessary.

This research thesis proposes that an architectural experience can be designed to achieve a sense of retreat similar to the enlightened state of mind upon which both Plato's theory of Forms and ancient Greek Stoicism are centred. Stoicism held that through an understanding of "universal reason", the logos, the stoic sage could remain detached from overwhelming emotions and irrationality, thereby achieving an enlightened state of mind. Plato's theory of Forms revealed that the only way to remove oneself from the cacophonous illusions of the sensible realm (and achieve an enlightened state of mind), was by engaging in dialogue to attain an understanding of truth. Each of these ancient Greek philosophies holds that retreat can be achieved through understanding of the logos and of truth respectively.

Plato's notion of the 'sensible' and 'intelligible' realms (from his theory of Forms) was compared with Louis Kahn's architectural notions of the 'measurable' and 'immeasurable' realms, which Kahn developed into his theory of Silence and Light. While basing 
their theories on very similar ideas, this investigation revealed that Kahn eventually departed from Plato due to a greater interest in the threshold between Silence and Light, the point at which the 'measurable' and 'immeasurable' are in dialogue.

The Eleatic Stranger, a character in Plato's dialogue Sophist, employed dialogue in order to lead a Student (Theaetetus) to an understanding of the definition of sophist. Plato's use of dialogue in the theory of Forms and Kahn's interest in the dialogue between Silence and Light led the research to test the use of dialogues as a methodology for achieving the primary architectural goal of the thesis. The result is an architectural experience of retreat in the form of a multi-layered dialogue within architecture (represented by The Eleatic Stranger), designed for people desiring retreat during the day or patients in need of triage during the night (represented by The Student).
The implementation of dialogues in architecture allowed this thesis to make a proposition on the nature of architecture itself, a visual 'manifesto' that contemporary architecture should reveal its fundamental 'truths'. One of the most important conclusions arising from this thesis is that truthful dialogues in architecture can be revealed without resorting to $20^{\text {th }}$ century notions of blunt minimalist exposure or deconstruction. The dialogues of the design research intervention evidence the subtly complex relationships between and within the elements and forces that support architecture. Visitors and inhabitants of the architecture can be much more positively affected - emotionally and psychologically if they participate in these dialogues in a way that leads them to an intuitive realisation of these interactions.

The design intervention allows its visitors to experience a sense of understanding and nurturing, a sense of retreat, by revealing 
that their architectural environment fits into a clear balance. Early $20^{\text {th }}$ Century Minimalism, on the other hand, stripped away these qualities. Since Minimalism primarily acts as a counterpoint to decadence and decoration, it is always acting in response to 'something'; it represents one side of the dialogue: the rational to the irrational, the calm to the chaos, the restrained to the decadent. Therefore, Minimalism's obfuscation of structure and construction evidences an imbalance to its visitors: its structure can appear to float unsupported, obviating an intuitive understanding of how the architecture works.

$20^{\text {th }}$ century architecture was minimised, functionalised, internationalised, modernised, structuralised and deconstructed. This thesis concludes with a recommendation for fundamental truth in our architecture of the $21^{\text {st }}$ century. As the design intervention of this thesis demonstrates, the revelation of fundamental truths requisite to architecture can create a sense of understanding, a sense of retreat. Therefore the thesis posits that other architectural programs, not just retreats, that adhere to and subtly reveal these fundamental truths, will be able to engender a sense of understanding and stability within our future, and our ever more chaotic urban environments. 


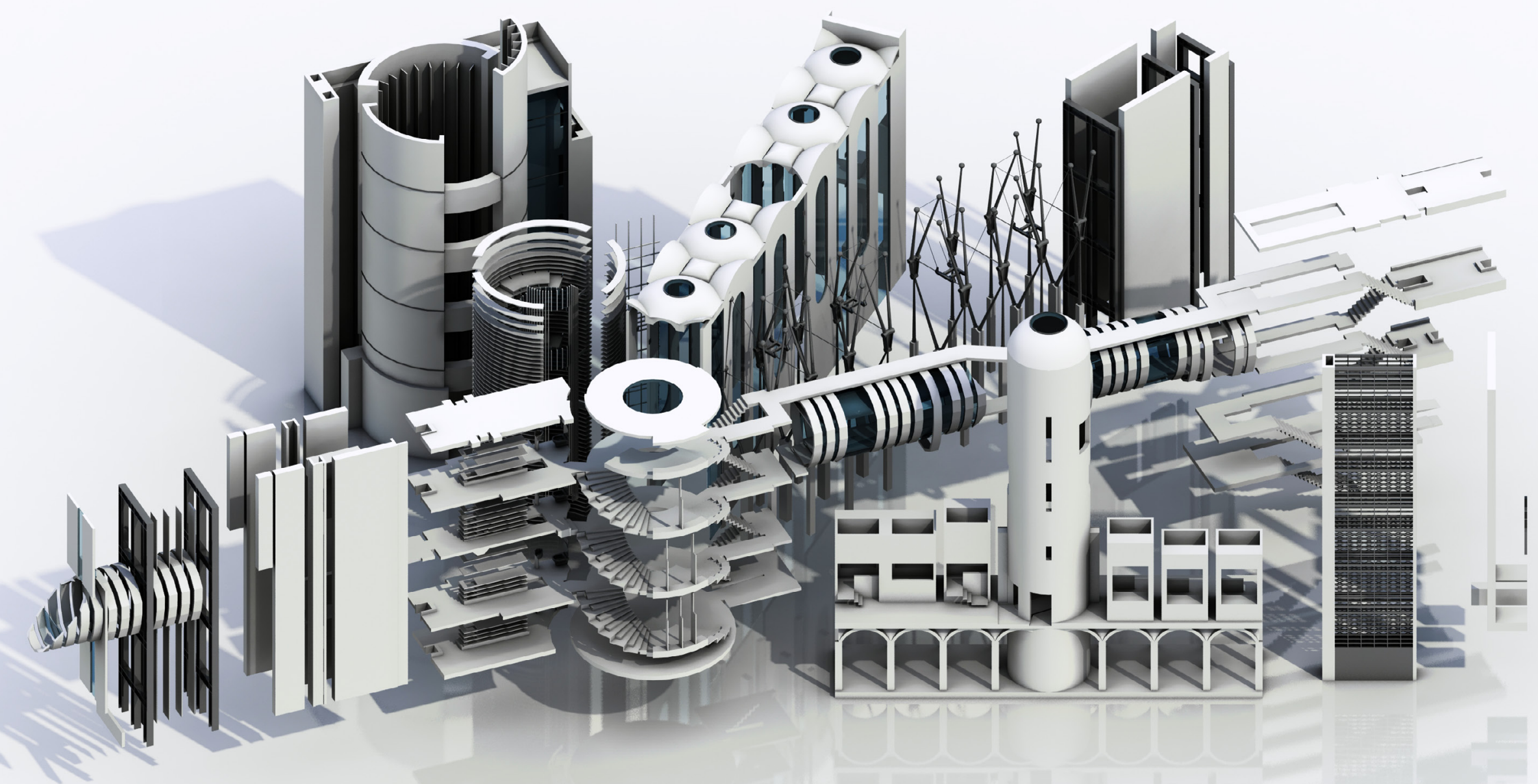




\section{LIST OF FIGURES}

Fig. 1: "Drunk lost and alone" by Flickr user 'A thinking photo' (2009). Source: http://www.flickr.com/photos/athinkingphoto/3669520200/

Fig. 2: "I've lost my keys" by Flickr user 'Around the Lense' (2009). Source: http://www.flickr.com/photos/aroundthelens/5246869297/

Fig. 3: "Binge Drinking" by Flickr user 'chrisie.b' (2010). Source: http://www.flickr.com/photos/chrisieb/4903529064/

Fig. 4: "Stanza della Segnatura -The School of Athens" by Raphael (1509). Source: http://en.wikipedia.org/wiki/File:Raphael_School_of_Athens.jpg

Fig. 5: Stoa of the Attalos at the Ancient Agora of Athens (159 BC-138 BC). Source: http://upload.wikimedia.org/wikipedia/commons/1/10/Stoa_of_Attalos_at_the_Ancient_Agora_of_Athens_3.jpg

Fig. 6: Plato's allegory of the divided line. Author's own image (2012).

Fig. 7: Plato's allegory of the cave. Author unknown. Source: http://politika-gr.blogspot.co.nz/2012/01/blog-post_1070.html

Fig. 8: Plato's allegory of the cave engraved by Jan Saenredam (1604). Source: http://commons.wikimedia.org/wiki/File:Platon_Cave_Sanraedam_1604.jpg 
Fig. 9: Salk Insitute for Biological Studies, California by Louis Kahn (1962). Photograph by Alfred Essa (2006). Source: http://www.flickr.com/photos/ tatler/339218853/

Fig. 10: Matrix comparing Plato and Kahn. Author's own image (2012).

Fig. 11: Plan of the Domus Aurea, Rome (64-68 AD). Source: http://www.greatbuildings.com/cgi-bin/gbc-drawing.cgi/Domus_Aurea.html/Domus_Aurea_Plan_2.jpg

Fig. 12: Plan of the National Assembly of Bangladesh by Louis Kahn (1962-74). Source: http://adoogcdnb.archdaily.net/wp-content/ uploads/2010/10/1287536642-national-assembly-plano-1.jpg

Fig. 13: Lantern slide of Sakkara, Egypt. From the Brooklyn Museum. Source: http://www.flickr.com/photos/brooklyn_museum/2489659724

Fig.14: Kimbell Art Museum, Texas by Louis Kahn (1966). Photograph by Larry Harris (2009). Source: http://www.flickr.com/photos/2328oo22@ No8/3189918013/

Fig. 15: Site plan. Author's own image (2012). 
Fig. 16: Site plan. Author's own image (2012).

Fig. 17: Author's own image (2011).

Fig. 18-22: Ibid.

Fig. 23: "Helping hand", by Craig Simcox, Fairfax NZ (2011). Source: http://static.stuff.co.nz/1326910176/834/6280834.jpg

Fig. 24: Still image from "Courtenay triage" video by Luke Appleby, Fairfax NZ (2011). Source: http://www.stuff.co.nz/dominion-post/news/6279484/ Courtenay-triage-may-be-permanent

Fig. 25: Still image from: Media 7 (03 Nov. 2011). Top Shelf Productions, TVNZ. Source: http://tvnz.co.nz/media7/s7-e13-video-4502283

Fig. 26: Author's own image (2012)

Fig. 27: Author's own image (2011).

Fig. 28: Matrix of the dialogues in the thesis. Ibid. 
Fig. 29: Formal development. Author's own image (2012).

Fig. 30: Ibid.

Fig. 31: Ibid

Fig. 32: Image from Entretiens sur l'architecture by Viollet-le-Duc (1858-72). Source: http://3.bp.blogspot.com/-OfolFpolP-M/TuaevYuZU8I/ AAAAAAAAB8Y/43TByww3IWo/s16oo/LeDuc.jpg

Fig. 33: Image from Entretiens sur l'architecture by Viollet-le-Duc (1858-72). Source: http://upload.wikimedia.org/wikipedia/commons/6/64/Viollet-leDucConc

Fig. 34: Matrix of Oppositional and Liminal dialogues. Author's own image (2011).

Fig. 35: Ibid.

Fig. 36: Ibid. 


\section{BIBLIOGRAPHY}

Baltzly, D. (2010) Stoicism. The Stanford Encyclopedia of Philosophy (Winter 2010 ed.). E. N. Zalta, (Ed.). Retrieved from http://plato.stanford.edu/archives/win2010/entries/stoicism

Becker, L. (1998). A New Stoicism. Princeton, NJ: Princeton University Press.

Becker, L. (2004). Stoic emotion. In K. Strange \& J. Zupko (Eds.), Stoicism: Traditions and Transformations (250-257). New York, NY: Cambridge University Press.

Cerver, F. A. (1997). The architecture of minimalism. New York, NY: Arco.

Chapman, K. (2011). Our kid care doesn't rate. The Dominion Post (14 Aug. 2011). Fairfax NZ News.

Dastgheib, S. (2012). Courtenay triage may be permanent. The Dominion Post (19 Jan. 2012). Fairfax NZ News. Retrieved from http://stuff.co.nz/dominion-post/news/6279484/Courtenay-triage-may-be-permanent

Duff, M. (2011). 'Pressure valve' medics patch up night's drunks. The Dominion Post (8 Aug. 2011). Fairfax NZ News. Retrieved from http://www.stuff. co.nz/national/health/5404909/Pressure-valve-medics-patch-up-nights-drunks 
Giblin, R. (2010). No, not the Brothel Brothers. The Dominion Post (20 Dec. 2010). Fairfax NZ News. Retrieved from http://stuff.co.nz/dominion-post/ news/big-reads/4473003/No-not-the-Brothel-Brothers

Gill, M. L. (2009). Method and meta-physics in Plato's Sophist and Statesman. The Stanford Encyclopedia of Philosophy (Winter 2009 ed.). E. N. Zalta, (Ed.). Retrieved from http://plato.stanford.edu/entries/plato-sophstate

Fleming, S. (2006). Theorising daylight: Kahn's Unitarian church and Plato's super-form, the Good. Architectural Research Quarterly, 10(1), $25-37$.

Hunt, T. (2012). Warning to bingers as triage centre set to stay. The Dominion Post (20 Feb. 2012). Fairfax NZ News.

Jencks, C. (1973). Modern movements in architecture. London: Penguin.

Jencks, C. (1977). The Language of Post-Modern Architecture. London: Academy Editions.

Kahn, L. (1961). Form and design. Architectural Design, 31(4), 145-54 
Kahn, L. (1969) Architecture: Silence and Light. In R. McCarter (2005). Louis I Kahn (472-479). New York, NY: Phaidon.

Lobell, J. (Ed.). (1979). Between Silence and Light: Spirit in the architecture of Louis I. Kahn. Boulder, CO: Shambhala Publications Inc.

Malnar, J. M, \& Vodvarka, F. (2004). Sensory Design. Minneapolis, MN: University of Minnesota Press.

McCarter, R. (2005). Louis I Kahn. New York, NY: Phaidon.

McQuade, M. (1957). Architect Louis Kahn and his strong boned structures. Architectural Forum, 107(Oct), 134-143.

Newton, K. (2011). Medics call for permanent base in Courtenay Place. The Dominion Post (11 Oct. 2011). Fairfax News NZ. A3.

Plato. (1966). Plato in Twelve Volumes, Vol. 1 (H. N. Fowler, Trans.). Introduction by W.R.M. Lamb. Cambridge, MA: Harvard University Press. Retrieved from http://www.perseus.tufts.edu/hopper/text?doc=Perseus\%3Atext\%3A1999.01.0170\%3Atext\%3DEuthyph.

Plato. (1969). Plato in Twelve Volumes, Vol. 5 \& 6 (P. Shorey, Trans.) Cambridge, MA: Harvard University Press. Retrieved from http://www.perseus. tufts.edu/hopper/text?doc=Perseus\%3Atext\%3A1999.01.0168\%3Abook\%3D1\%3Asection\%3D327a 
Plato. (2008). Sophist. (B. Jowett, Trans.). Salt Lake City, UT: Project Guthenberg. Retrieved from http://www.gutenberg.org/files/1735/1735-h/1735-h. htm

Ronner, H., Jhaver, S. \& Vasella, A. (1977) Louis I. Kahn: complete works,1935-1974. Boulder, CO: Westview Press.

Schaal, H. D. (1993). Paths and passages. Berlin: Ernst \& Sohn.

Spektor, T. (2006). The morals of modernist minimalism. Harvard Design Magazine, 25, 84-90.

Toy, M. (Ed.). (1999). Architectural Design Profile no. 139: Aspects of Minimal Architecture II, 69(5).

Tyng, Alexandra (1984). Beginnings: Louis I. Kahn's Philosophy of Architecture. New York, NY: John Wiley and Sons.

Wong, D. (2006) The meaning of detachment in Daoism, Buddhism, and Stoicism. Dao: A Journal of Comparative Philosophy, 5(2), 207-219.

Wurman, R. S. (1986). What will be has always been: The words of Louis I. Kahn. New York, NY: Rizzoli. 
